

\section{EUROSIM Conferences and Congress}

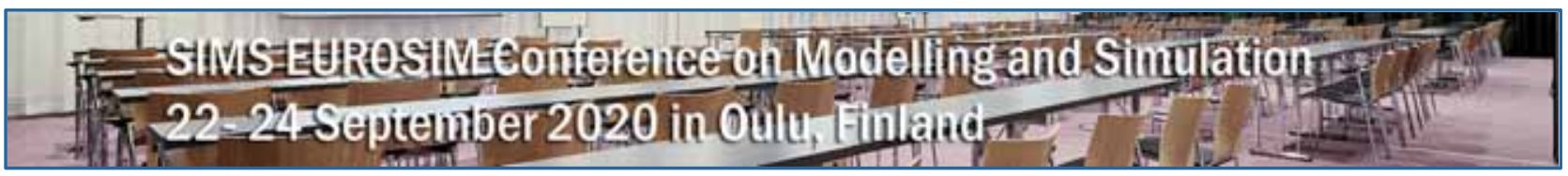

The first SIMS EUROSIM Conference on Modelling and Simulation, SIMS EUROSIM 2020, will take place on September 22-24, 2020 in Oulu, Finland. The background of this conference series is in the 60-years history of the Scandinavian Simulation Society, SIMS. The conference will be organized every third year by SIMS and the Federation of European Simulation Societies, EUROSIM. The 61st International Conference of the Scandinavian Simulation Society (SIMS 2020) is embedded with this first conference organized by SIMS, EUROSIM, the Finnish Automation Forum (FinSim), the Finnish Society of Automation (FSA) and the University of Oulu. The Original Sokos Hotel Arina Conference Center in the middle of the city serves as the venue.

SIMS EUROSIM 2020 provides a forum where automation professionals from industry and science exchange knowledge, experiences and strengthen multidisciplinary network. On the stage visions are presented and shared with old and new colleagues. The SIMS EUROSIM 2020 is expected to participants worldwide in the field of modelling and simulation. The EUROSIM 2016 Congress in Oulu had almost 200 participants from 33 countries. The program of the congress has a multi-conference structure with several special topics related to methodologies and application areas. The programme includes invited talks, parallel, special and poster sessions, exhibition and versatile technical tours.

For more details please visit www.automaatioseura.fi/simseurosim2020/

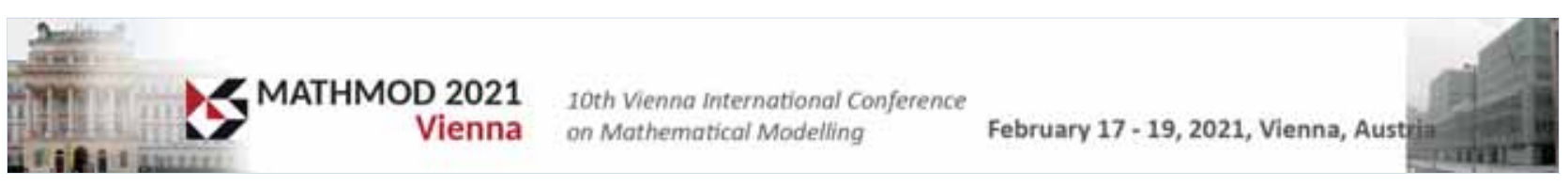

MATHMOD 2021 continues the conference series MATHMOD Vienna in February 2021. It provides a forum for professionals, researchers, and experts in the field of theoretic and applied aspects of mathematical modelling for systems of dynamic nature.

The scope of the MATHMOD 2021 conference covers theoretic and applied aspects of various types of mathematical modelling (equations of various types, automata, Petri nets, bond graphs, qualitative and fuzzy models) for systems of dynamic nature (deterministic, stochastic, continuous, discrete or hybrid).

For more details please visit www.mathmod.at

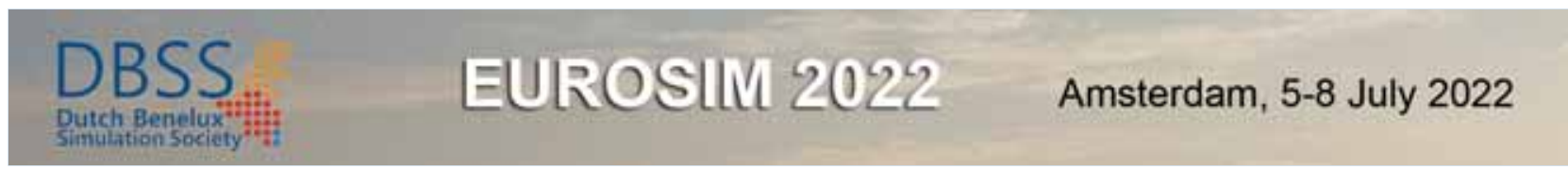

EUROSIM 2022, the 11th EUROSIM Congress, will take place in Amsterdam, The Netherlands, July 4-8, 2022. It will be organized by the Dutch Benelux Simulation Society (www.dutchbss.org) supported mainly by their corporate members like TUDelft, Amsterdam University of Applied Sciences, EUROCONTROL and IGAMT (www.igamt.eu). For this event, also international societies from the globe focusing in Simulation will support the event; therefore, we expect a record of participation.

Due to the growth of Simulation and its relationship with other analytical techniques like Big Data, Al, Machine Learning, Large Scale Simulation and others, the event will be structured, for the first time, in dedicated tracks focused on different areas and applications of Simulation ranging from aviation to health care and humanitarian activities. We have the ambition to attract at the congress participants from Academia, industry and governmental representatives to share the latest developments in Simulation and related activities and applications.

Please follow the news and activities towards the EUROSIM 2022 at www.eurosim2022.eu 


\section{Editorial}

Dear Readers, Thirty Years SNE - we are pleased that for SNE Volume 30 again Vlatko Čerić, past president of the Croatian Simulation Society, provides his algorithmic art as design for SNE cover pages. 'Algorithms, mathematics and art are interrelated in an art form called algorithmic art. Algorithmic art is visual art generated by algorithms that completely describe creation of images. This kind of art is strongly related with contemporary computer technology, and especially computer programming, as well as with mathematics used in algorithms for image generation'as Vlatko Čerić defines. The artist and simulationist Vlatko Čerić has chosen four algorithmic art pictures from the series LABYRINTH for covers of SNE Volume 30.

The cover of this issue SNE 30(1) presents LABYRINTH no. 6, and at right a preview for the cover for SNE 3O(2) - LABYRINTH no. 7. For further info, please visit vceric.net.

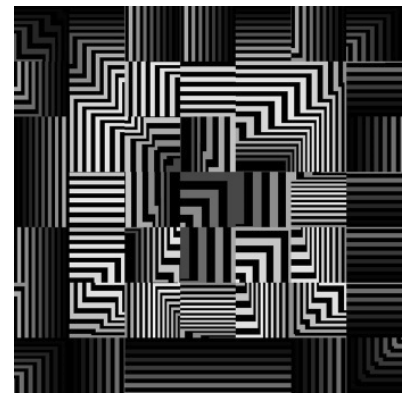

SNE 3O(1) again underlines SNE's publication strategy - contributions on developments and trends in modelling and simulationsubmitted directly by simulationists for quick publication, and post-conference publication for conferences of EUROSIM societies. In this issue, the directly submitted contributions deal with classical and non-classical simulation applications: analysis of aircraft availability (M. Bieber et al), and incivility analysis of political speeches (D. Kapla, M. Wastian). Post-conference contributions from the ASIM Symposium Simulation Technique Hamburg 2018 show the broad variety of simulation - from performance modelling in production systems (J. Sundermayer et al.) and self-organizing production systems (T. Munkelt, M. Krockert) via parameter optimization in biogas plants models (D. Wagner, W. Schlüter) to multiple-criteria ranking to simulate building renovation in cities (A. Jamil et al.). Two post-conference publications from MATHMOD Vienna 2018 on EDDY current simulation (M. Schöbinger, J. Schöberl, K. Hollaus) conclude this issue.

I would like to thank all authors for their contributions to SNE 30(1) - and thanks to the editorial board members, and to the organizers of the EUROSIM conferences for co-operation in post-conference contributions. And last but not least thanks to the SNE Editorial Office for layout, typesetting, preparations for printing, electronic publishing, and much more.

Felix Breitenecker, SNE Editor-in-Chief,eic@sne-journal.org; felix.breitenecker@tuwien.ac.at

\section{Contents SNE 30(1)}

Online SNE 30(1), DOI 10.11128/ sne.30.1.1050

ARGESIM Publisher, Vienna, www.argesim.org

Print SNE 30(1) ISBN 978-3-903311-01-5,

TU Verlag Vienna, Print-on-Demand, www.tuverlag.at

An Incivility Analysis of Austrian Political Speeches.

D. Kapla, M. Wastian

Proposing Multiple-Criteria Ranking to Simulate Building Renovation in Cities. A. Jamil, N. Weiss, T. Preisler, W. Renz

Optimization of Operational Parameters in Biogas Plants using the Anaerobic Digestion Model Number 1 (ADM1).

D. Wagner, W. Schlüter

Development of a Simulation Model to Analyze the Performance of Decentral Rescheduling Algorithms in Production Systems. J. Sundermeier, F. Gehlhoff, A. Fay .... 15

An Approach to a Self-organizing Production in Comparison to a Centrally Planned Production. T. Munkelt, M. Krockert . 23

Model-based Analysis of Maintenance-induced Availability of Aircraft in an Airline Network. M. Bieber, B. Glock, A. Plagemann, N. Popper

MOR for the MSFEM of the Eddy Current Problem in Linear Laminated Media. K. Hollaus, J. Schöberl, M. Schöbinger 35

MSFEM for the Linear 2D1D-Problem of Eddy Currents in Thin Iron Sheets. M. Schöbinger, J. Schöberl, K. Hollaus 39

EUROSIM Societies Short Info N1 - N8

\section{SNE Contact \& Info}

\section{SNE Online ISSN 2306-0271, SNE Print ISSN 2305-9974}

$\rightarrow$ www.sne-journal.org

害=”- office@sne-journal.org, eic@sne-journal.org

$\triangle$ SNE Editorial Office

Johannes Tanzler (Layout, Organisation),

Irmgard Husinsky (Web, Electronic Publishing),

Felix Breitenecker (Organisation, Author M entoring) ARGESIM / M ath. M odelling \& Simulation Group, Inst. of Analysis and Scientific Computing, TU Wien Wiedner Hauptstrasse 8-10, 1040 Vienna, Austria

\section{SNE SimULATION NOTES EUROPE}

WEB: $\rightarrow$ www.sne-journal.org, DOI prefix 10.11128/sne Scope: Developments and trends in modelling and simulation in various areas and in application and theory; comparative studies and benchmarks (documentation of ARGESIM Benchmarks on modelling approaches and simulation implementations); modelling and simulation in and for education, simulation-based e-learning; society information and membership information for EUROSIM members (Federation of European Simulation Societies and Groups).

Editor-in-Chief: Felix Breitenecker, TU Wien, M ath. Modelling Group 帮=7Felix.Breitenecker@tuwien.ac.at, 玤- eic@sne-journal.org

Print SNE and Print-on-Demand: TU-Verlag, Wiedner Hauptstrasse 8-10, 1040, Vienna, Austria - www.tuverlag. at Publisher: ARGESIM ARBEITSGEM EINSCHAFT SIM ULATION NEWS c/o M ath. Modelling and Simulation Group, TU Wien / 101, Wiedner Hauptstrasse 8-10, 1040 Vienna, Austria; www.argesim.org, $=$ info@argesim.org on behalf of ASIM www.asim-gi.org and EUROSIM $\rightarrow$ www.eurosim.info (c) ARGESIM / EUROSIM / ASIM 2020 


\section{SNE - Aims and Scope}

Simulation Notes Europe (SNE) provides an international, high-quality forum for presentation of new ideas and approaches in simulation - from modelling to experiment analysis, from implementation to verification, from validation to identification, from numerics to visualisation - in context of the simulation process.

SNE seeks to serve scientists, researchers, developers and users of the simulation process across a variety of theoretical and applied fields in pursuit of novel ideas in simulation and to enable the exchange of experience and knowledge through descriptions of specific applications. SNE follows the recent developments and trends of modelling and simulation in new and/or joining application areas, as complex systems and big data. SNE puts special emphasis on the overall view in simulation, and on comparative investigations, as benchmarks and comparisons in methodology and application. For this purpose, SNE documents the ARGESIM Benchmarks on Modelling Approaches and Simulation Implementations with publication of definitions, solutions and discussions. SNE welcomes also contributions in education in/for/with simulation.

A News Section in SNE provides information for EUROSIM Simulation Societies and Simulation Groups.

SNE, primarily an electronic journal, follows an open access strategy, with free download in basic layout. SNE is the official membership journal of EUROSIM, the Federation of European Simulation Societies and Simulation Groups - www.eurosim.info. Members of EUROSIM societies are entitled to download SNE in an elaborate and extended layout, and to access additional sources of benchmark publications, model sources, etc. Print SNE is available for specific groups of EUROSIM societies, and starting with Volume 27 (2017) as printon-demand from TU Verlag, TU Wien. SNE is DOI indexed by CrossRef, identified by DOI prefix 10.11128, assigned to the SNE publisher ARGESIM (www.argesim.org).

Author's Info. Individual submissions of scientific papers are welcome, as well as post-conference publications of contributions from conferences of EUROSIM societies. SNE welcomes special issues, either dedicated to special areas and/or new developments, or on occasion of events as conferences and workshops with special emphasis.

Authors are invited to submit contributions which have not been published and have not being considered for publication elsewhere to the SNE Editorial Office.

SNE distinguishes different types of contributions (Notes), i.e.

- TN Technical Note, 6-10 p. $\quad$ EN Education Note -6-8 p.

- PN Project Note 6-8 p. - SN Short Note, max. 6 p.

- SW Software Note, 4-6 p. - BN Benchmark Note, 2-8 p.

- ON Overview Note - only - EBN Educational Benchmark

$$
\text { upon invitation, up to } 14 \mathrm{p} \text {. Note, } 2-10 \mathrm{p}
$$

Further info and templates (doc, tex) at SNE's website. www.sne-journal.org

\section{SNE Editorial Board}

SNE - Simulation Notes Europe is advised and supervised by an international scientific editorial board. This (increasing) board is taking care on peer reviewing of submission to SNE:

Felix Breitenecker, Felix.Breitenecker@tuwien.ac.at TU Wien, Math. Modelling, Austria, Editor-in-chief David Al-Dabass, david.al-dabass@ntu.ac.uk, Nottingham Trent University, UK

Maja Atanasijevic-Kunc, maja.atanasijevic@fe.uni-lj.si Univ. of Ljubljana, Lab. Modelling \& Control, Slovenia

Aleš Belič, ales.belic@sandoz.com Sandoz / National Inst. f. Chemistry, Slovenia

Peter Breedveld, P.C.Breedveld@el.utwente.nl University of Twente, Netherlands

Agostino Bruzzone, agostino@itim.unige.it Universita degli Studi di Genova, Italy

Francois Cellier,fcellier@inf.ethz.ch, ETH Zurich, Switzerland

Vlatko Čerić,vceric@efzg.hr, Univ. Zagreb, Croatia

Russell Cheng,rchc@maths.soton.ac.uk University of Southampton, UK

Roberto Cianci, cianci@dime.unige.it, Math. Eng. and Simulation, Univ. Genova, Italy

Eric Dahlquist, erik.dahlquist@mdh.se, Mälardalen Univ., Sweden Umut Durak,umut.durak@dlr.de German Aerospace Center (DLR)Braunschweig, Germany

Horst Ecker,Horst.Ecker@tuwien.ac.at TU Wien, Inst. f. Mechanics, Austria

Vadim Engelson,vadime@mathcore.com MathCore Engineering, Linköping, Sweden

Peter Groumpos,groumpos@ece.upatras.gr Univ. of Patras, Greece

Edmond Hajrizi, ehajrizi@ubt-uni.net University for Business and Technology, Pristina, Kosovo

Glenn Jenkins, GLJenkins@cardiffmet.ac.uk Cardiff Metropolitan Univ., UK

Emilio Jiménez,emilio.jimenez@unirioja.es University of La Rioja, Spain

EskoJuuso,esko.juuso@oulu.fi Univ. Oulu, Dept. Process/Environmental Eng., Finland

Kaj Juslin, kaj.juslin@enbuscon.com, Enbuscon Ltd, Finland Andreas Körner, andreas.koerner@tuwien.ac.at TU Wien, Math. E-Learning Dept., Vienna, Austria

Francesco Longo,f.longo@unical.it Univ. of Calabria, Mechanical Department, Italy Yuri Merkuryev,merkur@itl.rtu.lv, Riga Technical Univ. David Murray-Smith, d.murray-smith@elec.gla.ac.uk University of Glasgow, Fac. Electrical Engineering, UK

Gasper Music,gasper.music@fe.uni-lj.si Univ. of Ljubljana, Fac. Electrical Engineering, Slovenia

Thorsten Pawletta, thorsten.pawletta@hs-wismar.de Univ. Wismar, Dept. Comp. Engineering, Wismar, Germany Niki Popper,niki.popper@dwh.at, dwh Simulation Services, Austria

Kozeta Sevrani, kozeta.sevrani@unitir.edu.al Univ. Tirana, Inst.f. Statistics, Albania

Thomas Schriber, schriber@umich.edu University of Michigan, Business School, USA

Yuri Senichenkov, sneyb@dcn.infos.ru St. Petersburg Technical University, Russia

Michal Štepanovský, stepami9@fit.cvut.cz Technical Univ. Prague, Czech Republic

Oliver Ullrich, oliver.ullrich@iais.fraunhofer.de Fraunhofer IAIS, Germany

Siegfried Wassertheurer, Siegfried.Wassertheurer@ait.ac.at AIT Austrian Inst. of Technology, Vienna, Austria

Sigrid Wenzel, S.Wenzel@uni-kassel.de Univ. Kassel, Inst. f. Production Technique, Germany

Grégory Zacharewicz, gregory.zacharewicz@mines-ales.fr IMT École des Mines d'Alès, France 


\title{
An Incivility Analysis of Austrian Political Speeches
}

\author{
Daniel Kapla , Matthias Wastian ${ }^{2 *}$ \\ ${ }^{1}$ Institute of Analysis and Scientific Computing, TU Wien, Wiedner Hauptstraße 8-10, 1040 Wien \\ ${ }^{2}$ dwh GmbH, Neustiftgasse 57-59, 1070 Wien; *mathias.wastian@dwh.at
}

SNE 30(1), 2020, 1-6, DOI: 10.11128/sne.30.tn.10501

Received: September 15, 2019; Revised: January 10, 2020;

Accepted: February 10, 2020

SNE - Simulation Notes Europe, ARGESIM Publisher Vienna, ISSN Print 2305-9974, Online 2306-0271, www.sne-journal.org

Abstract. The state of the art technology in natural language processing (NLP) is dominated by neural networks. On the one hand, neural networks are used to learn how to calculate word embeddings, some of which are particularly well-suited for representing meaning and relations between words. On the other hand, neural networks make use of these word embeddings as input for additional NLP-related tasks such as sentiment analyses. The goal of this paper is an incivility analysis of Austrian parliamentary speeches. Therefore, different neural network types in combination with different word embeddings are compared in terms of performance and suitability. The best model was chosen to classify the given data set and analyze how incivility changes over time.

\section{Introduction}

The state of the art technology in natural language processing (NLP) are neural networks. The goal of this article is to compare different embeddings and network structures in order to find a well-suited neural network with a word embedding, which is particularly wellsuited for representing meaning and relation between words, to analyze the political landscape according their incivility. Referring to the work of [1] and [2] two classifiers were trained and used for classifying 56.000 Austrian parliamentary speeches. Finally, building upon the classified speeches two examples of analysis interpretations are given.

\section{Data}

The text corpus considered is gathered from press releases of Austrian political parties, parliamentary speech transcripts and media reports from 1996 to 2013. In total, these are 56.000 speeches, consisting of more than 2 million sentences.

\subsection{Training Set}

The training data consists of more than 20.000 labeled sentences with labels from 0 to 4 where 0 means neutral and 4 stands for very negative. The sentences are taken from the previously mentioned text corpus and were labeled via crowd coding. The human crowd coders were asked to classify training sentences without any context, meaning only the sentence itself was presented. To obtain a single score for a sentence the mean of all answers was computed for each sentence. Furthermore, each single coder was checked for cheating or spamming by adding validation sentences with a predefined score into the data the coders were asked to score. Then all results of coders which did not reach an accuracy of over $75 \%$ at these test sentences were removed from the calculation of the final score. This led to a continuous score of negativity between 0 to 4 for each sentence in the data set. With these scores the sentences were grouped into three classes, namely neutral $C_{0}$, negative $C_{1}$ and very negative $C_{2}$. The decision boundaries were chosen as $4 / 3$ and $8 / 3$, see Figure 1 .

In addition to the original training data an augmented set was created which added further labeled sentences to the 20.000 sentences. The amount of added sentences consists of only 20 sentences. They comprise of common phrases in the German language, especially in political speeches, like salutations. The need for these additions arose from a qualitative analysis of classifications performed by trained classifiers. Their analysis showed that almost all salutatory addresses were recognized as negative. Searching the training data set 


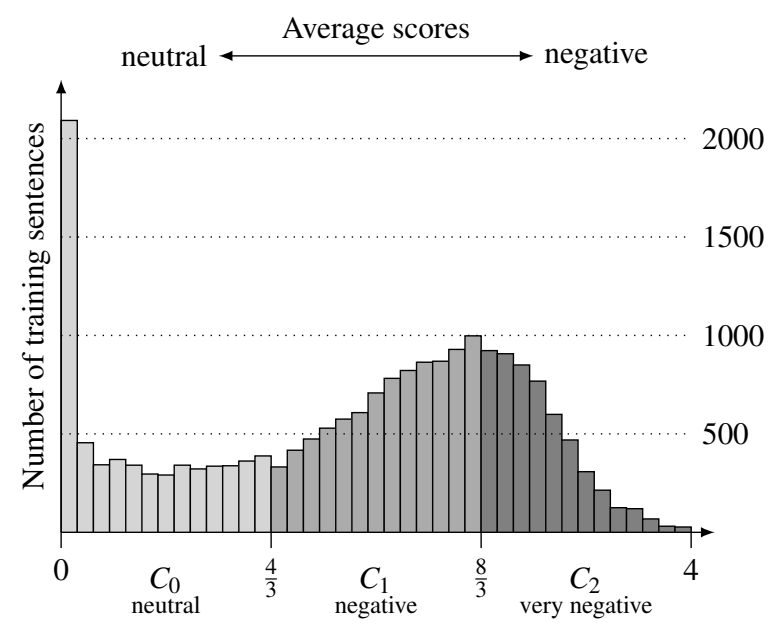

Figure 1: Average score distribution of all training sentences divided into three classes $C_{0}$ (neutral), $C_{1}$ (negative) and $C_{2}$ (very negative).

revealed that there are no positive occurrences of such phrases, but they were part of longer sentences in an ironical manner.

\section{Word Embeddings}

A word embedding is basically a vector representation for words. Their intention is to capture semantic and syntactic information within the relations between embedded words.

A basic principle within most word embeddings is well explained through a quote from John Rupert Firth (* Keighley 1890; † Lindfield 1960);

"You shall know a word by the company it keeps."

The following two embeddings are reviewed: the word2vec embedding introduced in $[6,7]$ and the fast Text embedding from [8].

The Continuous Bag-of-Words (CBOW) variant of the word2vec model is basically a log-linear classifier. The main objective is to train the classifier to predict a word given its context within a text corpus. The context of a word is the set of all $c$ previous and following words. The second variation is the SkipGram model which is structurally similar except that it is trained to predict context words given one word. They are intended to be very simple and efficient in training while having high quality representations. To get the efficiency in perspective the word2vec models are created to be able to be trained on multiple billions of words for vocabularies of millions of words. The quality is measured on different word similarity tasks. One such task is simple word similarity; for instance, Hund and Katze (In English: dog and cat) are close in the resulting vector space (according to cosine distance). Also more complex similarity tasks like if groß is similar to größer in the same sense as klein to kleiner (In English: big to bigger as small to smaller) were considered. To validate these similarities the authors used algebraic operations on the word vectors and computed $v(g r o ̈ ß e r)-v($ groß $)+$ $v(\mathrm{klein})$ and searched for the closest vector which is $v$ (kleiner). Even more remarkable is that when trained on huge data sets even more complex relations are encoded in the embedding structure like

$$
v(\mathrm{USA})-v(\text { Obama })+v(\text { Putin }) \simeq v(\text { Russland }) .
$$

The fast Text embedding comes in the same two flavors and is very closely related to the word2vec embedding. In comparison the fast Text embedding reaches higher qualitative measures. This results from a combination of multiple well-known techniques for training word vectors. In addition, the capability of embedding out of vocabulary words is added by using subword information for computing vector representations.

\section{Neural Networks}

This chapter gives a short overview of neural networks required in the following. For more details see [2, 3, 4].

A Neural Network is a network of neurons, where each neuron is a simple model of an actual neuron in the brain. One such model of a single neuron is the Rosenblatt's Perceptron. It assumes multiple inputs and a single binary output. The model computes a weighted sum plus a bias and then applies the Heaviside function. Learning is done by adapting the weights and the bias. For a neuron in a neural network this model is slightly altered by replacing the Heaviside function through a more general function $\phi$ called $a c$ tivation function. Among the most common activation functions are nowadays the rectified linear unit (ReLU) $x \mapsto \max (0, x)$, the hyperbolic tangent and the logistic function $\sigma(x)=\left(1+e^{-x}\right)^{-1}$. Let $w \in \mathbb{R}^{n}$ be a vector representing the weights for each of the $n$ inputs, $b \in \mathbb{R}$ the bias and $\phi$ an activation function. Now a single neu- 
ron is modeled by

$$
x \mapsto \phi(w \cdot x+b)
$$

A Multi Layer Perceptron (MLP) is a simple neural network which is constructed by stacking together multiple layers of parallel neurons. For every layer each neuron gets all the outputs of the previous layer as inputs.

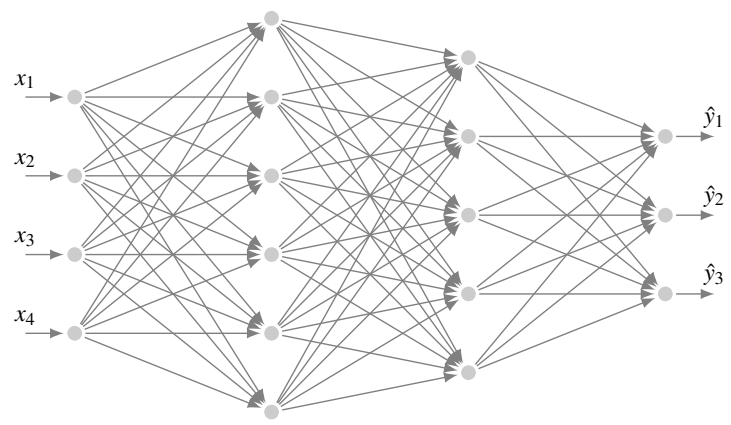

Figure 2: A three layer MLP (not counting the input layer). Each gray circle represents a single neuron.

A Convolutional Neural Network (CNN) is a neural network which uses parameter sharing and localization for processing structured data, for example images. Parameter sharing means that all neurons in one layer are using the same weights for processing their input. Localization means that a neuron is only connected to a small neighborhood of neurons of the consecutive layer.

A Recurrent Neural Network (RNN) is a network which uses back-references to keep track of previous information to process sequential data. The main working principle uses an internal state to summarize already processed data which is passed forwards while processing a sequence of data.

Assuming a finite sequence $\left(x_{t}\right) \subset \mathbb{R}^{n}$, for example a sequence of word vectors, a simple RNN layer could be constructed as follows. Let $h_{t}$ denote the internal state after step $t$ with an initial state $h_{0}$ (typically defaults to the zero vector). The weights are represented by three matrices $W, U$ and $V$. They are for processing the previous internal state, the current sequence input and the current step's output, respectively. With a bias vector $b$ and an activation function $\phi$ the next internal state is computed by summation of the transformed internal state, transformed input and the bias. Then the activation function is applied in an element-wise way. For computing an output $\hat{y}_{t}$ at step $t$ the internal state is transformed using $V$.

$$
\begin{aligned}
& h_{t}=\phi\left(W h_{t-1}+U x_{t}+b\right), \\
& \hat{y}_{t}=V h_{t} .
\end{aligned}
$$

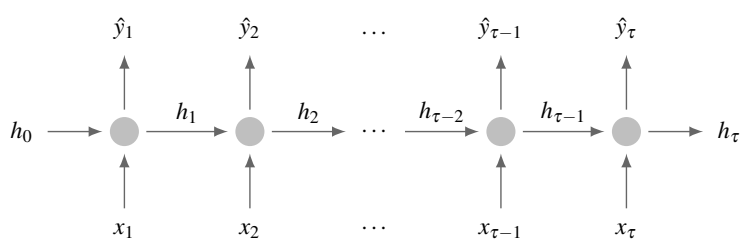

Figure 3: Information flow in an "unfolded" RNN layer for a sequence of length $\tau$. For each time step $t$ the network processes the current input $x_{t}$ as well as the last (initial) internal state $h_{t-1}$ and computes an output $\hat{y}_{t}$ while updating the internal state $h_{t}$ that is passed forward in time to be processed by the same cell for each time step.

These simple RNN constructs are hardly practical for complex tasks because they are extremely hard to train, especially for long-term dependencies. This problem was resolved by gated RNNs. The first presented gated RNN was the Long-Short Term-Memory (LSTM) network, see [2, 3]. Years later the Gated Recurrent Unit (GRU) was introduced in [4]. It uses two gates, namely a reset gate and an update gate, to control the information flow while processing a sequence. The reset gate controls how much of the previous information is considered for computing the new hidden state. If the reset gate is closed, the past is ignored by "resetting" the hidden state leaving only the current input. The update gate then decides how much of the previous hidden state shall be propagated forwards in combination with the new hidden state. The recursive definition for the update gate $u_{t}$ and reset gate $r_{t}$ with their own weights as well as the hidden state $h_{t}$ reads as

$$
\begin{aligned}
r_{t} & =\sigma\left(W_{r} h_{t-1}+U_{r} x_{t}+b_{r}\right), \\
u_{t} & =\sigma\left(W_{u} h_{t-1}+U_{u} x_{t}+b_{u}\right), \\
h_{t} & =u_{t} \odot h_{t-1}+\left(1-u_{t}\right) \odot \phi\left(W\left(r_{t} \odot h_{t-1}\right)+U x_{t}+b\right) .
\end{aligned}
$$




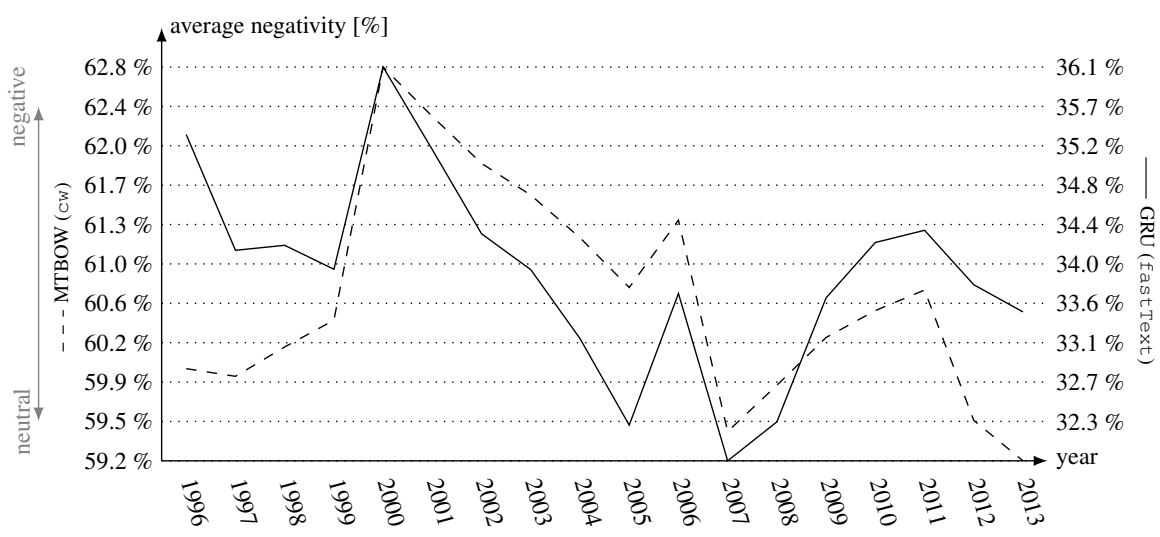

Figure 5: Comparison of Average Negativity of Speeches over Years labeled by MTBOW (cw) and GRU (fast Text).

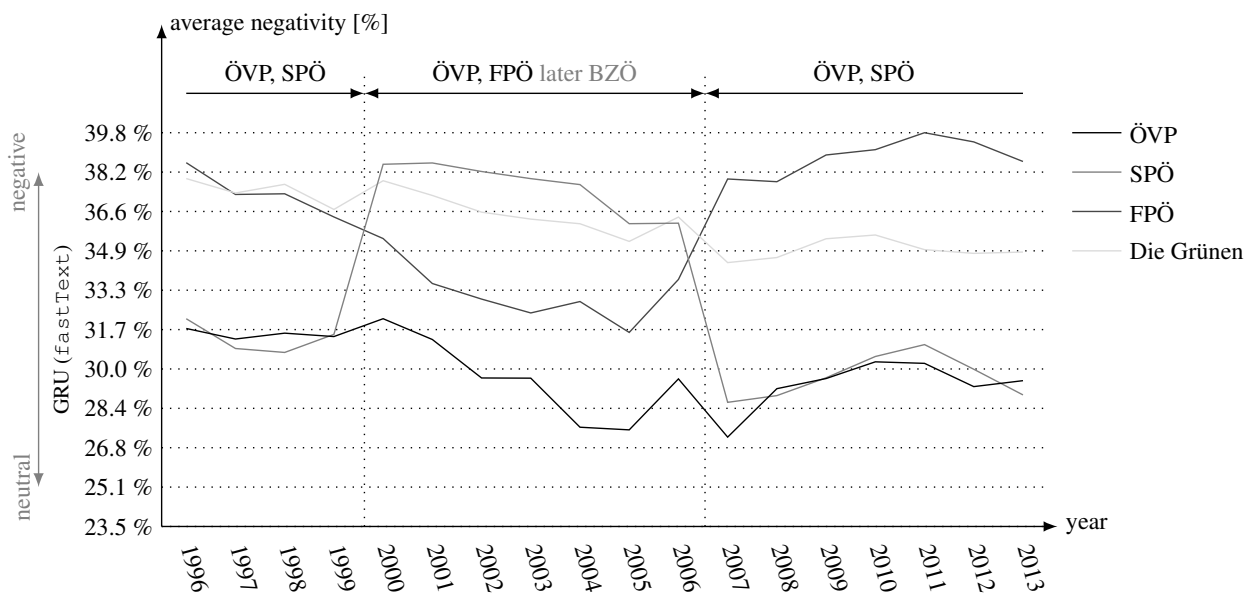

Figure 6: "Average Negativity" of Speeches over Years grouped by a subset of parties with indication of coalition.

\section{Models}

For the incivility analysis two models were used, denoted as MTBOW (cw) and GRU (fastText). The MTBOW (cw) (More Than Bag Of Words) model was initially considered in [1] and consists of a MLP in combination with the $\mathrm{cw}$ embedding provided by the Polyglot library, where the MLP was compared against conventional NLP approaches like a Naïve Bayes classifier. Building on the work of [1], different word embeddings and more complex neural network types were compared for the same task in [2]. The comparison involved different types of qualitative mea- sures from simple classification accuracy as well as precision, recall and $F_{1}$ score on a per class basis. These measures were computed for different embeddings and architectures using a grid search with a 3-fold cross validation. The most significant result was the finding that the quality of the word embedding has a significant influence on the overall quality of the model. Therefore, the fast Text embedding was chosen which performed best. The best performing model using the $\mathrm{cw}$ embedding was outperformed by the best model with the fast Text embedding by $8 \%$ in the 3 class classification accuracy. Regarding the neural network type 


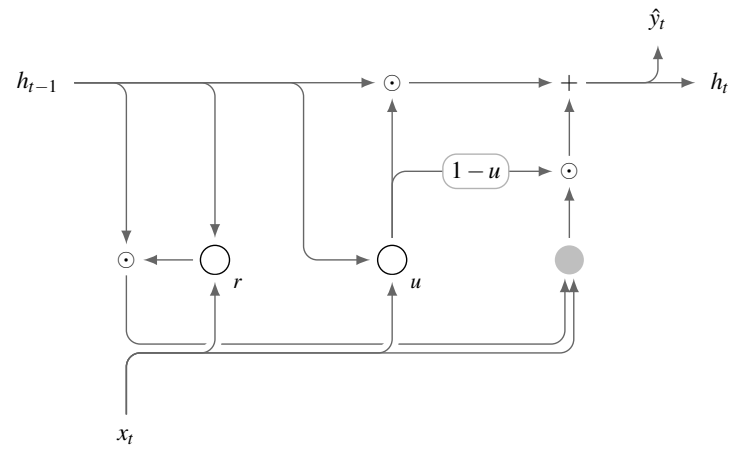

Figure 4: A single GRU cell. Inputs are $x_{t}$ and the previous hidden state $h_{t-1}$, The white circles $\bigcirc$ represent the gates where $r$ is the reset gate and $u$ the update gate. The $\odot$ operator is the element wise multiplication for applying the gating. Output is the new hidden state $h_{t}=\hat{y}_{t}$.

the gated RNN models are superior to other types like MLPs or CNNs over all used embeddings. This led to the choice of the GRU (fast Text) model for the incivility analysis.

Viewed from a modeling perspective, both models are trained in a semi-supervised manner. The word embedding was trained unsupervised in an unsupervised way, then parts of the word embedding model were frozen and transferred to the actual classification for providing embedded word vectors as input. This is also known under the term transfer learning. Then the classifier was trained in a supervised setup, using these embedded word vectors as input.

If the process of embedding words is considered as a part of the pre-processing, it can be argued that the training of the classifiers is completely supervised, especially when all used word embeddings are pretrained and provided through external sources. The Polyglot library [5] is the source of the cw embedding and the fastText embedding was provided by Facebook AI Research [8].

\section{Incivility Analysis}

Both the GRU (fastText) and the MTBOW (cw) models are used to classify all of the 56.000 speeches.

For a change of incivility over time see Figure 5 where the average incivility of all speeches per year is computed by both models. The average negativity is the average of a sentence negativity from all speeches in a specific year. The sentence negativity is set to $0 \%$ if the sentence is labeled to be $C_{0}$ (neutral), $50 \%$ if $C_{1}$ (negative) and $100 \%$ for $C_{2}$ (very negative).

There are two main points that have to be mentioned. First, there is a huge difference in the bias. Regarding who the average negativity is defined it is not reasonable to assume that the average negativity is around $60 \%$. The range of $32 \%$ to $36 \%$ seems a bit high but not unreasonable. Second, despite the bias difference both models capture a course which is quite alike. Both models agree that 2000 was a very rude year in politics. Surprisingly, from 2000 on the incivility in parliamentary speeches went down and never grew back to the tone in early 2000.

Another interesting comparison is to group the parliamentary speakers according to their party affiliation. Therefore, four parties were chosen, namely the ÖVP, SPÖ, FPÖ and the Green Party called Die Grünen. Now the average incivility for all speeches in one year grouped by the party affiliation was computed and visualized in Figure 6. Political science experts suggests that the opposing parties use a rougher tone in general which is supported by the results as follows: The ÖVP was a governing party while the Green Party were in opposition throughout the entire analyzed time period. Both were very stable in their tone like their parliamentary position and as stated in the hypothesis by political scientists the ÖVP used fewer sentences classified as containing uncivil content throughout that period than the Green Party. On the other hand the FPÖ and the SPÖ are switching between being a member of a governing coalition and opposition. In the case of the FPÖ, their incivility lowers as they gained power and finally managed to be a governing party in the beginnings of 2000. They got more and more polite until they reached the point of losing mandates to the newly founded party BZÖ and finally votes and governing power in the elections of 2007, which lead them back to a more frequent use of incivility in their parliamentary speeches. In contrast, the SPÖ was governing until the year 2000, suddenly losing in the elections and being left in the opposition. That led to an increase in the use of rude language until they got back to governing power in 2007. 


\section{References}

[1] Rudkowsky E, Haselmayer M, Wastian M, Jenny M, Emrich Š, Sedlmair M. More than Bags of Words: Sentiment Analysis with Word Embeddings. Communication Methods and Measures, Special Issue on Computational Methods; 2017

[2] Kapla D. Comparison of Different Word Embeddings and Neural Network Types for Sentiment Analysis of German Political Speeches. [Diplomarbeit]. [Analysis und Scientific Computing]. Technische Universität Wien; 2019. URL: http:

//katalog.ub.tuwien.ac.at/AC15493712

[3] Goodfellow I, Bengio Y, Courville A. Deep Learning. MIT Press; 2016

URL: http: / / www . deeplearningbook . org

[4] Cho K, van Merrienboer B, Gülçehre Ç, Bougares F, Schwenk H, Bengio Y. Learning Phrase Representations using RNN Encoder-Decoder for Statistical Machine Translation. CoRR. 2014; abs/1406.1078

URL: http: / /arxiv.org/abs/1406.1078
[5] Rami A, Bryan P, Steven S. Polyglot: Distributed Word Representations for Multilingual NLP. Proceedings of the Seventeenth Conference on Computational Natural Language Learning; Aug. 2013; Association for Computational Linguistics: 183-192.

[6] Mikolov T, Chen K, Corrado G, Dean J. Efficient Estimation of Word Representations in Vector Space. CoRR. 2013; abs/1301.3781 URL: http: //arxiv.org/abs/1301.3781

[7] Mikolov T, Sutskever I, Chen K, Corrado G, Dean J. Distributed Representations of Words and Phrases and their Compositionality. CoRR. 2013; abs//1310.4546 URL: http: / /arxiv.org/abs/1310.4546

[8] Tomas M, Edouard G, Piotr B, Christian P, Armand J. Advances in Pre-Training Distributed Word Representations. LREC. 2018; abs/1712.09405 URL: http: //arxiv.org/abs/1712.09405 


\title{
Proposing Multiple-Criteria Ranking to Simulate Building Renovation in Cities
}

\author{
Arjun Jamil ${ }^{*}$, Nils Weiss, Thomas Preisler, Wolfgang Renz ${ }^{*}$ \\ Faculty of Engineering and Computer Science, Hamburg University of Applied Sciences, Berliner Tor 7, 20099 Hamburg, \\ Germany; * \{arjun.jamil, wolfgang.renz\}@haw-hamburg.de
}

SNE 30(1), 2020, 7 - 10, DOI: 10.11128/sne.30.sn.10502

Received: May 10, 2019 (Selected ASIM SST Hamburg 2018

Postconf. Publ.), Accepted: October 10, 2019

SNE - Simulation Notes Europe, ARGESIM Publisher Vienna ISSN Print 2305-9974, Online 2306-0271, www.sne-journal.org

Abstract. Building renovation plays a huge role in reducing $\mathrm{CO} 2$ emissions and energy demand. To understand the effects of different renovation strategies, expert users and decision makers need to explore renovation scenarios both spatially and temporally. The ongoing GEWISS project aims to do this by providing a GIS (Geographical Information System) to visualize energy demand per building as well as an interface to simulate possible renovation paths to its users. This white paper presents a novel proposal to simulate future renovation paths by utilizing different user scenarios containing multiple selection criteria to rank current building stock and consequently use optimization to pass them through the user selected renovation strategy in the most optimal way.

\section{Introduction}

Existing building stock contributes to up to $40 \%$ of the EU's total CO2 emissions [1]. Renovation of building stock to national standards such as the German energy saving ordinance (EnEV 2014) is critical to reducing Germany's carbon footprint and energy usage. The GEWISS (Geographical Heat Information and Simulation System, 2014-2019, (http://gewiss.haw-hamburg.de/)) project aims to analyse and visualise heating demand and $\mathrm{CO} 2$ emissions based on the existing building stock of cities and to construct an expert tool that would help decision makers to simulate different scenarios and find the ones that would have the maximum cost effectiveness in reducing emissions and heating demand [2].

As can be seen from its contribution to the Hamburg Wärmekataster [3], the GEWISS project approaches the problem in a spatial context, effectively making it a GIS tool with additional simulation support. Another question that the decision makers in Hamburg would like to explore is the organic expansion of district heating grids in Hamburg; the GEWISS project is expected to provide insights on which areas are worth expanding into with the district heating grid. Hence the simulation ideally should also consider the district heating parameters. By knowing what future grid expansions might provide the best reduction in emissions and heating demand, the city can expand the grid in the most costefficient way.

Using classifications provided by third party project partners to the project, an underlying deterministic data model is created, one which contains select information of all current buildings in the city of Hamburg (Figure 1).

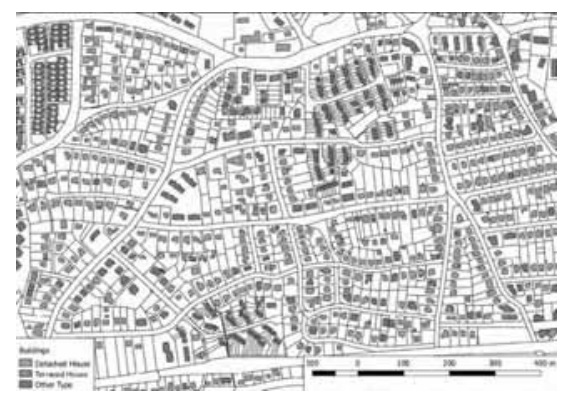

Figure 1: Map extract containing building geometry for each unique building (taken from [2]).

This data is obtained on the basis of the Hamburg ALKIS database [4] with an estimation of IWU building type [5] also for those $50 \%$ of houses where the building year is unknown [6].

Using building geometry as a metric, all the existing buildings are classified into different building types. These building types have standardised heating demand and other identifying parameters. Therefore, with this standardised building typology, a data model can be constructed, with standardised heating demand and emissions for every building unit. This paper uses this underlying data model to simulate building renovation. The data model is further explained in Section 1.

The GEWISS simulation team followed the rapid prototyping methodology and started with mock-ups based on multi-agent simulation tools [2]. The current approach is to rank all buildings in the data model and stochastically renovate ranked buildings in order according to a global renovation rate, for every year of the 
simulation run. The building's ranking score is affected by the following impact factors:

- Building type factor, maps the impact factor for different building types (IWU for residential and an Ecofys typology for non-residential buildings (Ecofys.com is GEWISS project partner)) for each year of the simulation.

- Location factor, mapping of the building's spatial allocation for each year of the simulation. Either on the level of districts, quarters or statistical areas in Hamburg to map socio-economic factors.

- Property factor, maps different impact factors for private, cooperative, company-owned and public owned property for each year of the simulation.

- Heritage protection factor, maps factors for buildings under monument protection for each year of the simulation.

To calculate scoring value, above parameters are factored only globally for every building in the current year of the simulation and are multiplied with some inherent factors, to give every building a rank. After the ranking process, a predefined percentage of the ranked buildings are stochastically renovated to a higher building standard. The current approach is limited in its flexibility, as the impact factors affecting the ranking score are based on single criteria. Therefore, only making it possible to affect the ranking of e.g. one-family houses and houses in the quarter Altona but not just 'single family houses in Altona'. Also, the current approach does not allow for temporal restrictions on selection of buildings, or the input of possible investment scenarios.

Based on the observation that the scenario modelling abilities are crucial for the applicability in studying what-if questions under various assumptions, this paper proposes a novel solution to the current limitations. First, the simulation would be user manipulatable, i.e. the user would be able to temporally and spatially identify a subset of buildings. Then, using a multi-criteria selection algorithm, the ranking of this building subset would be modified, within the entire set of buildings. This approach to referred to as the "Modifier Approach", further explained in Section 2.1. Finally, an outlook towards optimization of renovation to meet user criteria is provided in Section 3, along with suggestions for future research.

\section{Initial Parameters}

To understand the problem statement the GEWISS simulation aims to solve, a look at the available data model must be taken. The following subsection explores the foundational data model our simulation uses. Further on, the simulation's inherent properties are also explained with an outro towards the renovation thresholds in the later subsections.

\subsection{Available and Assumed Data}

The data model in consideration contains all current buildings in Hamburg as a unique entry. Their data is classified with the following attributes:
1. $B_{\mathrm{ID}}$
-Building Identifier (unique ID)
2. $B_{\text {ort }}$
-Location (District, Borough)
3. $B_{\mathrm{jahr}}$
-Construction year (estimated IWU epoch)
4. $B_{\text {typ }}$
-Building type (residential/non-residential)
5. $B_{\mathrm{ss}}$
Current renovation level (standard of renova tion)
6. $B_{\text {own }}$-Ownership of Building (Private, Public)
7. $B_{\mathrm{hs}}$-Current heating system (Gas, District heating, etc)
8. $B_{\mathrm{fw}} \quad$-Distance to the nearest district heating connection
9. $B_{\text {DMS }}$-Heritage protection status

An important parameter is current renovation level $B_{\mathrm{ss}}$ of a building. In our model, the renovation level is classified into 3 stages:

- 0 : Unrenovated state

- 1: Renovated to EnEV 2014 standards

- 2: Renovated to Passive house standards

Thereby, a renovation level of 0 means that the building has never been renovated since it was built, a renovation level of 1 means that the building has been renovated according to the German Passive House Standard which is also defined in the latest German energy saving ordinance (EnEV 2014) [7].

The simulation would operate on the selection of buildings using the above written parameters, as well as inherent factors that the simulation operates upon. These factors are explained in the following subsection.

\subsection{Inherent Simulation Operators}

The simulation operates upon two assumptions that are made of the simulated environment [2].

1. Age incentive $I_{\mathrm{rp}}-$ As age since last renovation increases, renovation chance of a building increases. Conversely; newly renovated buildings will not be considered for renovation again immediately.

2. Neighborhood Effect $I_{\mathrm{n}}-\mathrm{A}$ building's renovation affects the renovation chance of its neighbors. If a building is neighbored by renovated buildings, its renovation chance also increases.

These inherent operators define the environment of the simulation. They provide a base ranking to each build- 
ing that is then modified by user selected modifiers. Finally, depending on user prioritised modifiers, the selected buildings would then be passed through the selected renovation threshold. These are explained in the following subsection.

\subsection{Renovation Thresholds}

The simulation also relies on the following rates to change the state of considered buildings:

1. Global renovation rate $R_{\mathrm{g}}$ - Percentage of the buildings that would be renovated.

2. Passive house rate $R_{\mathrm{p}}$ - Percentage of the renovated houses that will be renovated to the passive house standard $\left(B_{\mathrm{ss}}=2\right)$

3. Rate of change of heating system $R_{\mathrm{h}}$ - Percentage chance of the change of heating system.

Using the criteria and factors explained above, the next section delves further into the proposed simulation logic.

\section{Proposed Approach}

The simulation engine is designed as a combination of multiple components. The simulation engine accepts data from the user through the "scenario editor" GUI, which supplies the simulator with the user scenarios. The simulator then outputs one list containing ranked renovation candidates. These buildings are then passed through the optimizer, that decides the optimal renovation levels for each building according to the renovation strategy. This process is pictured in figure 2 .

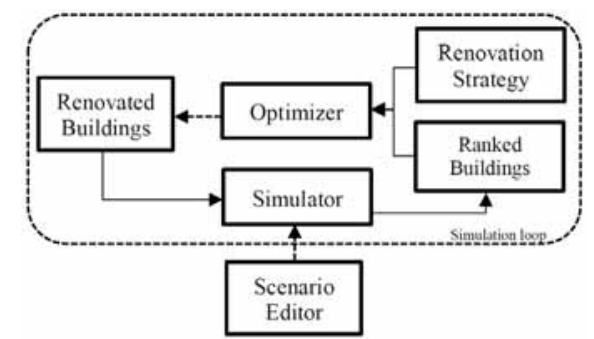

Figure 2: Proposed simulation logic. The simulation runs the ranking and renovation process for each simulation year.

Every year of the simulation run, every unique building is assigned a renovation score $\left(S_{\mathrm{i}}\right)$. The simulation ranks the buildings using the formula outlined here:

$$
S_{\mathrm{i}}=I_{r p} * I_{n}
$$

The simulation and optimizer logic are explored in detail below, with the help of an illustrative example.

\subsection{Modifier Approach}

The scenario editor uses GUI elements we call modifiers. Modifiers are criteria-based selectors, selecting a set of buildings according to user-specified criteria and modifying the rank of these buildings within the simulation. They are active for a specified finite period within the simulation. When a building satisfies the modifier criteria, the building rank of a building is altered by a user assigned modifier impact factor $\left(I_{\mathrm{m}}\right)$, in addition to the inherent operators in the simulation. Equation (2) demonstrates renovation score $S_{\mathrm{i}}$ for a building that matches criteria that was selected for modifiers $m_{1}, m_{2}$, $m_{3} \ldots m_{\mathrm{n}}$, during set time frame.

$$
S_{\mathrm{i}}=I_{r p} * I_{n} * I_{m_{1}} * I_{m_{2}} * I_{m_{3}} \ldots I_{m_{n}}
$$

Where $I \mathrm{~m}$ refers to the respective modifier impact factor set by the user. The primary objective of this approach is to allow the user to manipulate the simulation, to model stories that can represent complex real-world events.

These stories can represent financial promotion, legal incentives, or target emissions to be achieved. The following example is considered:

\section{"All unrenovated public buildings built before 1960 are renovated from gas to district heating $(F W)$ in 2025 "}

This user story uses the following parameters- renovation level $\left(B_{\mathrm{ss}}\right)$, ownership of Building (Bown), construction year $\left(B_{\text {jahr }}\right)$, heating system implemented $\left(B_{\mathrm{hs}}\right)$ and the time period of incentive. These parameters are clustered together and fed into the simulation engine in the form of a modifier. Assuming the modifier impact factor $\left(I_{\mathrm{m} 1}\right)$ to be 2 , the renovation score $\left(S_{\mathrm{i}}\right)$ of buildings selected by the modifier can be represented by:

$$
S_{\mathrm{i}}=I_{r p} * I_{n} * 2
$$

To illustrate the renovation score with the example given above, table 2 is input to the simulator as building data.

\begin{tabular}{|l|l|l|l|l|}
\hline $\begin{array}{l}\text { Build- } \\
\text { ing ID }\end{array}$ & $\begin{array}{l}\text { Renova- } \\
\text { tion level }\end{array}$ & Ownership & $\begin{array}{l}\text { Construction } \\
\text { Year }\end{array}$ & $\begin{array}{l}\text { Heating } \\
\text { system }\end{array}$ \\
\hline B1 & 0 & Private & 1960 & District \\
B2 & 0 & Public & 1920 & Gas \\
B3 & 1 & Public & 1970 & Gas \\
B4 & 2 & Private & 2000 & District \\
B5 & 0 & Public & 1940 & Gas \\
\hline
\end{tabular}

Table 2: Illustrative data input into simulation.

When the simulation is in the year 2025, the renovation ranking of selected buildings would be modified, which in this case are B2 and B5. Assuming values of Inherent operators, table 3 demonstrates renovation score for the above buildings for simulation year 2025 .

As can be seen in the above example, modifiers are able to prioritize buildings that match user specified criteria. One simulation run can take multiple modifiers into consideration, allowing the user high levels of control over the way the simulation ranks houses. 


\begin{tabular}{|l|l|l|l|l|}
\hline $\begin{array}{l}\text { Build- } \\
\text { ing ID }\end{array}$ & $\begin{array}{l}\text { Renovation } \\
\text { score }\end{array}$ & $\begin{array}{l}\text { Neighborhood } \\
\text { effect }\end{array}$ & $\begin{array}{l}\text { Modi- } \\
\text { fier 1 }\end{array}$ & $\begin{array}{l}\text { Renovation } \\
\text { score }\end{array}$ \\
\hline B1 & 1.2 & 1 & NA & 1.2 \\
B2 & 1.3 & 1 & 2 & 2.6 \\
B3 & 0.8 & 2 & NA & 1.6 \\
B4 & 0.5 & 1 & NA & 0.5 \\
B5 & 1.9 & 1 & 2 & 3.8 \\
\hline
\end{tabular}

Table 3: Illustrative ranking from simulation. Inherent factors are as- sumed values. B2 and B5 are ranked highest; modifiers are able to prioritise user selected buildings.

Taking the inherent operators into account, the simulation allows for differing values renovation rank every simulation year.

Modifiers are a form of reduced processing strategy, implemented to allow control over the decision overhead of the simulation, by allowing for multiple criteria ranking. The following section explains the steps the optimization engine takes to renovate buildings against a user set renovation strategy and concludes with an outlook.

\section{Conclusion \& Outlook}

\subsection{Renovation Strategies \& Optimization}

The user might also like to explore financial investment scenarios, or even heating demand/emission reduction scenarios. To perform these simulations, the ranked buildings must be evaluated against the renovation strategy, and then different renovation paths must be compared. This task is assigned to the optimizer. The optimizer uses global renovation rate $R 5$, passive house rate $R$ ) and heating system change rate $R$ ) as renovation thresholds. As seen in figure 2, the optimizer takes in the ranked building list from the simulation, and then passes them through the renovation thresholds optimally to match the user set renovation strategy. Given below is a list of renovation strategies considered:

1. Money invested annually to incentivize renovation.

2. Heating demand reduction

3. $\mathrm{CO}_{2}$ emission reduction

In the case of financial incentive, the user would specify a lump sum amount of money that would be invested into the city to renovate buildings through the simulation run. Using modifiers, the user can ensure that selected buildings are likelier to receive financial support. The end result in this case would show reduction in heating demand and $\mathrm{CO} 2$ emissions. When the strategy is to reduce heating demand and $\mathrm{CO} 2$ emissions, the user could specify targets that the simulation must achieve. The end result in this case would show money invested over the simulation run.
Depending on the renovation state of the building, there could be up to 2 state changes $(0 \rightarrow 1,1 \rightarrow 2)$ and/or a change in the heating system of the house. All these state changes result in differing levels of cost, and demand/emissions reduction.

Furthermore, these state changes are controlled with the renovation threshold described earlier. The optimizer must then, considering the set renovation strategy, find the best candidates in the ranking list to pass through the renovation thresholds.

\subsection{Outlook to Future Development}

Considering the optimization search space outlined in the previous subsection, the authors suggest the use of metaheuristics, with a preference towards ant colony optimisation (ACO). This would allow the optimizer to roam the search space for optimal solutions parallelly, reducing processing time and simulation overhead.

Future development might consider the implementation of renovation thresholds and strategies at a local scale, as the current implementation defines renovation thresholds and strategies globally. Using exclusion sets, the user would be able to restrict different renovation strategies spatially and temporally, allowing full control over the simulation results.

Finally, making the data model format open source might aid other researchers in the development of expert simulation and visualisation tools for other German cities.

\section{References}

[1] Balaras CA, et al. "European residential buildings and empirical assessment of the Hellenic build- ing stock, energy consumption, emissions and potential energy savings." Building and environment 42.3 (2007): 1298-1314.

[2] Preisler T, et al. "Towards an agent-based simula- tion of building stock development for the city of ham- burg." Computer Science and Information Systems (FedCSIS), 2017 Federated Conference on. IEEE, 2017.

[3] http://www.hamburg.de/energiewende/waermekataster/

[4] http://suche.transparenz.hamburg.de/dataset/alkisliegens chaftskarte-ausgewahlte-daten-hamburg

[5] Diefenbach N, et al. "Deutsche Wohngebäudety- pologie - Beispielhafte Maßnahmen zur Verbesserung der Energieeffizienz von typischen Wohngebäuden," IWU - Institut Wohnen und Umwelt, Tech. Rep., 2015. [Online]. Available: http://www.building-typology.eu/downloads/public/docs/brochure/DE_TABULA_TypologyBrochure_IWU.pdf

[6] Dochev I, et al. "Assigning IWU building types to buildings in the Hamburg ALKIS," 2017. 


\title{
Optimization of Operational Parameters in Biogas Plants using the Anaerobic Digestion Model Number 1 (ADM1)
}

\author{
David Wagner*, Wolfgang Schlüter \\ Department of Engineering, Hochschule Ansbach, Residenzstraße 8, 91522 Ansbach, Germany; \\ *david.wagner@hs-ansbach.de
}

SNE 30(1), 2020, 11 - 14, DOI: 10.11128/sne.30.sn.10503 Received: June 10, 2019 (Selected ASIM SST Hamburg 2018

Postconf. Publ.), Accepted: October 10, 2019

SNE - Simulation Notes Europe, ARGESIM Publisher Vienna

ISSN Print 2305-9974, Online 2306-0271, www.sne-journal.org

Abstract. While the main objective in energy production is the reduction of fossil fuels, CO2-production by fossil fuels increased over the last decade. Therefore the need for usage of regenerative energies is obvious. Biogas plants are advantageous because they can be used without spatial limitation and their substrate is abundant ubiquitously as it covers the whole range of produced organic matter from photosynthesis, municipal, industrial and animal waste. Although the need for optimization strategies is given, the fermentation process in biogas plants is complex and therefore traditional optimization approaches are cumbersome and carry the risk of complete plant failure. In this paper the optimization potential of the ADM1, which represents a detailed description of the anaerobic digestion process is analysed and compared to the standard ADM1 setup. Technical parameters like substrate composition and dilution rate are optimized to yield a high methane gas flow. It is shown that the optimization of substrate composition has a direct impact on the maximum applicable dilution rate. It is also shown that the feeding rate can be increased to yield higher productivities with optimized substrate compositions.

\section{Introduction}

In first half year of 2018 renewable energy sources replaced coal as the major energy resource with around 117,8 TWh [1]. From these energies, biomass is, due to its wide abundance, a perfect complement to wind and solar energy. Biomass is a prerequisite for biogas production. The fermentation process needed for biogas production is consisting of a multitude of consecutive steps with several bacterial species involved. The anaerobic digestion can be used to break down any given substrate besides wood. The need for rational optimization is given because the process complexity makes traditional optimizations difficult. Process optimization with the help of experimental design methods would be expensive and time-consuming. Although it is known that high protein amount yields higher theoretical methane production, the additionally produced ammonia is limiting the reaction rate. A condition for the usage of optimization algorithms is a suitable anaerobic digestion model. Many models are available describing the process in differing detail. However, only two of them can be seen as state of the art, the Siegrist model [2] and the anaerobic digestion model No. 1 (ADM1) [3]. Both of them were developed in 2002. Compared to the ADM1 the Siegrist model is smaller, which means lower simulation times at the price of less details. Due to its versatility the ADM1 is used more often. In the case of ADM1, Parker points out, that the validation against different anaerobic digestion scenarios is only a matter of detailed feed characterization [4]. This is also one reason why the acceptance of the model in research is higher than in industry [5]. Further reasons are the complexity of the ODEs and the need for exactly characterizing feedstock as input feed [6]. However, in a recent paper this model is described as the most comprehensive one [7]. The proposed reaction scheme of the sequential steps in the ADM1 is shown in Figure 1.

The fermentation is characterized by the following steps: A - Disintegration, B - Hydrolysis, C - Acidogenesis, D - Acetogenesis, E - Methanogenesis. While other models only include the fermentation process the 
ADM1 also considers disintegration and mass-transfer as well as cell death, which also contributes to additional particulate and inert matter (not shown in Figure 1). Therefore the strength of the model is the detailed description of underlying phenomena in the process. Hence the ADM1 is a powerful tool to tune the biogas production by applying optimization strategies. To ensure a broader industrial application of this model, in this paper the optimization potential is analysed and compared to the standard values in the ADM1 by simulation.

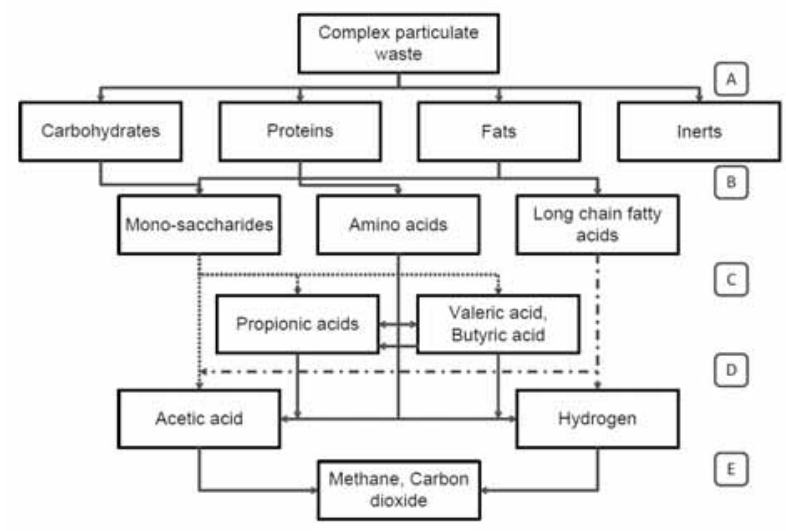

Figure 1: Biogas fermentation process depicted by ADM1 (derived and changed from [3]).

\section{Materials and Methods}

\subsection{ADM1 - Model description}

The model used in this article is an extended variation of the ADM1 of Batstone 2002. The ADM1 originally consists of 32 ordinary differential equations, while the one used in this work includes 39 state variables. Compared to the original model, equations for lactate and calcium are added. Lactate is one of the fatty acids produced in the process, while calcium is used to describe precipitation, which was not included in former models. The model itself is highly nonlinear and includes all steps shown in Figure 1. Due to the complexity, it shows some numerical inconsistencies in specific ranges. It includes physicochemical processes like gas-liquid and liquid-liquid transfer as well as disintegration steps. The hydrolysis step is divided into carbohydrates, lipids and proteins which are all first order reactions with different rate parameters. Starting parameters are the standard values described in Batstone 2002 [3] with the initial composition of particulate matter as shown in Table 1.

\begin{tabular}{llll}
\hline Carbohydrate & Fat & Protein & Inert \\
\hline Standard $20 \%$ & $25 \%$ & $25 \%$ & $30 \%$ \\
\hline
\end{tabular}

Table 1: Composition of the standard substrate.

\subsection{Simulation and Optimization}

The initial values for the optimization approach are taken from the standard substrate in Table 1 and additional parameters can be found in [3]. Simulations are done using the ode15s-solver in Matlab 9.2. If not stated otherwise the optimization is done with the tool fmincon from the Matlab Optimization Toolbox. The solver is gradient-based, fast and suited for large problems with certain constraints. A scheme of the optimization procedure is shown in Figure 2. The objective function is always the mean of maximum steady state gas flow of methane (qCH4). The optimized variables are the substrate composition (containing carbohydrates, proteins, fat and inert material) and the applied dilution rate. This leads to a five dimensional optimization problem with the additional constraint that the sum of substrate components is $100 \%$.

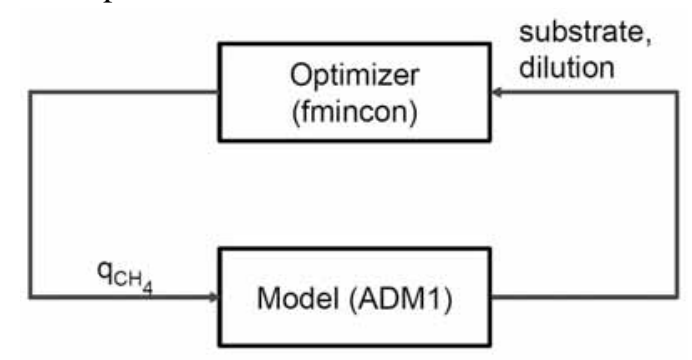

Figure 2: Scheme for optimization with fmincon.

\section{Results and Discussion}

Due to the diversity in the steps leading to methane the possibilities to optimize the process are manifold. From the available technical parameters the most important one is the dilution- or loading-rate which is directly depending on the substrate composition. Additional parameters are the initial $\mathrm{pH}$-value and the temperature. Nevertheless various inhibitory effects hinder the prediction of optimal operation points. While high protein content is favored for methane production, the ammonia originating from proteins can result in process failure [8]. The high ammonia content is especially affecting methanogenic bacteria [9] in consequence VFAs (volatile fatty acids) are accumulated and the $\mathrm{pH}$ drop leads to declining ammonia concentrations. 
Besides the aforementioned substrate, the temperature plays a main role in all (bio-) chemical reactions and is therefore a valuable optimization parameter. However $\mathrm{pH}$ and temperature are not addressed in this study because in the ADM1 the temperature effects are described by the Arrhenius equation only. This makes a detailed analysis of the temperature effects impossible. Additionally it can be concluded that the initial $\mathrm{pH}$ value has only a minor influence. While the other factors are influencing the complete time course of the process, the $\mathrm{pH}$ is changing rapidly due to the reactions in the reactor and reaches equilibrium conditions very fast. Substrate composition and dilution rate have to be optimized simultaneously.

\subsection{Substrate composition}

The substrate composition is essential in the biogas production process. It is widely acknowledged in literature that it has a big influence on the methane yield [10]. Carbohydrates are degraded faster than fats and proteins indicating higher space-time yields of methane. However this is only the case if the acetogenic steps are equally fast as the methanogenid steps. Otherwise fast accumulation of VFA results in a $\mathrm{pH}$ drop inhibiting methane production. The optimization process uses the initial parameters of substrate composition which are given in Table 1. The result of this optimization process is shown in Table 2.

\begin{tabular}{lllll}
\hline & Carbohydrate & Fat & Protein & Inert \\
\hline Optimized $0.1 \%$ & $13.8 \%$ & $86.1 \%$ & $0 \%$ \\
\hline
\end{tabular}

Table 2: Composition of optimized substrate.

It is obvious that $0 \%$ of inert material is favoured. As mentioned earlier high protein contents are also desirable.

However the optimization results are astonishing, because the optimized substrate contains nearly no carbohydrates. This fact is explicable by the fast hydrolysis of carbohydrates leading to high VFA content and a massive $\mathrm{pH}$ drop. Another significant fact is the ratio of approximately $6: 1$ between fat and protein in the optimized substrate. This result matches with literature values, shown in Table 3, demonstrating that the methane content in the biogas is increased significantly by such a ratio [10].

\begin{tabular}{lll}
\hline Substrate & Protein/ Fat ratio & Methane content \\
\hline Optimized & 6.2 & $56.8 \%$ \\
\hline Buckwheat & 6.7 & $57.4 \%$ \\
\hline Fodder radish & 5.7 & $55.1 \%$ \\
\hline
\end{tabular}

Table 3: Comparison of the optimized substrate regarding protein/fat ratio with other used substrates [10].

\subsection{Critical dilution rate (feeding rate)}

The dilution rate describes the flow rate of feed in and out of the biogas fermentation tank. Due to its continuous operation the amount of inflow is equivalent to the outflow. The feed usually contains only substrate, while the outflow contains substrate, product and biomass. Therefore biomass productivity and dilution rate are directly proportional up to the critical dilution rate dcrit. The higher the biomass productivity the more methane is produced. Therefore it is critical for process yield. The critical dilution rate defines the point where an increase of inflow leads to wash-out conditions of biomass and a resulting productivity drop. It is obvious that the maximum applicable dilution rate is coupled with the maximum bacterial growth rate. The ADM1 contains seven bacterial species, two of them are producing methane, the first one via the acetoclastic and the second via the hydrogenotrophic pathway (see Figure 1). Complete process failure is only achieved when both of them are washed out, however it is advisable not to interrupt any pathway. With the optimized substrate composition given in Table 2 the nutritional supply is higher and the applicable dilution rate is larger.

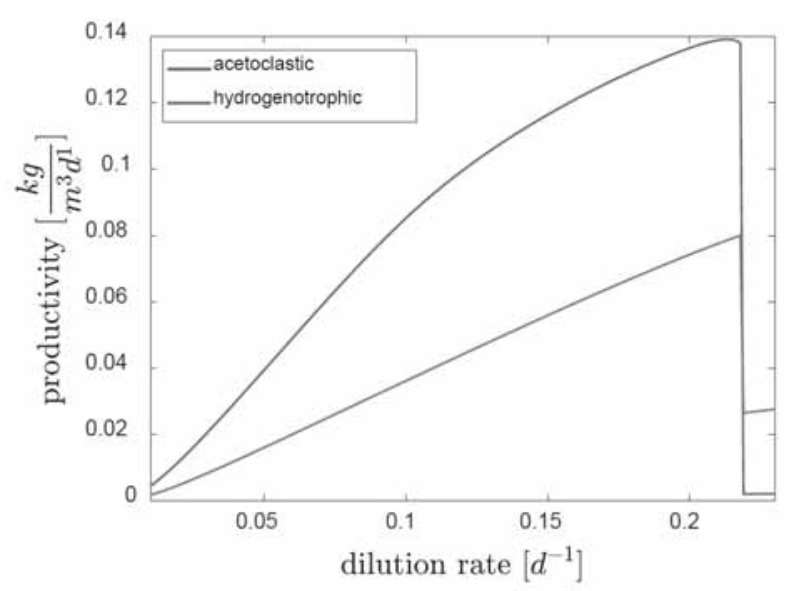

Figure 3: Critical dilution rate for acetoclastic and hydrogeotrophic biomass. 
At a dilution rate of $\sim 0.216 \mathrm{~d}-1$ complete wash-out condition is reached. An operation of $0.2 \mathrm{~d}-1$ should be favoured to maintain high methane yields respecting process fluctuations. In Figure 3 the critcal dilution rate dcrit is indicated by an abrupt productivity drop beyond a dilution rate of $0.216 \mathrm{~d}-1$.

\section{Conclusion \& Outlook}

Many experimental studies are available where different variables are tested to give highest possible methane yields in biogas plant operation. This is done either by using neural networks [11] or by hand, adding supplements to the process [12]. However, detailed experimental investigations of optimization approaches are only feasible in lab scale. The substrate optimization with the help of the ADM1 is not carried out so far. In this article it is shown that it is possible to find optimal operational parameters with the ADM1 model. The steady state methane yield was increased by $\sim 80 \%$ compared to standard values. It has to be mentioned that these are idealized values and it is doubtful that substrates are found fulfilling the optimized nutritional values. However in future applications the ADM1 could be used to define which substrate or substrate mixture should be fed in the biogas reactor. Moreover technical parameters like temperature and $\mathrm{pH}$-value could be incorporated after extending the ADM1. By carrying out these procedures the ADM1 would be a useful tool to increase the biogas production and raise the rentability of biogas plants.

\section{References}

[1] BDEW-Schnellstatistikerhebung Stat. Bundesamt 07/2018

[2] Siegrist H, Vogt D, Garcia-Heras JL, Gujer W. Mathematical model for meso- and thermophilic anaerobic sewage sludge digestion. Environ. Sci. Technol. 2002; 36: 1113-1123.
[3] Batstone DJ, Keller J, Angelidaki I, Kalyuzhnyi SV, Pavlostathis SG, Rozzi A, Sanders WTM, Siegrist H, Vavilin VA. The IWA Anaerobic Digestion Model No. 1 (ADM1). Water Sci. Technol. 2002; 45(10): 65-73.

[4] Parker WJ. Application of the ADM1 model to avanced anaerobic digestion. Biores. Technol. 2005; 96(16): $1832-42$.

[5] Batstone DJ, Keller J. Industrial applications of the IWA anaerobic digestion model No. 1 (ADM1). Water Sci Technol. 2003; 47(12): 199-206.

[6] Batstone DJ, Puyol D, Flores-Alsina X, Rodríguez J. Mathematical modelling of anaerobic digestion processes: applications and future needs. Rev. Environ. Sci. Biotechnol. 2015; 14(4): 595-613.

[7] Poggio D, Walker M, Nimmo W, Ma L, Pourkashnian M. Modelling the anaerobic digestion of solid organic waste - Substrate characterization method for ADM1 using a combined biochemical and kinetic estimation approach. Waste Manage. 2016; 53: 40-54.

[8] Chen Y, Cheng JJ, Creamer KS. Inhibition of anaerobic digestion process: A review. Biores. Technol. 2008; 99(10): 4044-64.

[9] Angelidaki I, Ellegaard L, Ahring BK. A mathematical model for dynamic simulation of anaerobic digestion of complex substrates: focusing on ammonia inhibition. Biotechnol. Bioeng. 1993; 42(2): 159-166.

[10] Herrmann C, Idler C, Heiermann M. Biogas crops grown in energy crop rotations: Linking chemical composition and methane production characteristics. Biores. Technol. 2016; 206: 23-35.

[11] Gueguim Kana EB, Oloke JK, Lateef A, Adesiyan MO. Modeling and optimization of biogas production on saw dust and other co-substrates using Artificial Neural network and Genetic Algorithm. Renew. Energy. 2012; 46: 276-281.

[12] Liu L, Zhang T, Wan H, Chen Y, Wang X, Yang G, Ren G. Anaerobic co-digestion of animal manure and wheat straw for optimized biogas production by the addition of magnetite and zeolite. Energy Converse. Manag. 2015; 97: 132-139. 


\title{
Development of a Simulation Model to Analyze the Performance of Decentral Rescheduling Algorithms in Production Systems
}

\author{
Julian Sundermeier*, Felix Gehlhoff, Alexander Fay \\ Helmut-Schmidt-University / University of the Federal Armed Forces Hamburg, Institute of Automation \\ Technology, Holstenhofweg 85, 22043 Hamburg, Germany; *Sundermeier.julian@hsu-hh.de
}

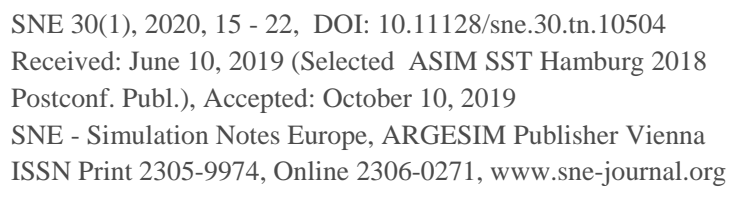

SNE 30(1), 2020, 15 - 22, DOI: 10.11128/sne.30.tn.10504

Received: June 10, 2019 (Selected ASIM SST Hamburg 2018

Postconf. Publ.), Accepted: October 10, 2019

SNE - Simulation Notes Europe, ARGESIM Publisher Vienna

ISSN Print 2305-9974, Online 2306-0271, www.sne-journal.org

\begin{abstract}
Real production systems that rely on manual productionand transportation processes are especially prone to disturbances. Thus, schedules often have to be revised on the spot by the operators using simple heuristics. These methods do not generate optimal solutions. Other approaches use agent-based control systems where the agents enable decentralized rescheduling based on local information. The following paper describes a simulation model of a production system that allows a quantitative comparison of the alternative control and planning logics by using the simulation software FlexSim ${ }^{\circledR}$.
\end{abstract}

\section{Introduction}

In today's competitive environment, manufacturing companies are confronted with the need of increasing flexibility [1]. This can be attributed to e.g. shortened product life cycles, increasing variety, and competitive pressure, which requires short and reliable delivery times [2]. Therefore, the production system must not only be able to produce efficiently, but moreover it needs to be resilient to disturbances and adaptable to changing demands. In addition, a modularized system architecture is advisable to enable system reconfigurations during ongoing production without having to adjust the control code.

Classic optimization or scheduling methods often struggle with these requirements [3]. Although these techniques can calculate an optimal solution, they require a considerable amount of time for complex problems. Furthermore, when using e.g. linear programming, it is neglected that significant and frequent changes to the production schedule create considerable noise and thus problems within the factory. Therefore, in many real production systems, classic optimization processes are usually not suitable for dynamic rescheduling. Instead, there are mostly two approaches to deal with rescheduling. One is that the operators make the dynamic control decisions on their own. Often these decisions consider only a fraction of the available information, e.g., what the operator assumes to be the most important job to fulfil next. Some companies employ software with simple algorithms which mimic such heuristics, e.g. the right shift (i.e. the postponement of all followup orders corresponding to the delayed order). This type of control results in production schedules that lag (far) behind an optimal solution, which could have been attained by using a more sophisticated algorithm.

In order to meet the stated requirements for flexibility and quality of the solution, several researchers propose agent-based control approaches. The agents enable decentralized decision-making and rescheduling based on local information. Usually, this interaction is much faster than classic optimization methods and allows a focused adaptation of the plan. However, the results achieved with decentral decision-making are usually not globally optimal.

The distribution of control intelligence and the information linked to it makes production systems more robust and represents a major goal in Industry 4.0 [4].

Despite an abundant amount of available literature on the development of multi-agent systems [1], there is still a lack of comparison - qualitatively and quantitatively - of agent-based control in case of disturbances with 'traditional' solutions [5]. Benchmark systems are one way to cope with this problem [6], but they mostly do not consider manual and thus less predictable processes. 
They also do not provide much help in terms of analysing the effects of rescheduling instead of just applying decentral control algorithms that take local decisions on the spot. Recent approaches, however, already give advice on how to measure qualitative factors such as robustness of a system that reacts to dynamic scenarios [7].

This paper describes a simulation model that enables the quantitative and qualitative comparison of different rescheduling algorithms - e.g. simulated operator decision-making, right-shift algorithms and agent-based dynamic rescheduling - to analyse the aforementioned effects. The context of the simulation model and the agentsystem is outlined in Section 1. Section 2 gives a brief introduction into the simulation software that was used to build the model. The communication scheme between the simulation and the decision maker (e.g. an MAS (multiagent system)) is explained in Section 3. This is followed by a description of the simulation model itself in Section 4. Section 5 briefly outlines the functionalities of the MAS and examines the interactions between simulation and the agents. The paper closes with a short validation of the developed simulation concepts in Section 6 and concludes in Section 7 with a brief summary and outlook.

\section{Application Context}

The simulation model resembles a factory where heavy single workpieces have to be moved between subsequent production steps. The factory comprises different production stages in two hall bays. In at least one process step, alternative workstations allow parallel processing of workpieces. Manually operated cranes in each hall bay connect the workstations. A limited number of operator teams operates the cranes. It is one goal of the simulation to replicate the estimated durations of these transport operations, as they have a significant impact on the overall productivity of the factory. These estimated durations stem from the ERP system of the considered factory and look similar to the following example in Table 1.

\begin{tabular}{lll}
\hline Start & Destination & Time needed [min] \\
\hline Workstation 1 & Workstation 2 & 30 \\
\hline Workstation 2 & Workstation 3 & 45 \\
\hline \multicolumn{2}{c}{... } &
\end{tabular}

Table 1: Excerpt of the ERP system transport data.
These times include the time that is necessary to load and unload the workpieces but do not include the time needed to reach the workpiece, i.e. the time to move the crane from its previous position to the start position of this transport.

Shuttle cars connect the two hall bays. Two product variants are produced that are made of one main body and one additional part. These additional parts require different work- and transportation processes (e.g. only one crane for transportation instead of two for the main body). One major problem is the coordination of the crane system. Due to various restrictions (e.g. the weight distribution on the ceiling construction), this task becomes particularly challenging.

If disturbances occur during production, today's human endeavours mainly constitute the right-shift after a delayed order and on the spot decisions by e.g. crane operators. This has to be replicated within the simulation model. Furthermore, it is necessary that the simulation is able to follow a specified production schedule, which is stored in a database.

In addition, there must be the possibility that an agent-based decentralized planning algorithm (or any other algorithm) can dynamically adjust or replace the production schedule when disturbances occur and thus control the simulation. If the simulation is controlled by an external planning algorithm it strictly follows the production schedule that is provided by the algorithm via the database. It does not execute any planning or rescheduling functions itself (e.g. right-shift).

\section{FlexSim ${ }^{\circledR}$ Simulation Software}

FlexSim ${ }^{\circledR}$ is an object oriented, discrete-event simulation software distributed by FlexSim Software Products Inc. (Orem, Utah, USA). Also declared as applicationoriented simulation package [8], it is especially common for the simulation of production and intra-logistic processes. FlexSim ${ }^{\circledR}$ offers a GUI with a $2 \mathrm{D}$ or $3 \mathrm{D}$ view of the model and several standard library objects that can be included into the model via drag $\&$ drop.

Generally, FlexSim ${ }^{\circledR}$ can process numerical and string values which can be stored in global variables or tables or locally in labels on an object. For further information on the capabilities of FlexSim® see [9].

FlexSim ${ }^{\circledR}$ has been chosen due to two advantages compared to other simulation software [10]: on the one hand, all library objects can be edited and complex logic can be integrated into their event-triggers by using 
FlexScript, an embedded programming language. Logic can also be added by use of $\mathrm{C}++$, but this code needs to be compiled before the model can be run. On the other hand, FlexSim ${ }^{\circledR}$ provides a standard interface to a MySQL database, which can be used for the necessary access to the production schedule. The use of a standard interface facilitates the data exchange, as no new interface has to be configured.

\section{Connecting to the Simulation via MySQL}

To ensure the required data exchange, the communication scheme depicted in Figure 1 was used.

Both, the decentralized planning algorithm and the simulation model in FlexSim ${ }^{\circledR}$ act as MySQL-clients

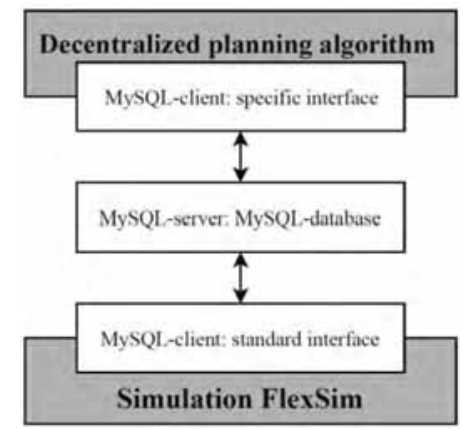

Figure 1. Communication scheme between simulation and agent-system. via appropriate interfaces to a MySQL-server with the MySQL-database. The database itself contains the three tables 'productionplan', 'resources' and 'monitoring'.

In the table 'productionplan' (see Table 3), all orders are listed according to their unique value of the label 'ID', which is used inside the simulation model. Starting at column two, every seventh column contains the title of a production step. The value of the element that is at the intersection of a row and such a column indicates the assignment of a workstation for an explicit order. The columns in between are used for data collection of the target start/finish and actual start/finish date of a process and whether the processing of an order has already been started or completed.

In the table 'resources' (see Table 4), all workstations are listed according to their unique value of the label 'Object_ID' which is used in the simulation model. In addition, the table provides information on the respective operating status of a workstation and contains information on when and where a disturbance has occurred.

For the decentralized planning algorithm only those entries are relevant which concern the occurrence of a disturbance. For this reason, a third table called "monitoring" has been created, consisting of only one element. This element serves as a binary indicator of whether rescheduling is required or not. Thus, the decentralized planning algorithm only has to monitor this value and only become active when there is a change.

\begin{tabular}{|c|c|c|c|c|c|c|c|c|}
\hline ID & Step1 & $\begin{array}{l}\text { Target start } \\
\text { time } 1\end{array}$ & $\begin{array}{l}\text { Target finish } \\
\text { time } 1\end{array}$ & $\begin{array}{l}\text { Processing } \\
\text { started } 1\end{array}$ & $\begin{array}{l}\text { Actual finish } \\
\text { time } 1\end{array}$ & $\begin{array}{l}\text { Processing } \\
\text { finished } 1\end{array}$ & Step 2 & ... \\
\hline 1 & $\begin{array}{l}\text { Value of the label } \\
\text { "Object ID" indicates } \\
\text { on which workstation } \\
\text { from the table "re- } \\
\text { sources" the order } \\
\text { should be processed }\end{array}$ & $\begin{array}{l}\text { Elapsed } \\
\text { simulation } \\
\text { time at } \\
\text { which pro- } \\
\text { cess step } 1 \\
\text { should start }\end{array}$ & $\begin{array}{l}\text { Elapsed simula- } \\
\text { tion time at } \\
\text { which the pro- } \\
\text { cessing of pro- } \\
\text { cess step } 1 \text { has } \\
\text { actually started }\end{array}$ & $\begin{array}{l}=1, \text { if pro- } \\
\text { cessing of } \\
\text { process } \\
\text { step } 1 \text { has } \\
\text { started; }=0 \text {, } \\
\text { otherwise }\end{array}$ & $\begin{array}{l}\text { Elapsed } \\
\text { simulation } \\
\text { time at } \\
\text { which pro- } \\
\text { cess step 1 } \\
\text { should end }\end{array}$ & $\begin{array}{l}=1, \text { if pro- } \\
\text { cessing of } \\
\text { process } \\
\text { step } 1 \text { has } \\
\text { ended; }=0 \text {, } \\
\text { otherwise }\end{array}$ & $\begin{array}{l}\text { Value of the label } \\
\text { "Object_ID" indicates } \\
\text { on which workstation } \\
\text { from the table "re- } \\
\text { sources" the order } \\
\text { should be processed }\end{array}$ & $\ldots$ \\
\hline .. & $\ldots$ & $\ldots$ & $\ldots$ & $\ldots$ & $\ldots$ & $\ldots$ & $\ldots$ & $\ldots$ \\
\hline
\end{tabular}

Table 3: Schematic structure of the table 'productionplan'.

\begin{tabular}{|c|c|c|c|c|c|}
\hline Object_ID & designation & WIP/BU & On/Off & Error_Type & Error_Occure_Time \\
\hline 1 & $\begin{array}{l}\text { Designation of the } \\
\text { workstation where } \\
\text { the label 'Object ID' } \\
\text { has the value } 1 \text { in } \\
\text { the simulation }\end{array}$ & $\begin{array}{l}=1 \text { if an order is } \\
\text { being processed in } \\
\text { the workstation / } \\
\text { buffered in a buffer; } \\
=0 \text {, otherwise }\end{array}$ & $\begin{array}{l}=1 \text { if the workstation } \\
\text { is functional; }=0 \text {, if } \\
\text { there is a disturbance } \\
\text { and the workstation } \\
\text { is not available }\end{array}$ & $\begin{array}{l}=1 \text { if a defect in the } \\
\text { wokpiece itself has } \\
\text { been detected; }=\ldots \text {,., is } \\
\text { not considered in this } \\
\text { paper }\end{array}$ & $\begin{array}{l}\text { Past simulation time at } \\
\text { which the disturbance } \\
\text { occurred }\end{array}$ \\
\hline$\ldots$ & $\ldots$ & $\ldots$ & $\ldots$ & $\ldots$ & $\ldots$ \\
\hline
\end{tabular}

Table4: Schematic structure of the table 'resources'. 
This value also serves as an auxiliary value for the algorithm to detect whether it has already responded to a disturbance or not. The database that serves as an interface between the simulation and a planning algorithm is integrated within the process depicted in Figure 2.

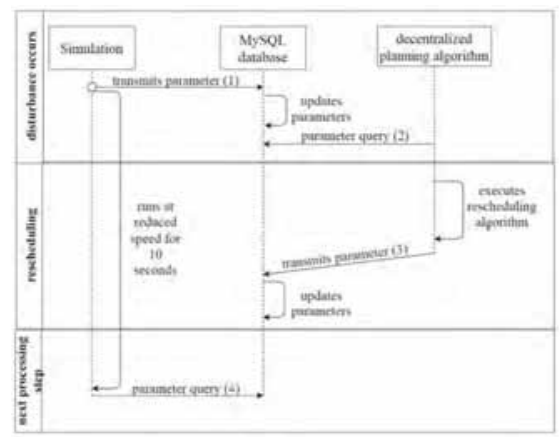

Figure 2: Sequence diagram of disturbance handling between simulation and MAS.

This process shows how the simulation and the decentralized planning algorithm interact in case of disturbances. Section 5.2 explains the details of this interaction. Due to the intended application of the decentralized planning algorithm within a real factory (see section 5.1) there should be no more than ten seconds between the occurrence of a disturbance and further processing after the rescheduling algorithm has been executed.

For the execution of the rescheduling algorithm, the decentralized planning algorithm might need up to nine of the ten seconds available. In the remaining second, there are four accesses to the database (see numbers one to four in Figure 2). First, a disturbance occurs in the simulation and the simulation sets corresponding parameters in the database. Second, the decentralized planning algorithm reads these parameters and executes the rescheduling algorithm. Third, after the execution is completed, the production schedule is updated in the database. Finally, the simulation queries the database to receive the updated production schedule and runs the model accordingly.

To validate if this concept is feasible it should be determined whether the access time to the database can fulfil a real-time criterion of a maximum of $250 \mathrm{~ms}$ (four accesses in one second). Within that access time, the connection to the database must be established and all query parameters exchanged. To analyse the access times a proof of concept model has been created (see Figure 3).

A source object creates 'flowitems' that are buffered in a queue object. The transport from the queue object to the processor object can be done either by an operator or by a transporter. The respective assignment is stored in a MySQL database. After processing on the processor object, the 'flowitems' leave the system via a sink object. If either the operator or the transporter fails during a simulation run, an agent system is activated which adjusts the assignments in the database to transport all 'flowitems' from the remaining resource.

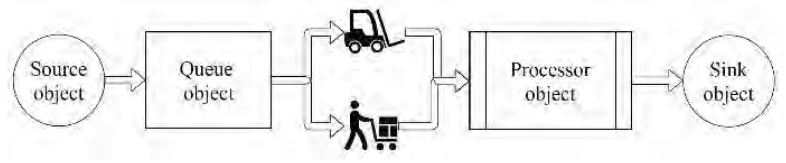

Figure 3: Structure of the proof of concept model.

In the proof of concept model, parameters from the database were queried and / or manipulated by firing individual event triggers. To determine the required access time for such an operation, the FlexSim ${ }^{\circledR}$ internal FlexScript Code Profiler tool was used (see Figure 4).

\begin{tabular}{|c|c|c|c|}
\hline \multicolumn{4}{|c|}{ Fexsopt Code Profie } \\
\hline \multicolumn{2}{|c|}{ QEnable Flesscrot code Proffing } & \multicolumn{2}{|c|}{ Reset Code Profle Data } \\
\hline If Self The (ms) & Total Time (ns) & Het count & Path \\
\hline 10674.21 & 10683.79 & 1192 & 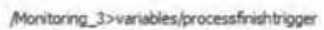 \\
\hline 29.65 & 29.65 & 4 & /Tools/MTBFMTTR/G1 2variables/downtrigge \\
\hline 26.01 & 26.01 & 3 & /Tools/MTBFMTTR/O1 2 variables/downtroper \\
\hline 24.49 & 24,49 & 3 & Mools MTEFMTTR/G1 1 variables ivptioger \\
\hline 17.16 & 27.16 & 5 & Rueve 10 svarisbles/transportidspotoner \\
\hline
\end{tabular}

Figure 4: Excerpt from the FlexScript Code Profiler tool.

Lines two through four include function calls that both query and manipulate parameters from the database. In the simulated time, the functions were called four times (see second row, third column) or three times (see third and fourth row, third column). Overall, the function calls in total according to the second column have required between $29.65 \mathrm{~ms}$ and $24.49 \mathrm{~ms}$. This results in an average access time of $5.666 \mathrm{~ms}$ per function call for reading and writing a parameter into the database. The fifth row contains a trigger in which only one value is entered (not read) into the database. This results in an access time of $3.432 \mathrm{~ms}$ per function call. In summary, access times are short enough to guarantee the real-time capability of $250 \mathrm{~ms}$.

\section{Simulation Model}

This section first discusses the conception of the simulation model. For this purpose, the basic requirements and the particular restrictions are emphasized. Subsequently, the respective implementation will be briefly discussed. 


\subsection{Conception}

A basic requirement for the control of the simulation model is that the orders run through the system according to the given production schedule. It must be ensured that the sequence of the production processes is adhered to and the actual start and finish dates are entered into the database.

Beside the basic material flow, particular restrictions must be respected during implementation. This includes e.g. compliance with follow-up constraints arising from production requirements.

The crane system is a key component of the production system, because it is indispensable for the material flow. In this context, a transport can be understood as a process characterized by a movement to the pick-up location and a transport time. These times correspond to the set-up and processing time in a production process. For this reason, a crane in the simulation model can also be represented by the standard object 'processor'. Although this abstraction restricts the visualization of the material flow in the model, it also offers an advantage. Namely, the routing of the 'flowitems' can be more easily controlled because the behavior of the input and output ports of a processor object can be specified via appropriate event triggers. Both, the time for the movement to the pick-up location as well as the transport time are stored in the database. If the production schedule was created by a decentralized planning algorithm, the time required for the movement to the pick-up location is eliminated since this movement is anticipated in advance.

In order to avoid coordination problems due to overlapping work areas of the cranes in a hall bay, capability profiles are created which define the executable transport processes of a crane. As these profiles are mutually exclusive, there are only very few possible collision points. These can be disregarded due to the very low probability and the capability of human operators in the real application to avoid the actual collision (e.g. by waiting until the other crane has been removed).

A last challenging problem occurs from the restriction that FlexSim ${ }^{\circledR}$ does not provide an option within its standard commands to cancel the processing of a 'flowitem' on a processor object. However, this is exactly what should happen when a material defect is detected so that the 'flowitem' can be transported to another workstation for a post-processing.

\subsection{Implementation}

To facilitate later adaptation or reconfiguration of the model, only standard library objects have been used for the implementation.

The routing of the 'flowitems' and the associated adherence to the process sequence is ensured by the two labels 'ID' and 'NextStep', which are stored on each 'flowitem'. While the value of the label 'ID' is constant, the value of the label 'NextStep' is adapted dynamically after the successful completion of a production step.

This is done via the 'OnProcessFinish' trigger of each processor object that represents a workstation in the simulation model. The value of the label 'NextStep' starts at 2, so it points to the second column of the table 'production-plan', where the assignment of the workstation for production step 1 takes place (compare Table 3 ). After the production step finished, the value is increased by the value 7 so it points to the ninth column etc.

For the modeling of the cranes, a pull system was implemented, which ensures that a 'flowitem' is not transported until its processing is completed and the following workstation is idle. If both conditions are fulfilled, the 'flowitem' gets pulled and the value of the label 'NextStep' is read out. Thereafter, the 'flowitem' is processed (this represents the ongoing transport) and finally send to the target workstation. The processing times correspond to the estimated times from the ERP and are chosen according to the destination. Each crane is connected to other workstations through its output ports, which reflects the implementation of its capability profile.

The actual start and finish date of a production step is set by the 'OnEntry' and 'OnExit' trigger of a processor object which represents a workstation.

Compliance with the follow-up constraints can easily be achieved due to the routing concept used.

In order to simulate the detection of a material defect, including all subsequent repair processes, a slightly more cumbersome solution was implemented. For this, a queue object was created for each workstation and then connected via the center port. After that, a separate mean time between failure / mean time to repair (MTBF / MTTR) object was created for each workstation, which is not intended to control the failure behavior of a work-station, but instead simulates the detection of a material defect. For this reason, the MTTR has been set to a very small value. 
The 'OnBreakdown' trigger contains the functions that cause the canceling of the current production step.

The 'flowitem', which is located on the workstation whose 'OnBreakdown' trigger was fired, is duplicated and the duplication is send to the connected queue object. Then the original 'flowitem' is destroyed, which represents the cancellation of the processing. When executing this command while processing a 'flowitem' on a processor object, the FlexSim ${ }^{\circledR}$ engine can no longer execute the other scheduled events of the processor object (e.g. completion of processing).

For this reason, another command must destroy all scheduled events. At the same time, this command causes the affected processor object to never receive 'flowitems' again, even if it is intended in the production plan. However, this can be removed by executing a command that resets the properties of the processor object.

After all commands of the 'OnBreakdown' trigger have been executed, post-processing of the duplicated 'flowitem' must be scheduled by the decentralized planning algorithm. This process - among others - is explained in the next section.

\section{Interaction Between}

\section{Simulation and Decentralized Planning Algorithm}

This section examines the interactions that take place between the decentralized planning algorithm (henceforth, an MAS is assumed to fulfil this role) and the simulation in case of disturbances as well as the functionalities of the MAS itself. The detailed design of the MAS is not a part of this paper, however, it is briefly outlined which functionalities are provided by the MAS.

\subsection{Functionalities of the MAS}

Starting point for the interaction between the MAS and the simulation is the creation of an initial schedule. The MAS in place is designed similar to approaches like [11] or [12]. Workpiece agents are responsible for the fulfilment of all necessary production steps for the workpiece which they represent. Requirements regarding the number and type of workpieces to be produced as well as the production plan for each type of workpiece are stored in the database. A production plan looks similar to the following example.

\begin{tabular}{llllll}
\hline ID & $\begin{array}{l}\text { Product } \\
\text { Name }\end{array}$ & Step & $\begin{array}{l}\text { Operation } \\
(0 p)\end{array}$ & $\begin{array}{l}\text { First } \\
\text { Operation }\end{array}$ & $\begin{array}{l}\text { Last } \\
\text { Operation }\end{array}$ \\
\hline $\mathbf{1}$ & A & 1 & Op_1.1 & 1 & 0 \\
\hline $\mathbf{1}$ & A & 2 & Op_1.2 & 0 & 0 \\
\hline
\end{tabular}

Table 2: Exemplary excerpt of a production plan.

All information regarding the resources is also stored in the database. The agent system uses the same table for this information as the simulation. Each resource has a certain capability. These capabilities are mapped to operations that can be accomplished by the resource.

This design, which uses a database to store all necessary information for products and resources, makes the MAS easily adjustable to changing needs and production technologies as there are no changes necessary within the code of the agents itself. When all agents are created, which happens automatically based on the information in the database, the workpieces use an auction-based process based on the Contract Net [13], which is the most common coordination mechanism for MAS [14]. As the MAS is implemented in JADE [15], the workpiece agents can search for resources that provide certain operations by using the so-called Directory Facilitator of the JADE platform.

The main goal of the agent system is to reschedule in case of disturbances. Thus, the scheduling process is not focussed on creating the optimal solution for the factory for all orders at the same time but instead schedules one job after another and tries to keep as close to already scheduled operations as possible. This results in a completely decentralized approach in which no supervisory component or agent knows all information and each agent manages its own schedule.

Each workpiece schedule is created including the transport processes, as these might be a bottleneck within the production system. To achieve this, the operations at workstations (WS) are scheduled as depicted in Figure 5, similar to [12].

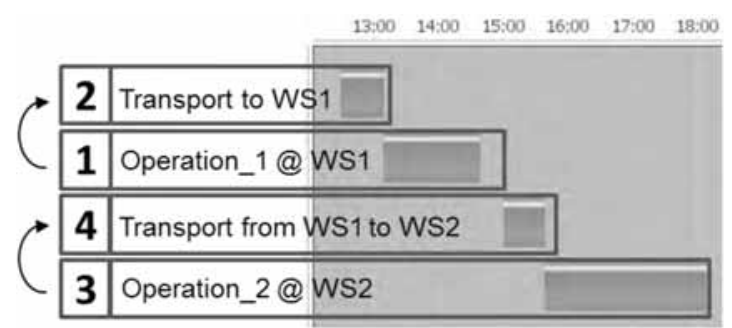

Figure 5: Exemplary scheduling in a regular case. 
The workpiece agent uses an estimation of the transport time as the earliest possible start date for the initial production operation request or CFP (call for proposal).

After the transport operations have been scheduled, the agent sends messages to the production resource agents that inform them about the actual arrival and departure times. In case the transport process is the bottleneck, the production step is cancelled and rebooked at the earliest possible arrival time. This time is derived from the best proposal of all transport resources. If a disturbance has happened that demands a deviation from the initial production plan - here a repair process at another workstation - the scheduling process follows a similar approach. The difference is that not only the production operation has to be scheduled but also the buffering and repair process. The production operation has to be scheduled first because the necessary duration, i.e. the end of the buffering process, depends on the earliest start of the production process.

\subsection{Interaction in case of disturbances}

Different situations can trigger a rescheduling process by the MAS. These vary from equipment breakdowns to process delays. The focus of this paper is on defects that are detected in the workpiece itself. When combining the MAS with the simulation, the simulation has to set the triggers for the MAS in the database that will start a rescheduling process (as shown in Figure 2).

The information provided include the error type and occurrence time in the resource table at the applicable resource. In addition, the parameter in the table 'monitoring' is set to true. The simulation also goes into a mode of slower simulation speed. This is necessary because the FlexSim ${ }^{\circledR}$ engine does not offer an opportunity to completely stop a simulation run for a certain period of time. The dynamic adaptation of the simulation speed uses the object orientation of FlexSim ${ }^{\circledR}$. Thus, the 'OnBreakdown' trigger, which is fired anyway in the detection of a material defect, spawns a new 'flowitem' in a specially created Queue object. This 'flowitem' fires the 'OnEntry' trigger of the Queue object, which reduces the simulation speed to one hundredth of the original simulation speed. In addition, the 'OnEntry' trigger sends a message to a second Queue object with a delay of 10 real-time seconds. Upon receiving the message, the second Queue object increases the simulation speed to its original value.
This procedure does not prevent the case that, during the time when the simulation is running at a reduced speed, another event occurs which relies on information from the database. However, this case is considered very unlikely and thus acceptable.

The MAS monitors a parameter that triggers its activities. If this parameter is set, the agent detects this change and reads all necessary disturbance information from the database. Afterwards the parameter in table 'monitoring' is set back to false. The information at which resource and what time the disturbance occurred enables the agent to conclude which workpiece agent is involved and needs to be contacted. The disturbance information is sent to the corresponding agent. The workpiece agent in turn up-dates its own schedule with the process finished values from the database that the simulation has set for each operation. The workpiece agent then determines which actions are needed for the disturbance that occurred. In this case, all operations that are not finished yet have to be cancelled and the already explained error handling with booking of a buffer place is started.

After the new schedule is complete, the agent sends this schedule to an agent that has the capability to insert this schedule correctly into the database (DB Connector). A socalled Sniffer Agent that comes with the JADE platform can automatically monitor and visualize the exchange of messages. An abbreviated (as can be seen from the number of messages on the left) and commented example is shown in Figure 6.

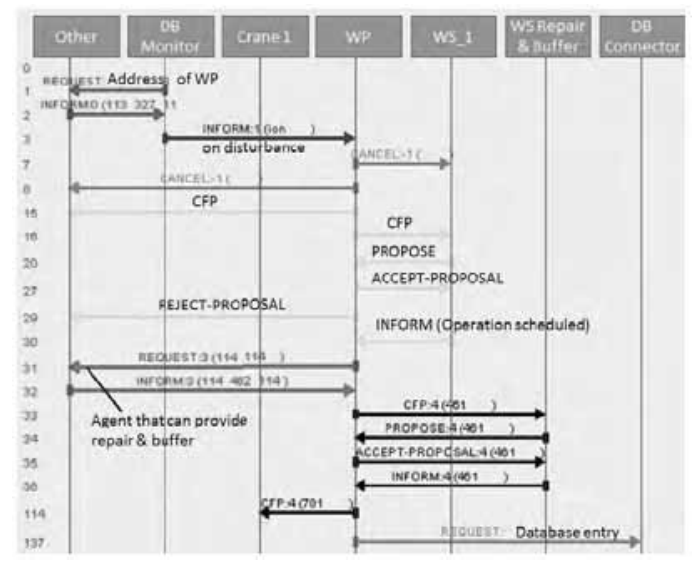

Figure 6: Sequence diagram of disturbance handling within the MAS.

The simulation now uses these actualized values to determine the correct destinations of the objects within the simulation. 


\section{Validation and Analysis}

It is necessary to validate whether the simulation model does correctly implement the production schedule that the agent system has provided and show the effects of default solutions in case of incorrect schedule data. In addition, it must be analyzed whether the production schedule is correctly implemented after a rescheduling by the agent system.

In order to validate that a provided production schedule is implemented correctly, two labels were stored on each flowitem. The production schedule as provided in advance is stored on one label. On the other label, the actual process sequence that a 'flowitem' passes through is plotted during a simulation run. When a 'flowitem' reaches the sink and both labels match, the production schedule was implemented correctly. This result was achieved in the evaluation of several simulation runs. If the rescheduling algorithm was executed during a simulation run, probably the labels no longer match. In this case, it is currently necessary to manually check whether the updated production schedule has been adhered to.

On the other hand, it could be shown that the simulation model cannot implement incorrect production schedules. If the simulation implements such a production schedule, the material flow stagnates and the simulation run is aborted.

The provided target times could be adhered to with minor deviations. This results from the comparison of the corresponding values in the database with the actual times entered by the simulation.

\section{Conclusion and Outlook}

This paper presents an approach how control algorithms, such as a decentralized planning algorithm, can be tested in combination with a simulation model in FlexSim ${ }^{\circledR}$, linked via a production schedule in a database. Since it is possible to link arbitrary algorithms to the database, the simulation model can be used to compare algorithms which implement different production schedules. Possible metrics that can be examined are e.g. the throughput time of the orders, the makespan or the impact of the occurrence of a disturbance.

\section{References}

[1] Leitão P. Agent-based distributed manufacturing control. A state-of-the-art survey. In: Engineering Applications of Artificial Intelligence 22 (7), pp. 979-991.
[2] Wiendahl HP, ElMaraghy HA, Nyhuis P, Zäh MF, Wiendahl HH, Duffie N, Brieke M. (2007) Changeable Manufacturing - Classification, Design and Operation. In: CIRP Annals 56 (2), pp. 783-809.

[3] Paolucci M, Sacile R. (2005) Agent-based manufacturing and control systems. New agile manufacturing solutions for achieving peak performance. Boca Raton Fla.: CRC Press

[4] Spath D, (Hrsg.) Ganschar O, Gerlach S, Hämmerle M, Krause T, Schlund S. Studie des Fraunhofer-Insti-tut für Arbeitswirtschaft und Organisation IAO: Produktionsarbeit der Zukunft - Industrie 4.0, Stuttgart 2013.

[5] Wior I, Jerenz S, Fay A. Automated transportation systems subject to interruptions in production and intralogistics - a survey and evaluation. In: International Journal of Logistics Systems and Management (IJLSM), Vol. 30, No. 4, 2018. DOI: http://dx.doi.org/10.1504/IJLSM.2018.10011675

[6] Schreiber S, Fay A. ARGESIM Benchmark C20 'Complex Production System' - Definition and Call. In: SNE Simulation Notes Europe, vol. 21 (3-4), 2011.

[7] Trentesaux D, Pach C, Bekrar A, Sallez Y, Berger T, Bonte T, Leitão P, Barbosa J. (2013) Benchmark-ing flexible job-shop scheduling and control systems. In: Control Engineering Practice 21 (9), pp. 1204-1225.

[8] Law AM. Simulation Modelling \& Analysis. New York: McGraw-Hill, 2007, pp. 182-185

[9] Beaverstock M, Greenwood A, Lavery E, Nordgren W. Applied Simulation: Modelling and Analysis Using FlexSim. Orem, Utah, USA: Flexsim Simulation Software, 2011.

[10] Swain JJ. Simulation software survey: Simulated worlds. In: OR/MS Today, Vol. 42, No. 5, October 2015, pp. 3649.

[11] Heinze M, Lüder A, Gantner W, Kühnle H, Peschke J. (2008) Structure and Functionality of a PABADIS'PROMISE Agent System. In: Klaus-Dieter Thoben (Hg.): ICE2008. The 14th International Conference on Concurrent Enterprising, a new wave of innovation in collaborative networks, Lisbon, Portugal, 23 - 25 June 2008

[12] Badr I, Schmitt F, Göhner P. (2010) Integrating Transportation Scheduling with Production Scheduling for FMS: An Agent-Based Approach. In: IEEE International Symposium on Industrial Electronics (ISIE), 2010.

[13] FIPA Contract Net Interaction Protocol Specification, Geneva 2002. URL: www.fipa.org/specs/fipa00029/SC00029H.pdf (Stand 26.07.2018)

[14] Caridi M, Cavalieri S. (2007) Multi-agent systems in production planning and control. An overview. In: Production Planning \& Control 15 (2), S. 106-118.

[15] Bellifemine F, Caire G, Greenwood D. Developing Multi-Agent Systems with JADE, Chichester 2007. 


\title{
An Approach to a Self-organizing Production in Comparison to a Centrally Planned Production
}

\author{
Torsten Munkelt*, Martin Krockert \\ Dresden University of Applied Sciences Faculty of Computer Science, \\ Friedrich-List-Platz 1, Dresden, 01069, GERMANY *torsten.munkelt@htw-dresden.de
}

SNE 30(1), 2020, 23 - 30, DOI: 10.11128/sne.30.tn.10506

Received: June 10, 2019 (Selected ASIM SST Hamburg 2018

Postconf. Publ.), Accepted: October 10, 2019

SNE - Simulation Notes Europe, ARGESIM Publisher Vienna

ISSN Print 2305-9974, Online 2306-0271, www.sne-journal.org

\begin{abstract}
Industry 4.0, a part of the German high tech strategy, prefers self-organization in production over central production planning for the sake of greater flexibility, faster response to disruptions and to deviations, and less effort. Current planning systems usually plan centrally. We developed a universal self-organizing production and empirically compared its performance to a centrally planned production. Compared to most other approaches, the self-organizing production does not just schedule already existing operations, but starts with material requirements, explodes the bills of materials, creates production orders, and schedules backwards. The self-organizing production is based upon agents. For better comprehensibility, we additionally implemented central planning. The results of self-organization in production are promising in relation to central planning; especially when disruptions and deviations occur. Furthermore, the results suggest as best solution a combination of rough central planning and self-organization.
\end{abstract}

\section{Introduction}

Current ERP, APS, and ME systems plan, control, and optimize production rather centrally. The systems provide "naive" resources with the following targets: when, what, where, how much, and by what means to purchase, to produce, to store, etc. Thereupon, the resources give feedback regarding time, quantity, and completion of production. According to the feedback, the above systems plan, control, and optimize anew after every shift or just every night; some are even able to react event-based but still plan centrally.
Industry 4.0 turns away from central planning, control, and optimization and promotes self-organization in production [1] which is expected to result in greater flexibility, in faster response to disruptions of the production and deviations in processing times, and in less computational effort. In this contribution, we confirm empirically that pure self-organization in production is possible. We compare a centrally planned and a selforganizing production empirically. Our experiments confirm that a self-organizing production performs as good as a centrally planned production [2] in most cases and often even better; especially when disruptions or deviations of processing times occur.

\section{Self-organization in Our Production}

Since self-organization is always an ability of a system, we initially define a system: A system is a set of components, which interact with each other and differ from the environment of the system [2]. There are many different definitions of self-organizing systems, e.g. "A self-organizing system is a system that changes its basic structure as a function of its experience and environment." [3] and "[A self-organizing system is a system in which] pattern formation occurs through interactions internal to the system, without intervention by external directing influences." [4].

In literature, the following properties are attributed to self-organizing systems $[5,4,6]$. Those properties may not be mutually exclusive and collectively exhaustive:

1. Openness: The system exchanges matter, energy, or information with its environment, and the exchange is the cause of the development of the system.

2. Adaptiveness: The systems adapts to changes in its environment.

3. Autonomy: The system and its components process all (external) stimuli from the environment according to internal mechanisms. 
4. Nonlinearity: The output of the system does not always change proportionally to its input.

5. Indeterminism: The system develops in a way, which is hard to predict because it depends on random events, or almost equal inputs lead to completely different paths of development.

6. Attraction: Over time, the system converges asymptotically to a region (a socalled attractor) in the state space of the system, and if the environment disturbs the system only slightly, the system will stay near the region.

7. Path dependence/operational closedness: The history (path of development) of the system influences the further development of the system much more than the environment of the system does.

8. Emergence: The system develops new spatiotemporal characteristics or structures as result of the interaction of its components. Those new characteristics and structures cannot be explained by the rather simple behavior of the single components.

9. Autopoiesis: The system or its components can autonomously create the components of the system. Hence the systems preserves itself.

According to the above definitions, properties 1, 2, 3, 7 and 8 are essential for a self-organizing system. Thus, if a system exhibits these properties, we will call it a selforganizing system. A production is a system, which produces goods [7]. If the production is also a selforganizing system, then it is a self-organizing production (system). Productions often also exhibit property 5 . Because of property 5 , analytical methods often fail to analyze productions successfully. Hence, we analyze our production by means of discrete-event simulation.

Self-organization in production is a central topic of Industry 4.0. The German government introduced Industry 4.0 as part of its high-tech strategy in 2011 [8]. Industry 4.0 describes the tight interlinkage between industrial production and modern information and communication technology [10]. Industry 4.0 is supposed to enable self-organizing production. Industry 4.0 comprises "intelligent" resources and "intelligent" materials. Resources are humans, machines, means of transportation, and storage systems. Materials are raw materials, purchase parts, assembly groups as well as final products. Resources and materials communicate and cooperate directly and locally and should thereby self-organize the complete value-added network.
Communication and cooperation span all phases of the product lifecycle. Concepts, programs, or platforms similar to Industry 4.0 are US-American "Smart Manufacturing", "Advanced Manufacturing", or "Industrial Value-Chain Initiative" [9], or the Chinese "Made in China 2015".

Production planning, control, and optimization already successfully applied self-organizing systems like self-organizing maps, artificial ant colonies [10], artificial neural networks [11], and genetic algorithms. However the combination of self-organizing production and Industry 4.0 leads to intelligent autonomous behaviour of machines and material, their communication, distributed computation, and in the end to multi-agent systems (MAS). For a definition of MAS and its agents, we refer to the Foundation for Intelligent Physical Agents [14]. There are three possible relationships between the agents on one side and the "intelligent" resources and materials on the other: Resources and materials are (two types of) agents, or agents connect to resources and materials physically, or agents are digital twins [12] of resources and materials. In the latter two cases, the agents make resources and materials "intelligent". In either case, the agents communicate and collaborate. Thus, the production organizes itself. Additionally, our MAS exhibits property 9: The MAS and its agents can autonomously create its agents.

\section{A Giffler-Thompson-based Resource Planning to Challenge the Self-organized Productions}

We implemented our own central production planning in order to compare a self-organizing production and centrally planned production fairly and comprehensibly. We adopted and stripped data structures and algorithms from current ERP systems, like SAP, as far as possible.

Our algorithm for central planning adapts well known scheduling and planning algorithms. It works as follows: In the first phase, the algorithm creates recursively the network of requirements and satisfiers via bill of materials explosion. Requirements are positions of customer orders, positions of production orders, or stock requirements. Satisfiers are positions of purchase orders, positions of production orders, or stock. They satisfy the requirements. 
The algorithm starts with requirements, which are not yet satisfied. During the same phase, the algorithm merges and splits lots according to fixed lot sizes and it schedules the network backwards, starting at their due time. If at least one satisfier starts in the past, the algorithm will execute phase two and phase three: In the second phase, the algorithm schedules the network forwards. It begins with the satisfiers, which start in the past and have no predecessors. In phase three, the algorithm schedules the network backwards again. It starts at the maximum of two points in time: the due time or the end time calculated by forwards scheduling. Phase three of the algorithm guarantees that the satisfiers start as late as possible. Phase four of the central planning executes finite capacity planning. It adapts the algorithm of Giffler and Thompson [13], considers earliest start times additionally, and schedules first the operation of that production order with shortest remaining slack time. Our central planning deliberately omits the phases of infinite capacity demand planning and capacity levelling because existing planning systems also do not automate these steps. Instead, we adjusted the parameters manually to guarantee a high and steady capacity utilization. Our central production planning operates periodically. When it starts anew, it changes remaining processing times and quantities according to the feedback from the production. Moreover, every new planning run firstly discards all connections between requirements and their satisfiers and secondly creates new connections with respect to the current situation of the production.

\section{Our Production Created for the Comparison of Self- Organization and Central Planning}

In order to compare self-organization and central planning, we created a production (see Figure 1). It produces two products. The products are wooden toy trucks. The bill of material of each product is three levels deep and contains 30 materials. Each material is produced in up to three operations. The operations of one material can seize a machine more than once. The operations sum up to 20 per product. Transportation times are not yet considered, but can be represented by an additional operation assigned to the material.

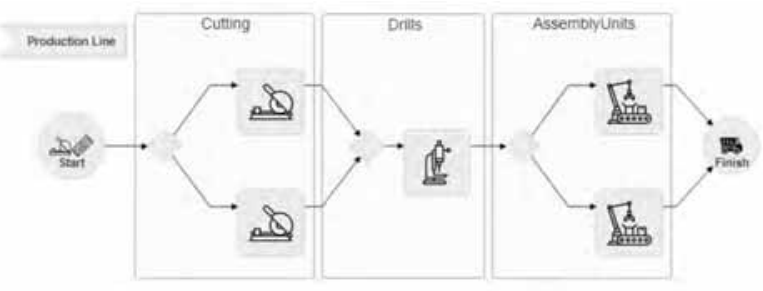

Figure 1: The main production flow involving two cutting machines, one drilling machine, and two assembly units. The production allows different routings for one product. The drilling machine is the bottleneck.

During the simulation of the production, new customer orders arrive at the production. The inter-arrival time of the orders is exponentially distributed as suggested in $[16,17]$. We choose an inter-arrival time, which leads to a well-utilized production but does not cause an overload. The production runs for two weeks, 24 hours a day. The production will produce approximately 35 products per day if the processing times do not deviate. To examine the flexibility of the production, we vary the processing times of the operations. According to [16] processing times are distributed log-normally. The inter-arrival times, the processing times, the capacity of the machines as well as the duration of the simulation can be configured separately for each simulation.

\section{Multi-agent-based Self- organization}

\subsection{Concept of a self-organizing production}

As defined in Chapter 2, a self-organizing production adapts to environmental changes. Although its components are able to build hierarchical structures, they interact as equals. Simulations of self-organizing systems commonly apply multi-agent systems [14]. The "intelligent" resources and material of Industry 4.0 also suggest a multi-agent-based approach to a self-organizing production. Hence, we also applied a multi-agent-based approach.

We defined eight different types of agents, which can be further divided into transient and persistent agents. The lifetime of transient agents starts and ends with their task. The lifetime of persistent agents starts and ends with the lifetime of the production. Figure 2 shows that all agents only know their direct neighbors. They are not aware of any other agent within the production. 


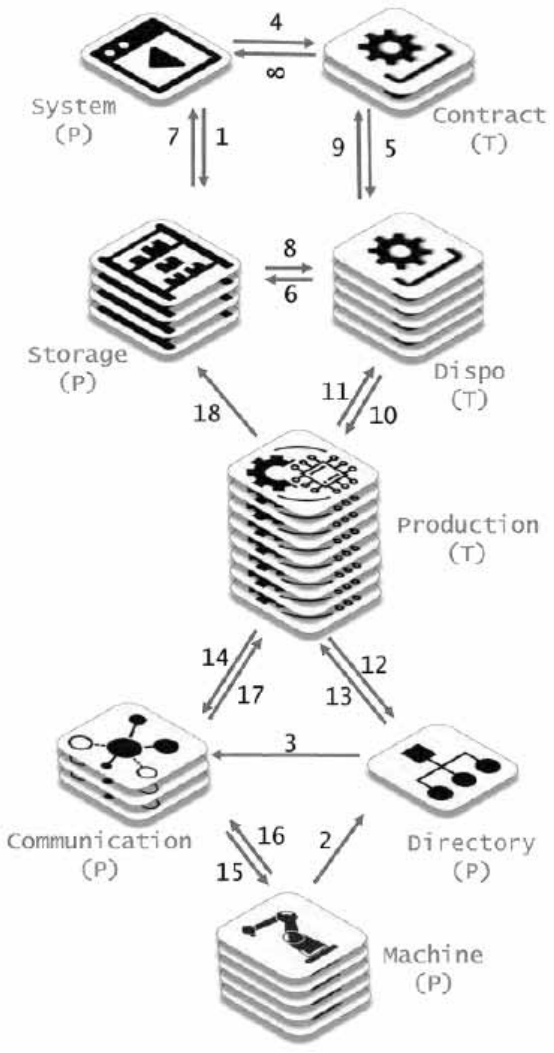

Figure 2: Concept of a multi-agent-based self-organizing production. Each symbol represents one type of agent. Each arrow is a communication path between two types of agents. In the text below, the numbers (\#number) refer to the communications paths. The letters in brackets describe the type of the agents according to their lifetime: $(\mathrm{P})$.. persistent and $(\mathrm{T})$.. transient.

Next, we explain the functionality of the multi-agentbased self-organizing production as well as the interactions between the agents. Therefore, we follow the processing of a single sales order throughout the production step by step.

\subsection{System initialization}

The MAS initializes the system, machine and directory agents during start-up and provides all required data, i.e. stock quantities to the storage agents (\#1), machine capabilities to the machine agents, etc. The agent initialized first during start-up, is the system agent, followed by the storage agents and the directory agent. The system agent is responsible for all in- and outbound communication of the MAS with its environment.
Second, the MAS creates all machine agents. The machine agents register at the directory agent and provide their capabilities (\#2). The directory agent creates and assigns a communication agent to each machine group (\#3) to provide a simple way of service discovery and to mediate between homogenous machines. Afterwards the production is ready to take orders and to start.

\subsection{Order processing}

If a new sales order arrives, the system agent will create a contract agent for this sales order (\#4). The contract agent supervises the order fulfillment. Therefore, the contract agent creates one dispo agent (\#5) for each product required to fulfill the order. The dispo agent represents a material in the real world: a digital twin. The dispo agent will ask the storage agent (\#6) if there is an equivalent product in stock at the time the sales order requires it. The storage agent will check if there is a product in stock or needs to be purchased by the system agent. (\#7). If the storage agent's response (\#8) to the request is positive, the dispo agent's task will be done and it will signal its parent agent, in this case the contract agent, that the task is finished (\#9). The contract agent signals the system agent that the contract is fulfilled $(\# \infty)$. If the storage agent's response is negative, the dispo agent will create a production agent for the required material (\#10). Then, the production agent instantiates new dispo agents for each of its components (\#11). The cycle will start again until the bill of material of the ordered product is fully processed. The contract agent does not ask the storage agent for available material directly but the newly created dispo agent does because the dispo agent has to ask for available material anyway when asked by a production agent. Thus, only one agent keeps the same functionality.

\subsection{Self-organizing scheduling with restricted horizon}

The task of each production agent is not only to order its components but also to organize all required operations to assemble its assembly group. All production agents are competing for the earliest production timeslot on a machine. Therefore, the production agent requests one communication agent for each of its operations from the directory agent (\#12). The directory agent returns the communication agent, which is responsible for the operation specified at the request (\#13). 
Afterwards, the production agent sends a "request for proposal" to the communication agent assigned to the operation (\#14), similar to the Contract Net Protocol [20]. The communication agent forwards each incoming request to all of its machine agents (\#15). Each machine agent calculates a possible start time based on the slack time of the operation and the current queue of the machine agent. That start time is returned as proposal by the machine agents (\#15) to the communication agent (\#16). After each machine agent returned a proposal to the communication agent, it decides for the proposal with the earliest start time and sends an acknowledgement to the assigned machine agent (\#15). Furthermore, the communication agent sends the assigned scheduling information to the requesting production agent (\#17).

The machine agent organizes the acknowledged proposals as operations in its own queue. Operations, which would not be processed for more than 60 minutes, are rejected with the prompt to try again after 45 minutes. Further analyses may address other time limits. If the machine agent receives an acknowledgement of an operation, this operation will be enqueued. Operations with a longer slack time than the previously enqueued operation are dropped from the queue, and the machine agent informs their communication agents to request new proposals for them (\#16). This way, another machine agent could respond with a better proposal.

After the machine processes a material, its machine agent sends a completion message to the communication agent (\#16). The communication agent forwards the message to the related production agent (\#17). The production agent receives the message and sets the status of the subsequent operation to ready, for machines are only allowed to process ready operations. If there is no subsequent operation, the production agent will assume that the material is fully processed and forward the completion message to the related dispo agent (\#11) which terminates itself because its task is done. The production agent also sends a message to the storage agent (\#18) and terminates itself because its task is also done. The storage agent provides the currently produced material to the requesting dispo agent (\#6) with the shortest slack time. After the dispo agent receives the required material, the production cycle starts over until the product is fully assembled.

\section{Results of the Empirical Comparison of a Self- organizing and a Centrally Planned Production}

\subsection{Parameters to vary}

The simulation applied the parameters specified in Table 1 . The production reached its steady state after approximately 24 hours. We added another 24 hours before we started the measurement of the KPIs. First, we chose a set of parameters both productions behaved well with: deviation of processing times $\pm 20 \%$, lot size 1 , planning scope $32 \mathrm{~h}$, planning horizon $24 \mathrm{~h}$, planning reset after $24 \mathrm{~h}$, and average time to delivery $72 \mathrm{~h}$. Applying these parameters, both productions had an average machine workload of $80 \%$ and delivered $100 \%$ of the sales orders in time. A major difference between the centrally planned and the self-organizing production was a significant deviation of lead times for both products. The centrally planned production had an average lead time of $4 \mathrm{~h}$ in contrast to the self-organizing production with an average lead time of $8 \mathrm{~h}$. This results from longer lay time between the operations which cause higher stock for all components (see Table 2).

The difference between the lay times and lead times of the centrally planned production and the selforganizing production leads back to two reasons: The self-organizing production starts as early as possible, and the Giffler-Thompson algorithm of the centrally planned production packs the operations tightly.

\begin{tabular}{ccccc}
\hline & Description & Type & \multicolumn{2}{c}{ Values } \\
\hline Deviation & $\begin{array}{c}\text { Time duration devia- } \\
\text { tion for operations }\end{array}$ & C/S & $0 / 20 / 40$ & $\%$ \\
\hline Lot-size & $\begin{array}{c}\text { Lot size for assembly } \\
\text { groups }\end{array}$ & C & $1 / 5 / 10$ & pcs. \\
\hline $\begin{array}{c}\text { Planning } \\
\text { scope }\end{array}$ & $\begin{array}{c}\text { Limit time up which } \\
\text { orders are taken } \\
\text { into account }\end{array}$ & C & $8 / 24 / 32$ & $\mathrm{~h}$ \\
\hline Planning & $\begin{array}{c}\text { Time for rescheduling } \\
\text { reset }\end{array}$ & $\mathrm{C}$ C all remaining and & $8 / 24$ & $\mathrm{~h}$ \\
\hline new orders & & & \\
\hline Order due & $\begin{array}{c}\text { Average time from or- } \\
\text { der placement to } \\
\text { delivery }\end{array}$ & $\mathrm{C} / \mathrm{S}$ & $48 / 72$ & $\mathrm{~h}$ \\
\hline
\end{tabular}

Table 1: Parameters, their descriptions, and their values for the initial simulation run, [C]entrally planned and [S]elf-organizing production. 


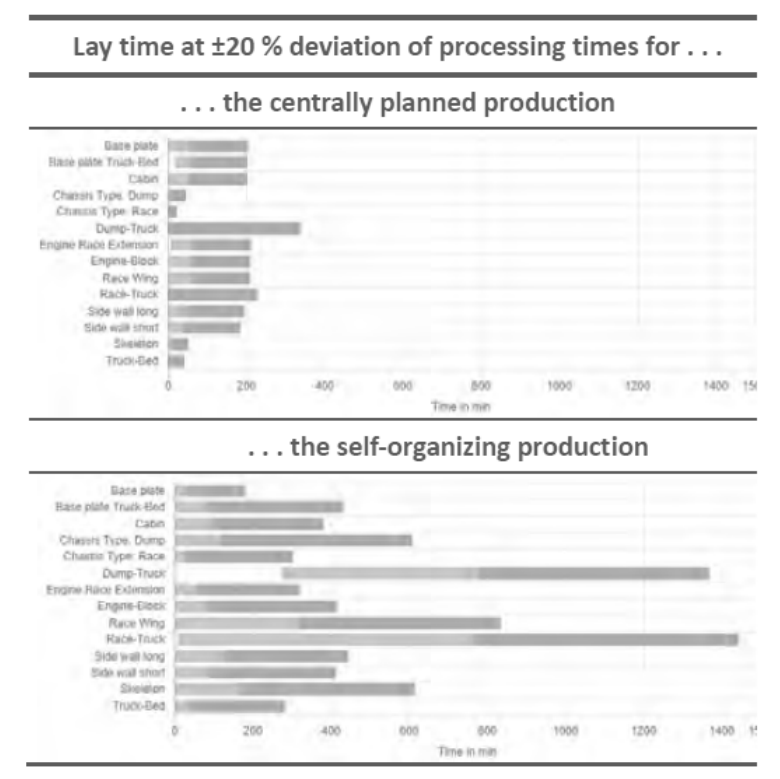

Table 2: Lay time range for each component. Green equals the lower half and red equals the upper half of the average lay time. The median lies at the transition from green to red.

\subsection{Shortening the time to delivery}

We shortened the time to delivery, to examine the performance of both productions under stress. Therefore, we ran the simulation with $\pm 20 \%$ deviation, lot size 1 , planning scope and reset after $24 \mathrm{~h}$, and in average $48 \mathrm{~h}$ to delivery. Again, both productions reached a similar average machine workload of $80 \%$. The lead time for the products increased moderately by about $\pm 20 \%$. But the centrally planned production only delivered $14 \%$ of the products in time. In contrast, the self-organizing production was able to adapt and delivered $100 \%$ of the products in time. Table 3 shows the results of the simulation and visualizes that the self-organizing production was not only able to produce everything in time, but also produced 41 more end products during the analyzed period of time.

We tried to increase the timeliness of the centrally planned production. For this purpose, we tested fixed lot sizes with 5 and 10 pieces; but the timeliness increased only marginally. In further tests, we allowed the centrally planned production to plan anew every 8 hours but the timeliness did not improve either, because new customer orders enter the system more often and processing times deviate all the time. This leads us to the conclusion that our central planning is not able to cope with shorter times to delivery. That is why we will apply professional planning systems for further comparison.

\begin{tabular}{lcc}
\hline Parameter & \multicolumn{2}{c}{ Values } \\
\hline Simulation Type & $\begin{array}{l}\text { centrally } \\
\text { planned }\end{array}$ & self-organizing \\
\hline total timeliness in [\%] & $18 \%$ & $100 \%$ \\
\hline Quantity in [pcs.] & 385 & 423 \\
\hline $\begin{array}{l}\text { Max/Min deviation from } \\
\text { delivery time in [min] }\end{array}$ & $-320 / 385$ & $-1431 /-7$ \\
\hline
\end{tabular}

Table 3: Product timeliness with $\pm 20 \%$ deviation and an average of 48 hours to delivery for all orders.

We tried to increase the timeliness of the centrally planned production. For this purpose, we tested fixed lot sizes with 5 and 10 pieces; but the timeliness increased only marginally. In further tests, we allowed the centrally planned production to plan anew every 8 hours but the timeliness did not improve either, because new customer orders enter the system more often and processing times deviate all the time. This leads us to the conclusion that our central planning is not able to cope with shorter times to delivery. That is why we will apply professional planning systems for further comparison.

\subsection{Varying the deviation of processing times of operations}

Many disruptions and deviations may occur during the manufacturing of a product. Machines may break down, products may be rejected because of quality issues, personnel may drop out, operations may take more or less time than originally planned, etc. All these disruptions and deviations lead to deviating processing times of operations. We varied the duration of processing times of operations randomly by $\pm 20 \%$ and $\pm 40 \%$ to examine the influence of the variations on the KPIs. The self-organizing production was able to handle both. It handled $\pm 20 \%$ deviation with ease, and even at $\pm 40 \%$ deviation, it delivered $94 \%$ of all incoming sales orders in time. The centrally planned production performed even worse than expected: At $\pm 20 \%$ deviation, the centrally planned production reached $14 \%$ timeliness only, and at $\pm 40 \%$ deviation, it was not able to finish any product in time. Due to the high deviation of processing times and the rather long time between two consecutive central planning runs, the average lead times grew from $200 \mathrm{~min}$ (at $\pm 20 \%$ deviation) up to $3000 \mathrm{~min}$ (at $\pm 40 \%$ deviation). In contrast, the selforganizing production had a maximum of average lead time of $1100 \mathrm{~min}$ (see Table 4). 


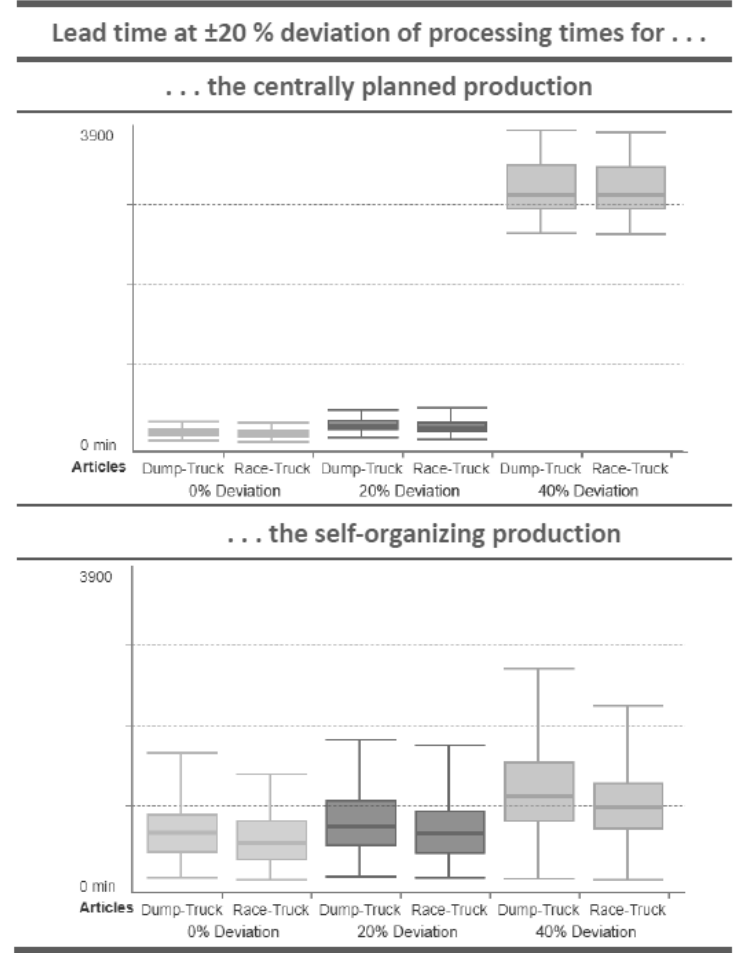

Table 4: Lead time comparison from left to right with $0 \%, \pm 20 \%$, and $\pm 40 \%$ deviation of processing times.

To reduce the lead times in the self-organized production, we delayed the production start like it is common [23]. Only when the time remaining until due time was equal to the upper fence [24] of the previous lead times, the production started. The deviation of the processing times of the operations stayed at $\pm 20 \%$. The delay led to lead times almost equal to the lead times achieved by the centrally planned production (see Table 5 ). Furthermore, the delayed start of the production reduced overall stock in the self-organizing production to values even lower than in the centrally planned production (see Table 6). Despite the delayed start of the production, the self-organizing production still completed all orders in time.

Table 5 also shows quartiles of the lead times of the self-organizing production. These quartiles are more than twice as wide as the quartiles of the lead times of the centrally planned production. To narrow the quartiles of the lead times of the self-organizing production, we will investigate how different priority rules and loaddependent start times influence lay times, lead times, and stock. In order to achieve even better results, we will combine rough central planning and our selforganizing production.

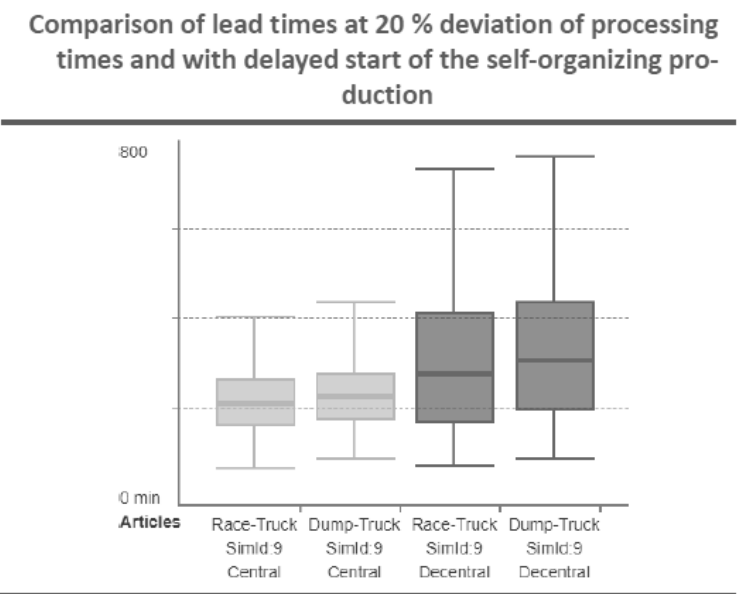

Table 5: Lead time comparison $([1,2]$ centrally planned production; [3, 4] self-organizing production).

Comparison of stock evolution at $\mathbf{2 0} \%$ deviation of processing times for...

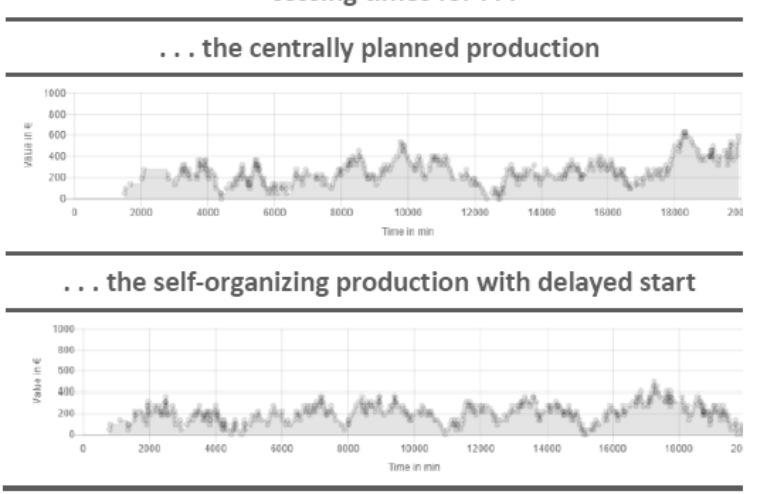

Table 6: Stock values over time in comparison.

\section{Conclusion and Outlook}

The target of our research was to develop a concept for a self-organizing production and prove the concept empirically. We developed the concept and a prototype of a self-organizing production. We let the prototype compete with a widely used and well-established algorithm for central production planning. We simulated a self-organizing and a centrally planned production with the same presets of random data and were able to prove the viability of the self-organizing production under the given circumstances. The results show that a selforganizing production is extremely robust against disruptions and deviations during physical production. While the centrally planned production stuck with its originally created plan, the self-organizing production timely adapted to deviations in processing times. 
The tradeoff were longer lay times, longer lead times, and higher stock.

Next, we will incorporate set-up times and dynamic lot-sizing in our production.

\section{References}

[1] Lasi H. Industrie 4.0,“ Wirtschaftsinformatik, pp. 261264, 04042014

[2] Scholz-Reiter B, Görges M, Philip T. „Autonomously controlled production systems-Influence of autonomous, “ in CIRP Annals -Manufacturing Technology, Bremen, 2009.

[3] Buckley WF, Society - a Complex Adaptive System: Essays in Social Theory, Amsterdam: Gordon and Breach, 1998.

[4] Clark W, Farley B. ,Simulation of self-organizing systems by digital computer, “ Transactions of the IRE Professional Group on Information Theory, Bd. 4, Nr. 4, p. 8, 1954.

[5] Camazine S, Deneubourg JL, Franks NR, Sneyd J, Guy T, Eric B. Self-Organization in Biological Systems, Woodstock: Princton University Press, 2003.

[6] Köhler-Bußmeier M. „Koordinierte Selbstorganisation und selbstorganisierte Koordination,“ Hamburg, 2010.

[7] Kauffman S. At Home in the Universe: The Search for the Laws of Self-Organization and Complexity, Oxford : Oxford University Press, 1996.

[8] Schuh G. Produktionsplanung und -steuerung, Aachen: Springer Verlag, 2006.

[9] Kagermann PDH, Wahlster PDW, Helbig DJ. „Umsetzungsempfehlungen für das Zukunftsprojekt Industrie 4.0,“"Frankfurt/Main, 2013.

[10] Bauernhansl T, Hompel MT. Industrie 4.0 in Produktion, Automatisierung und Logistik, Wiesbaden: Springer, 2014.

[11] Anderl R, Dumitrescu R, Eigner M, Ganz C, Huber AS, Michels JS, Rückert T, Tian S, Stark R, Zhi P. Industrie 4.0 genzenlos, U. Sendler, Hrsg., Heidelberg: Springer Vieweg, 2016.

[12] Klüver C, Klüver J, Jörn S. Modellierung Komplexer Prozesse durch naturanaloge Verfahren, 2 Hrsg., Wiesbaden: Spinger Verlag, 2012.

[13] Hammami Z, Mouelhi W, Said LB. ,A self-adaptive neural-agent-based decision support system for solving dynamic, " in Intelligent Systems and Knowledge Engineering, Tunis, 2015.

[14] Poslad S. „Specifying protocols for multi-agent systems interaction, " in ACM Transactions on Autonomous and Adaptive Systems, New York, 2007.
[15] Grieves DM. „Florida Institute of Technologie,“ 2014. [Online]. Available:

http://innovate.fit.edu/plm/documents/doc_mgr/9 12/1411.0_Digital_Twin_White_Paper_Dr_Griev es.pdf.

[16] Zäpfel G, Braune R. Moderne Heuristiken der Produktionsplanung, München: Vahlen, 2005.

[17] Košturiak J, Gregor M. Simulation von Produktionssystemen, Wien : Springer Verlag, 1995.

[18] Bronstein IN, Semendjajew KA, Gerhard M, Mühlig H. Taschenbuch der Mathematik, Frankfurt am Main: Harri Deutsch, 2016.

[19] Völker S. Reduktion von Simulationsmodellen zur simulationsbasierten Optimierung in der Termin- und Kapazitätsplanung, Frankfurt am Main: Peter Lang Verlag, 2003.

[20] Jonathan MEG, Hujun Y, Wright WA, Allinson NM. „Self-Organization, Emergence and Multi-Agent Systems, " in Neural Networks and Brain, 2005. ICNN\&B '05. International Conference onVolume: 3, Beijing, 2005.

[21] Ried S. „The Contract Net Protocol: High-Level Communication and Control in a Distributed Problem Solver," in Transaction on computers, Vol. C29 No 12, 1980.

[22] Corsten H, Gössinger R. Produktionswirtschaft, 13. Hrsg., München: Oldenbourg-Verlag, 2012.

[23] Mendenhall W, Beaver RJ, Beaver BM. Introduction to Probability and Statistics, Belmont, CA, USA: Cengage Learning, 2008.

[24] Dilger W. „Multiagentensysteme,“ Chemnitz , 2005.

[25] Hewitt C. ,A universal modular ACTOR formalism for artificial intelligence, " in IJCAI'73 Proceedings of the 3rd international joint conference on Artificial intelligence, Stanford, 1973.

[26] Kirmse P. „Platform Industrie 4.0,“ 2017. [Online]. Available: http://www.plattformi40.de/I40/Redaktion/DE/Anwendungsbeispiele/137wandelbare-r8-manufaktur/beitrag-wandelbare-r8manufaktur.html. [Zugriff am 1911 2017].

[27] Roth A. Einführung und Umsetzung von Industrie 4.0, Heidelberg: Springer Gabler, 2016.

[28] Soder J. Handbuch Industrie 4.0, 2 Hrsg., Bd. 1, B.Vogel-Heuser, T. Bauernhansl und M. ten Hompel, Hrsg., Springer, 2017.

[29] Schukraft S, Grundstein S, Scholz-Reiter B, Michael F. „Evaluation Approach for the Identification of Promising Methods to Couple Central Planning and Autonomous Control, “ in International Journal of Computer Integrated Manufacturing, 2015. 


\title{
Model-based Analysis of Maintenance-induced Availability of Aircraft in an Airline Network
}

\author{
Marie Bieber ${ }^{1 *}, 3$, Barbara Glock ${ }^{2}$, Alexander Plagemann ${ }^{1}$, Nikolas Popper ${ }^{3}$ \\ ${ }^{1}$ Airbus Operations $\mathrm{GmbH}$; *marietheresebieber@gmail.com \\ ${ }^{2}$ dwh GmbH simulation services, Neustiftgasse 57-59, 1070 Vienna, Austria \\ 3 Institute of Analysis and Scientific Computing, TU Wien, Wiedner Hauptstraße 8-10, 11040 Vienna, Austria;
}

SNE 30(1), 2020, 31 - 34, DOI: 10.11128/sne.30.sn.10507

Received: June 10, 2019 (Selected ASIM SST Hamburg 2018

Postconf. Publ.), Accepted: October 10, 2019

SNE - Simulation Notes Europe, ARGESIM Publisher Vienna

ISSN Print 2305-9974, Online 2306-0271, www.sne-journal.org

Abstract. Optimized aircraft maintenance concepts usually aim at increasing the aircraft availability and reducing costs. A model is presented that quantifies the effect of the increased aircraft availability when applying different maintenance concepts on an entire airline fleet. An agent-based approach is suggested: The aircraft with their maintenance tasks are dynamically assigned to the flight schedule. One major advantage of the presented methodology is that constraints for specific aircraft tails can be added easily. This is potentially of interest when testing new maintenance concept that are more focused on optimizing maintenance for single aircraft, by e.g. a stronger dependency on aircraft usage and findings.

\section{Introduction}

Currently a lot of studies are done on aircraft maintenance and its optimization to create more availability. In further consequence this leads to an economical and operational advantage for the airline operating the aircraft. Aircraft make money when they are flying. So, the baseline for airline planning is the sentence "The schedule is the king." Once the airline has flights scheduled and tickets sold, the most important thing is to operate those flights. Usually airlines plan in the following way:

1. Master Schedule design: An optimal set of flight legs is selected.

2. Fleet Assignment: The aim of the fleet assignment is to determine which type of aircraft should fly each flight leg.
3. Aircraft Scheduling: The schedule of each aircraft is determined including all maintenance tasks and the commercial constraints.

4. Tail assignment: According to the schedule and the aircraft schedules a tail number is assigned to flight legs. The master schedule is translated into an operational flight schedule.

5. Crew Assignment: To each flight leg a crew is assigned according to the working constraints of the crews.

Once the schedule is planned it is operated and continuously updated. Operational interruptions might occur and lead to delays or cancellations. This might have as a consequence changes in the operational flight schedule.

\section{Methods}

Clearly, changing the number of revenue flights means that the master schedule has to be changed. However, changing the master schedule has a big impact on airline operations and depends on a lot more factors than considered in this paper, like the airline policy. The approach used is to not change the master schedule itself but instead work with the currently used master schedule containing $\mathrm{n}$ flight legs and fix the fleet size as the smallest number of aircraft, such that all flight legs of the master schedule can be operated without any maintenance constraints. When taking into account maintenance the aircraft are able to operate $m \leq n$ flight legs of the master schedule. The number $m$ is the model output and can be used as a measurement of the effect of introducing the maintenance concept in the airline fleet. In fact, the problem that has to be dealt with is the tail assignment problem. 


\subsection{Linear Programming Approach}

In the classical approach, which is broadly used in the existing literature, the first task faced in solving the tail assignment is to identify a set of feasible flight routes that can be operated by a single aircraft. Often the maintenance constraints are already considered in this step of the tail assignment. In [1] this is described as "maintenance routing". Maintenance is often done at night due to flight restrictions. Considering this aspect [2] propose algorithms to model the aircraft routing due to these maintenance requirements. Another method to solve the maintenance routing problem is presented by [3]. As an input a fixed flight schedule with aircraft assigned to it is given, which is then optimized by reassigning the aircraft to flight routes (set of flight legs) in order to undergo different maintenance checks. A heuristic approach is provided to solve the problem of minimizing the maintenance cost and costs incurred during the reassignment of aircraft to flight segments.

The most common mathematical model used to describe the tail assignment problem is an integer linear program. This was already presented by [4]. The practise today is to combine the mathematical models with constraint programming techniques. While mathematical programming is more focused on optimization rather than on quickly obtaining a solution, constraint programming obtains a feasible solution quicker. The first approach combining the mathematical and constraints programming techniques to solve the tail assignment problem was presented by [1]. It is a very convenient approach since achieves both accuracy and is quick enough for practical use. In fact, the work has been the basis for various further studies on the tail assignment problem and is used by several airlines.

The main objective of an airline is to operate the master schedule. Operational interruptions of any kind should be avoided. The problem is examined by [5] in his doctoral thesis where two mathematical models for the robust tail assignment are proposed. They are solved by an extension of the standard solution methods presented in [1]. Another approach introduced by [6] addresses operational uncertainty by extending the oneday routes aircraft maintenance implicitly for the subsequent two days. However, here also the flight routes are given as an input, but can be modified by an iterative algorithm.

\subsection{Agent-based Modelling}

As opposed to the linear programming model, which is a top-down solution approach, an agent-based model provides a bottom-up approach. Rather than looking at the entire model system the focus lies upon each individual entity and its behaviour within the system. An agent-based system consists of one or more autonomous individuals, the agents. In [7] an 'agent' is characterized by autonomy, reactivity, pro-activeness and social ability, i.e. interaction with other agents. An agent-based model, as [8] states that 'An agent-based model is a simulation model that employs the idea of multiple agents situated and acting in a common environment as central modelling paradigm.'

The model presented in this paper is based on an agent-based approach mainly due to the adaptiveness of agent-based models. Maintenance tasks can be added to each aircraft, which allows the flexibility to define specific tasks depending on the aircraft usage or other factors. Another advantage of the agent-based approach is that instead of separating the airline planning process from the real aircraft operations, both are dynamically combined. Probabilities of delay, delay propagation and operational interruptions can bbe considered directly in the airline planning. This enables one to optimally plan airline operations in a robust and realistic way.

\section{The Agent-based Model}

The model consists of aircraft agents and the airline network represented through the master schedule that should be operated by the aircraft. The model returns the number of revenue flights operated in a specified period of time.

The main scope of the agent-based model is to show the effect of a maintenance induced increased availability of aircraft on airline operations. This is done by modelling the aircraft tails, their behaviour and movements and embedding them in the airline network. This can be seen in Figure 1, where the agents behaviour is described in a state chart. An aircraft agent can be assigned to a flight leg. After landing, if a maintenance task package is due, the aircraft undergoes maintenance. When the maintenance is finished, it is assigned a buffer time to be prepared for the next flight. If it does not undergo maintenance, the aircraft is directly assigned a buffer time when it landed. As soon as the buffer time passed, it becomes available for flights again. 


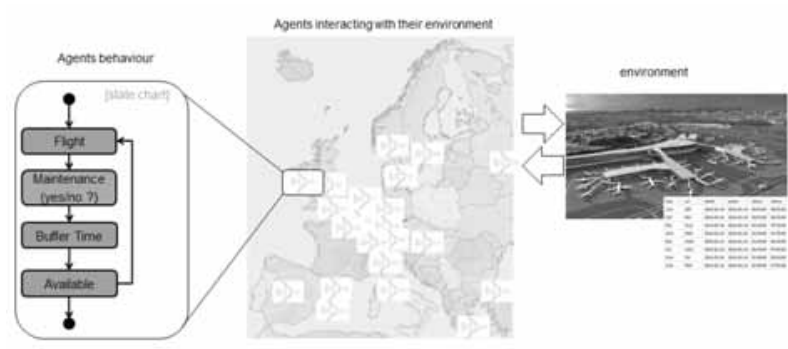

Figure 1. ABM generic architecture.

One of the characteristics of the model is that the operational flight schedule is created dynamically during a simulation run. The aircraft follow specific rules defining their behaviour. Flight legs, turn around times and maintenance tasks are assigned to the aircraft tails in the moment they occur. Therefore, not only the flight routes are created dynamically but also the ground times between flights and the maintenance ground times.

\section{Results}

Based on in-service data and real airline data the model was tested for various maintenance scenarios. One of those scenarios aimed at analysing the effect of check overruns. Scheduled maintenance includes regulated maintenance tasks, that have to be performed regularly. The most common maintenance packaging practise is to perform checks in regular intervals, such as daily or weekly checks. A typical task packaging setup is illustrated in Table 1.

\begin{tabular}{lll}
\hline maintenance type & frequency (days) & duration (hours) \\
\hline daily & 1.5 & 2 \\
\hline weekly & 8 & 3 \\
\hline A & 190 & 8 \\
\hline $1 C$ & 730 & 93 \\
\hline $2 C$ & 1460 & 140 \\
\hline $6 Y$ & 2190 & 350 \\
\hline $12 Y$ & 4380 & 730 \\
\hline
\end{tabular}

Table 1. Typical scheduled block type maintenance packages.

The term check overrun refers to the phenomena that performing a maintenance task package took for an unexpected reason longer than it was scheduled. But does reducing these overruns have a considerable impact on airline operations?
The scenario of a $1 \mathrm{C}$ check overrun is simulated for an example airline with a calibrated fleet size of 31 aircraft. Instead of the usual duration of 93 hours one assumes the check to take 98 hours (which equals an overrun of around 0.2 days). The overall results in terms of the number of revenue flights and the average ground times for the simulated period of time are given in Table 2 .

\begin{tabular}{llc}
\hline & no overrun & overrun \\
\hline $\begin{array}{l}\text { Number of revenue } \\
\text { flights }\end{array}$ & 6325 & 6325 \\
\hline $\begin{array}{l}\text { Average ground } \\
\text { time (seconds) }\end{array}$ & 12100.29 & 12095.13 \\
\hline
\end{tabular}

Table 2. Results for the Scenario 1C Check overrun.

In Figure 2 the number of revenue flights for every aircraft tail are listed where the tails that had to undergo a 1C checks are highlighted. Similarly, Figure 3 displays the average ground times for every aircraft tail.

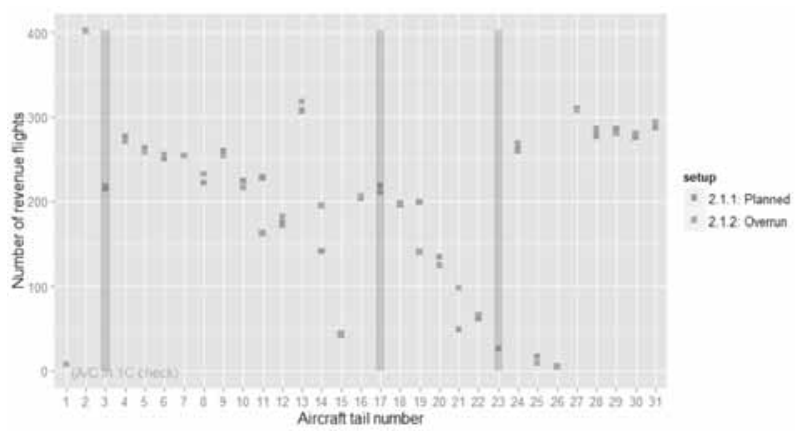

Figure 2. Number of revenue 2ights per aircraft tail for the $1 \mathrm{C}$ check overrun.

The simulation reveals that increasing the duration for a $1 \mathrm{C}$ check overrun does not have a significant impact, neither on the total number of revenue flights operated during the time frame nor on the average ground times. For the aircraft tails that had to undergo the $1 \mathrm{C}$ check the results are more in alignment to what is expected: For two aircraft tails the number of revenue flights decreased in the overrun setup and the average ground time increased.

A reasonable explanation for this is that the model dynamics causes an aircraft that is delayed unexpectedly to be replaced by another aircraft dynamically. As a consequence, delays are compensated directly and with a simplicity that is not feasible in reality. The fleet size of the airline is big enough to compensate a downtime of a single aircraft tail efficiently. 


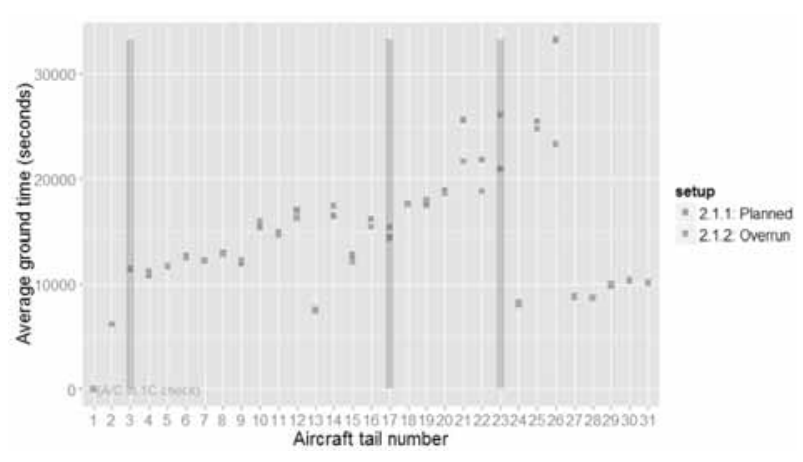

Figure 3. Average ground times per aircraft tail for the $1 C$ check overrun.

\section{Challenges and Future Developments}

During simulations it was observed that some unexpected results are due to a poor fleet size calibration. As a next step, it would be suggested to work on that matter.

One major limitation of the model was observed to be how it handles an unexpected delay, in this case for maintenance tasks. Rather than reflecting the effect of the very complicated process of adopting to unexpected changes, as it would happen in real airline operations, the model assigns a different aircraft tail to the flight that should be operated and therefore dynamically solves the interruption caused in airline operations. To see the effects of e.g. an overrun as it happens in reality better, a possibility would be to first run the model and than use the thereby created tail assignment as a constraint for the second run, where the aircraft operations are simulated.

\section{Conclusion}

The model performs quite well when tuning the input parameters to be very close to what is used for real flight operations. This is also true for the maintenance setup.
When changing the maintenance scenario significantly, the model adopts to the new setup. Then, the results for the number of operated revenue flights and average ground times are much closer to the classical maintenance scenario than what is observed for real flight operations.

All in all, the approach has the potential to be developed further for performing tail assignments that are adoptable to a wide range of maintenance scenarios and is adaptive to changes. Through using an agent-based approach a new methodology was devised that provides an alternative to the classical linear programming approach. In the agent-based approach constraints and attributes can be altered for single aircraft tails. One promising application for the model would be to analyze the effect of maintenance concepts that are more dependent on the usage in flight hours or flight cycles or individual findings or failures for single aircraft tails. The paper provides the framework for further investigations into this field.

\section{References}

[1] Grönkvist M. The tail assignment problem. Chalmers tekniska högskola. 2005.

[2] Gopalan R, Talluri KT. The Aircraft Maintenance Routing Problem. Operations Research. 1998; 46:260-271.

[3] Sriram C, Haghani A. An optimization model for aircraft maintenance scheduling and re-assignment. Transportation Research Part A: Policy and Practice. 2003;37(1):29-48.

[4] Levin A. Scheduling and fleet routing models for transportation systems. Transportation Science. 1971; 5(3):232-255.

[5] Dovica I. Robust tail assignment. 2014;

[6] Maher SJ, Desaulniers G, Soumis F. The tail assignment problem with look-ahead maintenance constraints. 2015;

[7] Wooldridge M. Agent-based software engineering, vol. 144. 1997.

[8] Siegfried R. Modeling and simulation of complex systems: A framework for efficient agent-based modeling and simulation. Springer. 2014. 


\title{
MOR for the MSFEM of the Eddy Current Problem in Linear Laminated Media
}

\author{
Hollaus Karl ${ }^{*}$, Schöberl Joachim, Markus Schöbinger \\ Department of Analysis and Scientific Computing, Vienna University of Technology, Wiedner Hauptstraße 8-10, \\ 1040 Vienna, Austria; *karl.hollaus@tuwien.ac.at
}

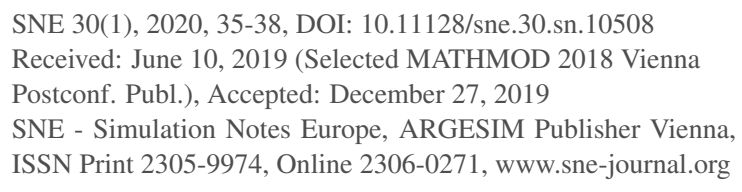

SNE 30(1), 2020, 35-38, DOI: 10.11128/sne.30.sn.10508 Received: June 10, 2019 (Selected MATHMOD 2018 Vienna

Postconf. Publ.), Accepted: December 27, 2019

SNE - Simulation Notes Europe, ARGESIM Publisher Vienna, ISSN Print 2305-9974, Online 2306-0271, www.sne-journal.org

Abstract. The multiscale finite element method has proven to be a powerful method in the simulation of eddy currents in laminated cores. However, the resulting equation systems of the problems relevant in electrical engineering are still too large to be solved conveniently. The use of model order reduction methods to overcome this shortcoming is obvious. The feasibility to exploit the specific approach of the multiscale finite element method in terms of a structural model order reduction method has been studied in this work. A small numerical example shows satisfactory results.

\section{Introduction}

The simulation of the eddy currents in electrical devices with the finite element method (FEM) is satisfactory. However, the large systems to be solved result in high computational costs, i.e. memory requirement and computation time. Although the multiscale finite element method (MSFEM) can be exploited to simulate eddy currents in laminated iron more efficiently the complexity of the problems are still too large to solve them conveniently. The computational costs are a multiple of the costs of anisotropic models in brute force methods according to the components used in the multiscale formulation, compare with [2].

Model order reduction (MOR) has proven to be a powerful methodology to reduce the costs and is well established for linear problems. MOR with proper orthogonal decomposition (POD) has been applied to solve large scale linear problems in computational electromagnetics very successful.
Strategies to select an optimal number of snapshots except those with the largest singular values can be found in [5] and [3]. Those MOR methods are interesting which exploit properties of specific problems. Splitting of the domain into a region where the solution changes strongly due to a parameter variation and the rest, MOR is applied to the rest with almost constant solution in [4]. For example, the speedup factor is about 1.6 for quasitatic problems in 2D by MOR with POD applied only to the linear domain in [6]. MOR is frequently used to facilitate the simulation of electrical machines, see for example [1]. A simple MOR method has been presented in [8] in the context of time stepping for nonlinear 3D problems and a method based on a mixed formulation [9], which can be easily implemented in an existing code for the mixed formulation and standard FEM.

In the present work, the idea is to exploit the specific structure of systems coming from the MSFEM for the eddy current problem (ECP) in laminated media for MOR. For example, the entire problem region can be subdivided into air and the laminated media on the one hand and, on the other, the total solution is composed of a large scale and fine scale part. This work focuses on the second aspect which will be called structural model order reduction (SMOR), see also [3, 7].

The aim is to study the feasibility to exploit the structure of specific systems arising out of MSFEM of ECPs with laminated media for MOR. Much more accurate results are expected by MSFEM with MOR than by FEM with MOR with the same effort.

First, the basic ECP studied in the present work uses a single component current vector potential (SCCVP) $T$ and is discussed in Section 2. Then, MSFEM for $T$ is introduced. Next, MOR and structural model order reduction (SMOR) are explained briefly in Section 3. A comparison of numerical results obtained by MOR and SMOR are presented in Section 4. 


\section{Higher Order MSFEM with the Single Component Current Vector Potential $T$}

\subsection{Boundary Value Problem with $T$}

A current vector potential $T$ can be introduced by $J=$ $\operatorname{curl} T$ fulfilling $\operatorname{div} J=0$ exactly. This work deals with the single component current vector potential $T$, e.g., pointing in $z$-direction $T=T e_{z}$ in the frequency domain. A simple boundary value problem (BVP) of the ECP in the frequency domain reads, see Figure 1:

$$
\begin{aligned}
\operatorname{curl} \frac{1}{\sigma} \operatorname{curl} T+j \mu \omega T & =0 \text { in } \Omega \subset \mathbb{R}^{2} \\
T & =T_{0} \text { on } \Gamma
\end{aligned}
$$

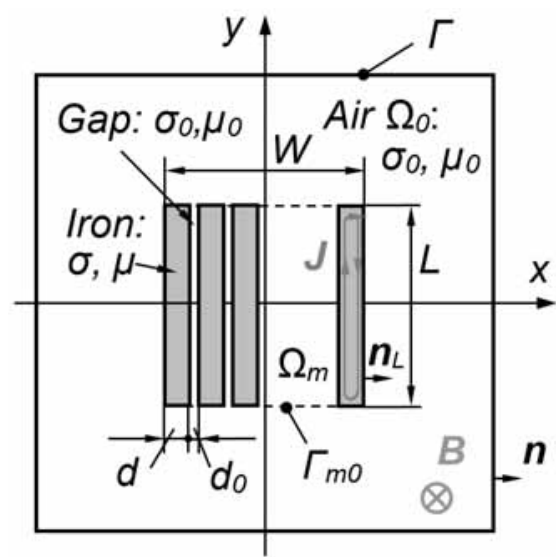

Figure 1: Eddy current problem in 2D.

\subsection{Weak Form with $T$}

The weak form for the FEM in the frequency domain reads:

Find $T_{h} \in V_{h, T_{0}}:=\left\{T_{h} \in \mathscr{U}_{h}: T_{h}=T_{0}\right.$ on $\left.\Gamma\right\}$, such that

$$
\int_{\Omega} \frac{1}{\sigma} \operatorname{curl} T_{h} \cdot \operatorname{curl} t_{h} d \Omega+j \omega \int_{\Omega} \mu T_{h} t_{h} d \Omega=0
$$

for all $t_{h} \in V_{h, 0}$, where $\mathscr{U}_{h} \subset H^{1}(\Omega)$.

\subsection{Higher Order Multiscale Finite Element Method with $T$}

The multiscale approach up to the order 4 for the single component current vector potential

$$
\tilde{T}(x, y)=T_{0}(x, y)+\phi_{2}(x) T_{2}(x, y)+\phi_{4}(x) T_{4}(x, y)
$$

is considered with even micro-shape functions $\phi_{2}$ and $\phi_{4}$ shown in Figure 2. Simply speaking $T$ corresponds to the magnetic field strength $H$ which is an even function in the lamination, therefore the micro-shape functions $\phi_{2}$ and $\phi_{4}$ are used in (4).

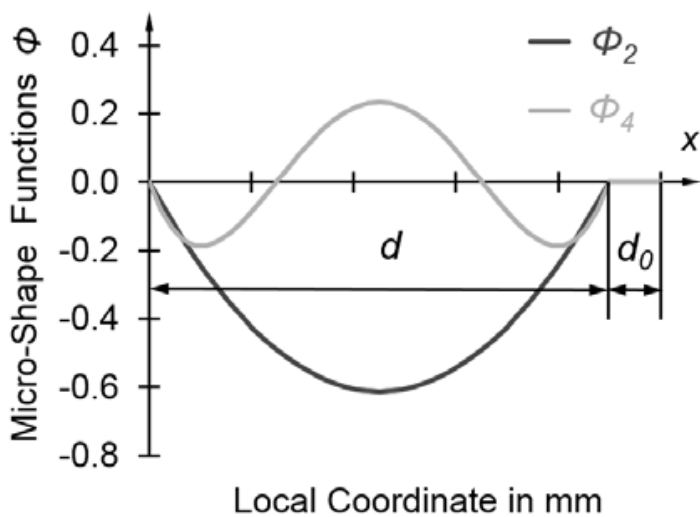

Figure 2: Even micro-shape functions $\phi_{2}$ and $\phi_{4}$.

\subsection{Weak Form of MSFEM with $T$}

The weak form reads as:

Find $\left(T_{0 h}, T_{2 h}, T_{4 h}\right) \in V_{h, T_{0}}:=\left\{\left(T_{0 h}, T_{2 h}, T_{4 h}\right): T_{0 h} \in\right.$ $\mathscr{U}_{h}, T_{2 h}$ and $T_{4 h} \in \mathscr{V}_{h}, T_{0 h}=T_{0}$ on $\Gamma$ and $T_{2 h}=0$ and $T_{4 h}=0$ on $\left.\Gamma_{m 0,1} \subset \Gamma_{m 0}\right\}$, such that

$$
\int_{\Omega} \frac{1}{\sigma} \operatorname{curl} \tilde{T}_{h} \cdot \operatorname{curl} \tilde{t}_{h} d \Omega+j \omega \int_{\Omega} \mu \tilde{T}_{h} \tilde{t}_{h} d \Omega=0
$$

for all $\left(t_{0 h}, t_{2 h}, t_{4 h}\right) \in V_{h, 0}$, where $\mathscr{U}_{h}$ is a subspace of $H^{1}(\Omega), \mathscr{V}_{h}$ of $H^{1}\left(\Omega_{m}\right)$ and $\phi_{2}$ and $\phi_{4} \in H_{p e r}^{1}\left(\Omega_{m}\right)$.

\section{MOR and SMOR}

Assume that the MSFEM (5) results in the linear equation system

$$
A x=f .
$$


Furthermore, $m$ snapshots $x_{i}$, i.e. solutions of $A_{i} x_{i}=f$ by modifying a parameter are calculated and inserted as column vectors in the snapshot matrix $S$ with dimension $n \times m$, where usually $n \gg m$ holds. The present work uses the relative permittivity $\mu_{r}$ as parameter. Next, for the POD based MOR a singular value decomposition (SVD)

$$
S=U \Sigma V^{*}
$$

the star marks conjugate transpose of $V$, is carried out. Matrices $U(n \times n)$ and $V(m \times m)$ are Hermitian matrices. The singular values $\sigma_{i}$ are arranged in the diagonal of $\Sigma$ with $\sigma_{i} \geq \sigma_{i+1}$. Now, an appropriate reduced basis

$$
W=\left[u_{1} \sigma_{1}, u_{2} \sigma_{2}, \ldots, u_{r} \sigma_{r}\right]
$$

matrix $W$ represents the projection matrix, is selected considering the essential singular values $\sigma_{i}$, where $r \geq$ $m$ is valid. With $x=W y$ the reduced order model

$$
W^{T} A W y=W^{T} f=K y=g
$$

is obtained. Similarly, SVDs are carried out of all partitions $S_{i}$, where $S=\left(S_{0}, S_{2}, S_{4}\right)^{T}$, according to the unknowns $T_{0}, T_{2}$ and $T_{4}$ in the approach (4). Therefore, SMOR yields a larger reduced model order than MOR.

\section{Numerical Results}

The model shown in Figure 1 consists of 10 laminates, $d=1.8 \mathrm{~mm}$, and air gaps in between, $d_{0}=0.2 \mathrm{~mm}$. The dimensions of the domains are $\left|\Omega_{m}\right|=20 \times 20 \mathrm{~mm}^{2}$ and $|\Omega|=40 \times 40 \mathrm{~mm}^{2}$. The frequency $f$ was chosen with $50 \mathrm{~Hz}$ and the conductivity $\sigma$ with $2 \cdot 10^{6} \mathrm{~S} / \mathrm{m}$.

The relative error presented in Figure 3 is defined by comparing the eddy current losses $P$ obtained by MOR or SMOR with those of MSFEM:

$$
\text { Relative error in } \%=\frac{P_{(S) M O R}-P_{M S F E M}}{P_{M S F E M}} \cdot 100
$$

For the snapshots, $\mu_{r}$ has been selected with 125,625 , 3125,15625 and 78125. The solutions in Figure 3 are calculated at $\mu_{r}$ equals $375,1875,9375$ and 46875 , i.e. $m=5$. The number of basis vectors used in the reduced basis is denoted by $k$. SMOR provides already for a very small reduced basis reasonable results. The error of MOR decreases for increasing $\mu_{r}$ clearly. MOR and SMOR reduce the MSFEM system by factor of about 100.

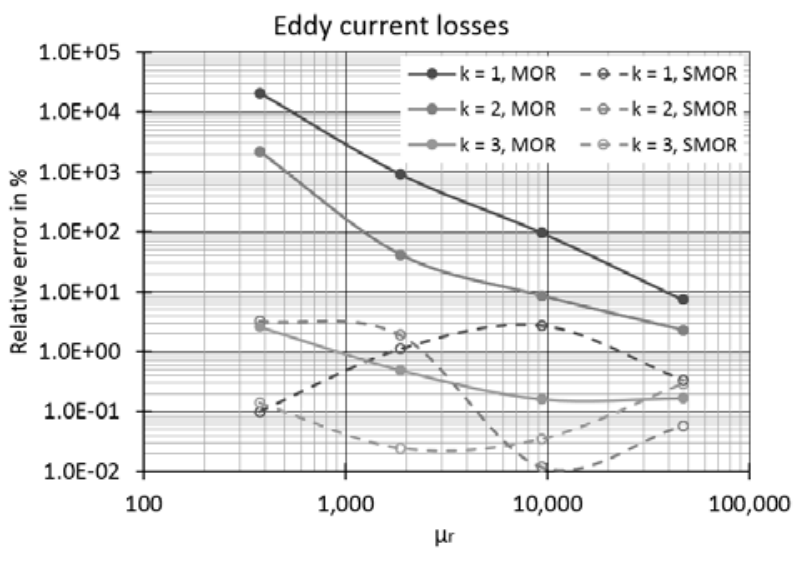

Figure 3: Comparison of model order reduction (MOR) with structural model order reduction (SMOR).

\section{Conclusion}

SMOR seams to be working properly already with very few basis vectors, i.e. low dimension of the reduced basis. An extension of SMOR to large and nonlinear problems in $3 \mathrm{D}$ will be studied in the future.

\section{Acknowledgement}

This work was supported by the Austrian Science Fund (FWF) under Project P 27028 and P 31926.

\section{References}

[1] Farzamfar M, Belahcen A, Rasilo P, Clenet S, Pierquin A. Model order reduction of electrical machines with multiple inputs. IEEE Trans. Ind. Appl.. 2017; 53(4): 3355-3360. doi: 10.1109/TIA.2017.2681967.

[2] Hollaus K, Schöberl J. Some 2-D Multiscale Finite-Element Formulations for the Eddy Current Problem in Iron Laminates. IEEE Trans. Magn. 2018; 54(4): 1-4 doi: 10.1109/TMAG.2017.2777395.

[3] Klis D, Burgard S, Farle O, Dyczij-Edlinger R. A Self-Adaptive Model-Order Reduction Algorithm for Nonlinear Eddy-Current Problems Based on Quadratic-Bilinear Modeling. IEEE Trans. Magn.. 2016; 52(3): 1-4. doi: 10.1109/TMAG.2015.2487601.

[4] Sato Y, Clemens M, Igarashi H. Adaptive Subdomain Model Order Reduction With Discrete Empirical Interpolation Method for Nonlinear Magneto-Quasi-Static Problems. IEEE Trans. Magn.. 2016; 52(3): 1-4. doi: 10.1109/TMAG.2015.2489264. 
[5] Sato Y, Igarashi H. Model Reduction of Three-Dimensional Eddy Current Problems Based on the Method of Snapshots. IEEE Trans. Magn.. 2013; 49(5): 1697-1700. doi: 10.1109/TMAG.2013.2241412.

[6] Schmidthäusler D, Schöps S, Clemens M. Linear Subspace Reduction for Quasistatic Field Simulations to Accelerate Repeated Computations. IEEE Trans. Magn.. 2014; 50(2): 421-424. doi: 10.1109/TMAG.2013.2280693.

[7] Montier L, Pierquin A, Henneron T, Clénet S. Model Reduction of Three-Dimensional Eddy Current Problems Based on the Method of Snapshots. IEEE Trans. Magn.. 2017; 53(6): 1-4. doi: 10.1109/TMAG.2017.2663761.
[8] Hollaus K, Schöberl J, Schöbinger M. MSFEM and MOR to Minimize the Computational Costs of Nonlinear Eddy-Current Problems in Laminated Iron Cores. IEEE Trans. Magn.. 2020; 56(2): 1-4. doi: 10.1109/TMAG.2019.2954392.

[9] Hollaus K, Schöbinger M. A Multiscale FEM for the Eddy Current Problem with $T, \Phi$ - $\Phi$ in Laminated Conducting Media. IEEE Trans. Magn.. 2020; 56(2): 1-4. doi: 10.1109/TMAG.2019.2954480. 


\title{
MSFEM for the Linear 2D1D-Problem of Eddy Currents in Thin Iron Sheets
}

\author{
Markus Schöbinger* , Joachim Schöberl, Karl Hollaus \\ Department of Analysis and Scientific Computing, Vienna University of Technology, Wiedner Haupstraße 8-10, \\ 1040 Vienna, Austria; *markus.schoebinger@tuwien.ac.at
}

SNE 30(1), 2020, 39-41, DOI: 10.11128/sne.30.sn.10509

Received: June 10, 2019 (Selected MATHMOD 2018 Vienna

Postconf. Publ.), Accepted: December 27, 2019

SNE - Simulation Notes Europe, ARGESIM Publisher Vienna,

ISSN Print 2305-9974, Online 2306-0271, www.sne-journal.org

Abstract. A 2D/1D method to simulate the eddy currents in a single thin iron sheet is presented. It utilizes ideas of the multiscale method by decomposing the solution with respect to its dependence on the coordinate directions. Instead of the three dimensional domain, the eddy current problem is solved only on the two dimensional cross section of the sheet, with the behavior of the solution along the thickness being simulated via an expansion into polynomial shape functions. This greatly reduces the number and the coupling density of the degrees of freedom. A numerical example shows a satisfying accuracy for both the $\mathbf{A}$ and the $\mathbf{T}$ formulation.

\section{Introduction}

In rotating electrical machines, it is reasonable to assume that each iron sheet is exposed to the same field, thus it suffices to simulate only one sheet. In the case of the thickness of the sheet being small compared to the other dimensions, the three dimensional problem may be further reduced to a two dimensional one, coupled with a separate one dimensional problem in the direction of the thickness, which will be assumed to be the $z$ axis throughout this contribution. Examples of such an approach have been presented in [1] and [4], where the coupling is realized via a nested iteration, and [2], where this principle was used in the context of homogenization.

This contribution presents a novel approach to this idea utilizing a multiscale finite element method (MSFEM, [3]). The main principle is to express the behavior of the solution along the $z$ axis via a polynomial ansatz which directly couples into the two dimen- sional problem, thereby eliminating the need to repeatedly solve two dependent problems. Such a method will be developed and tested for both the $\mathbf{A}$ formulation and the $\mathbf{T}$ formulation. All models assume a linear, timeharmonic setting.

\section{A Formulation}

In three dimensions, the weak form of the eddy current problem is given as: Find the magnetic vector potential A $\in H$ (curl), satisfying suitable boundary conditions, so that

$$
\int_{\Omega} \mu^{-1} \operatorname{curl} \mathbf{A} \cdot \operatorname{curl} v+i \omega \sigma \mathbf{A} \cdot \mathbf{v} d \Omega=0
$$

for all test functions $\mathbf{v} \in H$ (curl). In (1) $\mu$ denotes the magnetic permeability, $i$ the imaginary unit, $\omega$ the angular frequency and $\sigma$ the electric conductivity.

For the 2D1D model the ansatz

$$
\mathbf{A}=\left(\begin{array}{c}
A_{1,1}(x, y) \phi_{1}(z) \\
A_{1,2}(x, y) \phi_{1}(z) \\
0
\end{array}\right)
$$

is chosen. Here the dependency on the coordinate $z$, aligned with the sheet thickness, is modeled by the linear polynomial function $\phi_{1}$, which is normalized to vary between 1 and -1 along the thickness of the sheet, see Figure 1. $A_{1,1}$ and $A_{1,2}$ stand for the two components of one two dimension unknown $\mathbf{A}_{\mathbf{1}}:=\left(A_{1,1}, A_{1,2}\right)^{T} \in$ $H$ (curl). Here and in the following the space $H$ (curl) in two dimensions is defined via the two dimensional curl operator, which is given as

$$
\operatorname{curl} \mathbf{A}_{\mathbf{1}}:=\frac{\partial A_{1,2}}{\partial x}-\frac{\partial A_{1,1}}{\partial y}
$$

To derive the $2 \mathrm{D}$ problem, the ansatz (2) is used in the three dimensional relation (1) for the trial function and the test function, which leads to 


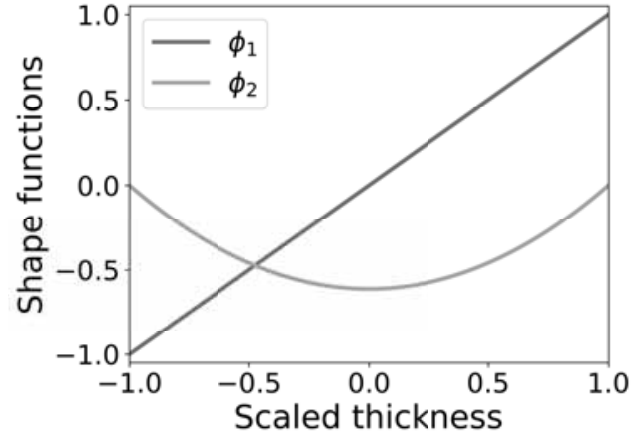

Figure 1: The shape functions $\phi_{1}$ and $\phi_{2}$ on the reference interval $[-1,1]$, which has to be scaled to $\left[-\frac{d}{2}, \frac{d}{2}\right]$ with the sheet thickness $d$.

$$
\begin{gathered}
\int_{\Omega} \mu^{-1}\left(\begin{array}{c}
-\phi_{1}^{\prime} A_{1,2} \\
\phi_{1}^{\prime} A_{1,1} \\
\text { curl } \mathbf{A}_{\mathbf{1}}
\end{array}\right) \cdot\left(\begin{array}{c}
-\phi_{1}^{\prime} v_{1,2} \\
\phi_{1}^{\prime} v_{1,1} \\
\text { curl } \mathbf{v}_{\mathbf{1}}
\end{array}\right)+ \\
i \omega \sigma\left(\begin{array}{c}
A_{1,1} \phi_{1} \\
A_{1,2} \phi_{1} \\
0
\end{array}\right) \cdot\left(\begin{array}{c}
v_{1,1} \phi_{1} \\
v_{1,2} \phi_{1} \\
0
\end{array}\right) d \Omega=0 .
\end{gathered}
$$

Decomposing the iron sheet $\Omega$ in the form $\Omega=$ $\Omega_{2 D} \times\left[-\frac{d}{2}, \frac{d}{2}\right]$ with the sheet thickness $d$, in (4) the integration over the $z$ coordinate can be carried out, using basic analysis for the integrals involving the known function $\phi_{1}$. This results in the two dimensional problem: Find $\mathbf{A}_{\mathbf{1}} \in H(\operatorname{curl})$ so that

$$
\begin{aligned}
& \int_{\Omega_{2 D}} \mu^{-1}\left(\frac{4}{d} \mathbf{A}_{\mathbf{1}} \cdot \mathbf{v}_{\mathbf{1}}+\frac{d}{3} \operatorname{curl} \mathbf{A}_{\mathbf{1}} \operatorname{curl} \mathbf{v}_{\mathbf{1}}\right)+ \\
& i \omega \sigma \frac{d}{3} \mathbf{A}_{\mathbf{1}} \cdot \mathbf{v}_{\mathbf{1}} d \Omega_{2 D}=0
\end{aligned}
$$

for all $\mathbf{v}_{\mathbf{1}} \in H(\operatorname{curl})$.

Because it is not straightforward to use physically meaningful boundary conditions in this setting, the problem is driven by first solving a corresponding magnetostatic problem, which is then used as a right hand side for (5).

\section{T Formulation}

For the $\mathbf{T}$ formulation the three dimensional problem is given as: Find the current vector potential $\mathbf{T} \in H$ (curl) so that

$$
\int_{\Omega} \rho \operatorname{curl} \mathbf{T} \cdot \operatorname{curl} \mathbf{v}+i \omega \mu \mathbf{T} \cdot \mathbf{v} d \Omega=0
$$

for all test functions $\mathbf{v} \in H$ (curl), with given Dirichlet boundary conditions for $\mathbf{T}$. Here $\rho=\sigma^{-1}$ denotes the electric resistivity.

For the 2D1D model, a similar ansatz as in the case of the A formulation is chosen:

$$
\mathbf{T}=\left(\begin{array}{c}
T_{2,1}(x, y) \phi_{2}(z) \\
T_{2,2}(x, y) \phi_{2}(z) \\
0
\end{array}\right)
$$

Here the behavior in the direction of the thickness is modeled using the even function $\phi_{2}$, which is a quadratic polynomial in $z$, see Figure 1 .

Analogous to the process for the $\mathbf{A}$ formulation, the ansatz (7) is plugged into (6) and the integration over the $z$ direction is carried out analytically, leading to the problem: Find $\mathbf{T}_{\mathbf{2}} \in H$ (curl) so that

$$
\begin{aligned}
& \int_{\Omega_{2 D}} \mu^{-1}\left(\frac{16}{3 d} \mathbf{T}_{\mathbf{2}} \cdot \mathbf{v}_{\mathbf{2}}+\frac{8 d}{15} \operatorname{curl} \mathbf{T}_{\mathbf{2}} \operatorname{curl} \mathbf{v}_{\mathbf{2}}\right)+ \\
& i \omega \sigma \frac{8 d}{15} \mathbf{T}_{\mathbf{2}} \cdot \mathbf{v}_{\mathbf{2}} d \Omega_{2 D}=0 .
\end{aligned}
$$

for all $\mathbf{v}_{\mathbf{2}} \in H$ (curl). The problem is again driven using the solution of an auxiliary problem for the right hand side.

\section{A Numerical Example}

In order to test the models developed in sections 1 and 2, a simple numerical example is carried out. The dimensions of the problem and the used material parameters can be taken from Figure 2.

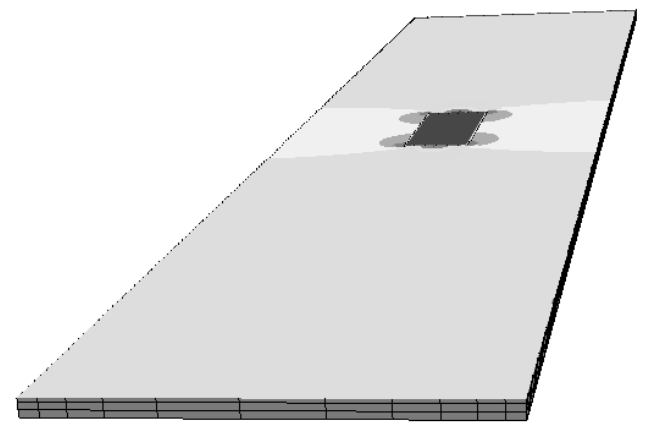

Figure 2: The iron sheet in the numerical example. Its dimensions are a width of $6 \mathrm{~mm}$, a length of $30 \mathrm{~mm}$ and $a$ thickness of $0.5 \mathrm{~mm}$. At the center of the sheet there is a hole of dimension $1.2 \mathrm{~mm}$ times $3 \mathrm{~mm}$. The material parameters are given as $\mu=1000 \mu_{0}$ and $\sigma=2.08 \times 10^{6} \mathrm{~S} / \mathrm{m}$. 
Figure 3 shows the relative error in the calculated losses. The reference solution was calculated by solving the original problems, (1) and (6), on a three dimensional mesh, respectively. It can be seen that the error increases with higher frequencies, as expected. Out of the given 2D1D models, the one for the $\mathbf{T}$ formulation performs better, because it is able to simulate the boundary effects, as can be seen in Figures 4 and 5. Further analysis of this problem and how to handle it can be found in [5].

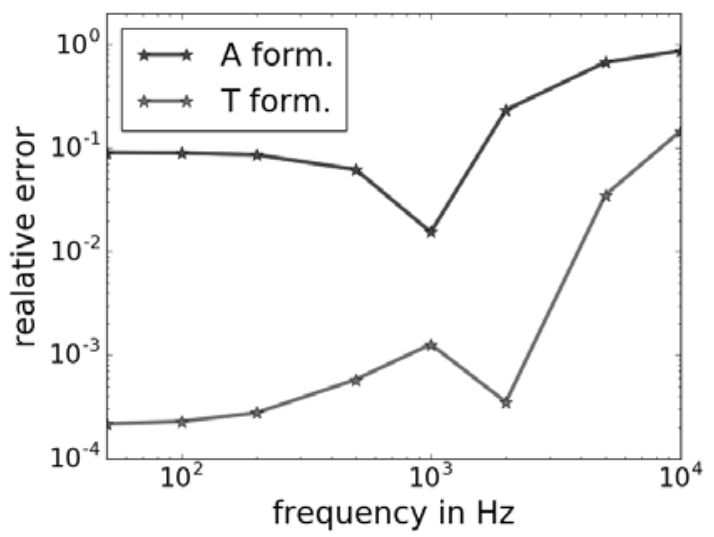

Figure 3: The relative error in the calculated losses for both formulations.

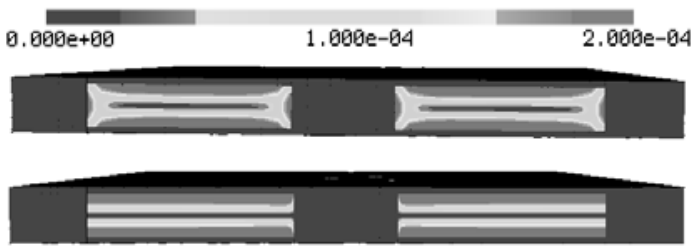

Figure 4: The absolute value of the magnetic vector potential $\mathbf{A}$ in a cross section of the sheet for the reference solution (top) and the 2D1D model (bottom) at $100 \mathrm{~Hz}$. Note that the edge effects are not resolved correctly by the 2D1D method.

\section{Conclusion}

The presented method allow for a reasonably precise calculation of the eddy current losses for low frequen-

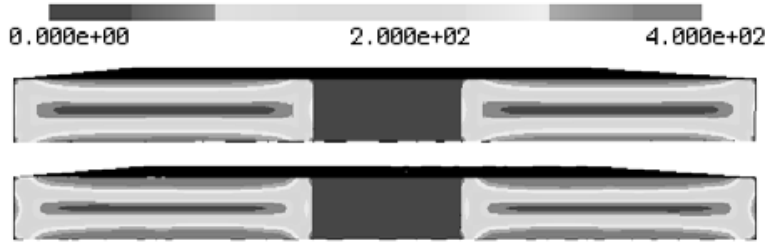

Figure 5: The absolute value of $\operatorname{curl} \mathbf{T}$ in a cross section of the sheet for the reference solution (top) and the 2D1D model (bottom) at $100 \mathrm{~Hz}$. Note that the edge effects are resolved correctly by the 2D1D method.

cies. An extension into a higher frequency range is possible by including additional ansatz functions. Future work will include testing the applicability of these models in the nonlinear setting.

\section{Acknowledgement}

This work was supported by the Austrian Science Fund(FWF) under Project P 27028 and P 31926.

\section{References}

[1] Bottauscio O, Chiampi M. Analysis of Laminated Cores Through a Directly Coupled 2-D/1-D Electromagnetic Field Formulation. IEEE Trans. Magn. 2002; 38(5): 2358-2360. doi: 10.1109/TMAG.2002.803573.

[2] Henrotte F, Steentjes S, Hameyer K, Geuzaine C. Pragmatic two-step homogenisation technique for ferromagnetic laminated cores. IET Sci. Meas. Technol. 2015; 9(2): 152-159. doi: 10.1049/iet-smt.2014.0201.

[3] Hollaus K, Schöberl J. Some 2-D Multiscale Finite-Element Formulations for the Eddy Current Problem in Iron Laminates. IEEE Trans. Magn. 2018; 54(4): 1-4 doi: 10.1109/TMAG.2017.2777395.

[4] Pippuri J, Belahcen A, Dlala E, Arkkio A. Inclusion of Eddy Currents in Laminations in Two-Dimensional Finite Element Analysis. IEEE Trans. Magn. 2010; 46(8): 2915-2918. doi: 10.1109/TMAG.2010.2044490.

[5] Schöbinger M, Schöberl J, Hollaus H. Multiscale FEM for the Linear 2-D/1-D Problem of Eddy Currents in Thin Iron Sheets. IEEE Trans. Magn. 2019; 55(1): 14. doi: 10.1109/TMAG.2018.2879030 



\section{SNE Simulation News}

\section{EUROSIM Data and Quick Info}

\begin{tabular}{|c|c|c|}
\hline 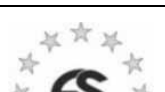 & S I M S & 20 \\
\hline $\boldsymbol{E}$ & 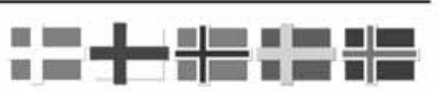 & , Finland wy \\
\hline
\end{tabular}

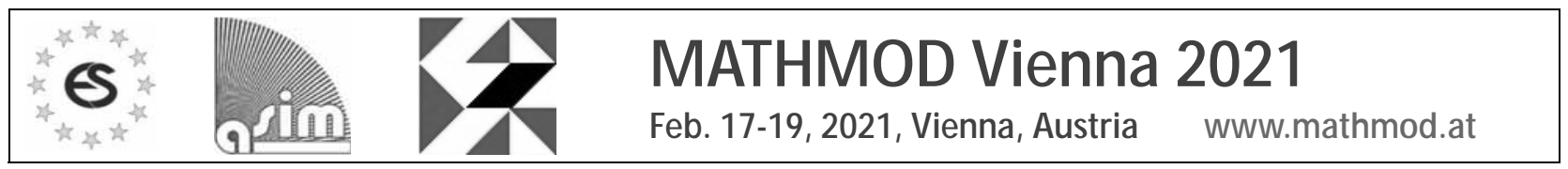

\begin{tabular}{|c|c|c|}
\hline & 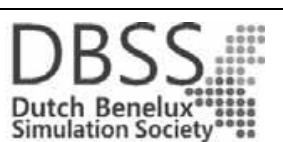 & $\begin{array}{l}\text { EUROSIM CONGRESS } 2022 \\
\text { July 4-8, 2022, Amsterdam, The Netherlands www.dutchbss.org }\end{array}$ \\
\hline
\end{tabular}

\section{Contents}

Short Info EUROSIM N2

Short Info ASIM, CEA-SM SG ...N3

Short Info CSSS, DBSS, LIOPHANT, LSS ... ..N4

Short Info KA-SIM, M IM OS, NSSM, PSCS ..N5

Short Info SIMS, SLOSIM, UKSIM ..N6

Short Info ROM SIM , Albanian Society ..N7

Short Info ARGESIM , SNE ... 8

Snapshots EUROSIM Congress 2019 Cover Inside

Simulation Notes Europe SNE is the official membership journal of EUROSIM and distributed / available to members of the EUROSIM Societies as part of the membership benefits.

If you have any information, announcement, etc. you want to see published, please contact a member of the editorial board in your country or the editorial office. For scientific publications, please contact the EiC.

This EUROSIM Data \& Quick Info compiles data from EUROSIM societies and groups: addresses, weblinks, and officers of societies with function and email, to be published regularly in SNE issues. This information is also published at EUROSIM's website www.eurosim.info.

\section{SNE Reports Editorial Board}

EUROSIM Miguel Mujica Mota,m.mujica.mota@hva.nl Nikolas Popper,niki.popper@dwh.at

ASIM A.Körner, andreas.koerner@tuwien.ac.at CEA-SMSG Emilio Jiménez, emilio.jimenez@unirioja.es CSSS Mikuláš Alexík, alexik@frtk.utc.sk DBSS M. Mujica Mota,m.mujica.mota@hva.nl LIOPHANT F. Longo,f.longo@unical.it LSS Juri Tolujew, Juri.Tolujew@iff.fraunhofer.de KA-SIM Edmond Hajrizi, info@ka-sim.com MIMOS Paolo Proietti, roma@mimos.it NSSM Y. Senichenkov, senyb@dcn.icc.spbstu.ru PSCS Zenon Sosnowski, zenon@ii.pb.bialystok.pl SIMS Esko Juuso, esko.juuso@oulu.fi SLOSIMVitoLogar,vito.logar@fe.uni-lj.si UKSIM David Al-Dabass.david.al-dabass@ntu.ac.uk ROMSIM Constanta Zoe Radulescu, zoe@ici.ro ALBSIM Majlinda Godolja, majlinda.godolja@feut.edu.al

\section{SNE Editorial Office / ARGESIM}

$\rightarrow$ www.sne-journal.org, www.eurosim.info

麦=7office@sne-journal.org,eic@sne-journal.org

$\triangle$ SNE Editorial Office

Johannes Tanzler (Layout, Organisation) Irmgard Husinsky (Web, Electronic Publishing) Felix Breitenecker EiC (Organisation, Authors) ARGESIM/Math. Modelling \& Simulation Group, Inst. of Analysis and Scientific Computing, TU Wien Wiedner Hauptstrasse 8-10, 1040 Vienna, Austria 


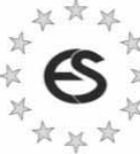

EUROSIM

\section{Federation of European Simulation Societies}

General Information. EUROSIM, the Federation of European Simulation Societies, was set up in 1989. The purpose of EUROSIM is to provide a European forum for simulation societies and groups to promote advancement of modelling and simulation in industry, research, and development. $\rightarrow$ www.eurosim.info

Member Societies. EUROSIM members may be national simulation societies and regional or international societies and groups dealing with modelling and simulation. At present EUROSIM has Full Members and $\mathrm{Ob}$ server Members, and member candidates.

\begin{tabular}{ll}
\hline ASIM & $\begin{array}{l}\text { Arbeitsgemeinschaft Simulation } \\
\text { Austria, Germany, Switzerland }\end{array}$ \\
\hline CEA-SM SG & $\begin{array}{l}\text { Spanish M odelling and Simulation Group } \\
\text { Spain }\end{array}$ \\
\hline CSSS & $\begin{array}{l}\text { Czech and Slovak Simulation Society } \\
\text { Czech Republic, Slovak Republic }\end{array}$ \\
\hline DBSS & Dutch Benelux Simulation Society \\
& Belgium, Netherlands \\
\hline KA-SIM & Kosovo Simulation Society, Kosovo \\
\hline LIOPHANT & LIOPHANT Simulation Club \\
& Italy \& International \\
\hline LSS & Latvian Simulation Society; Latvia \\
\hline PSCS & $\begin{array}{l}\text { Polish Society for Computer Simulation } \\
\text { Poland }\end{array}$ \\
\hline MIMOS & Italian M odelling and Simulation \\
& Association, Italy \\
\hline NSSM & $\begin{array}{l}\text { Russian National Simulation Society } \\
\text { Russian Federation }\end{array}$ \\
\hline ROMSIM & Romanian Society for M odelling and Simu- \\
& lation, Romania, Observer M ember \\
\hline ISCS & Simulation Society of Scandinavia \\
& Denmark, Finland, Norway, Sweden \\
\hline Societies in & Re-Organisation: \\
\hline CROSSIM & $\begin{array}{l}\text { Croatian Society for Simulation M odeling } \\
\text { Croatia }\end{array}$ \\
\hline SLOSIM & $\begin{array}{l}\text { Slovenian Simulation Society; } \\
\text { Slovenia }\end{array}$ \\
\hline United Kingdom Simulation Society \\
UK, Ireland
\end{tabular}

EUROSIM Board / Officers. EUROSIM is governed by a board consisting of one representative of each member society, and president, past president, and SNE representative. The President is nominated by the society organising the next EUROSIM Congress. Secretary, and Treasurer are elected out of members of the board.

\begin{tabular}{ll}
\hline President & $\begin{array}{l}\text { M. Mujica M ota (DBSS), } \\
\text { m.mujica.mota@ hva.nl }\end{array}$ \\
\hline Past President & $\begin{array}{l}\text { Emilio Jiménez (CAE-SM SG), } \\
\text { emilio.jimenez@ unirioja.es }\end{array}$ \\
\hline Secretary & Niki Popper, niki.popper@ dwh.at \\
\hline Treasurer & $\begin{array}{l}\text { Felix Breitenecker (ASIM) } \\
\text { felix.breitenecker@ tuwien.ac.at }\end{array}$ \\
\hline Webmaster & I. Husinsky, irmgard.husinsky@tuwien.ac.at \\
\hline $\begin{array}{c}\text { SNE } \\
\text { Representative }\end{array}$ & Felix Breitenecker \\
\end{tabular}

SNE - Simulation Notes Europe. SNE is a scientific journal with peer reviewed contributions as well as a membership journal for EUROSIM with information from the societies. EUROSIM societies distribute SNE to their members as official membership journal. SNE Publishers are EUROSIM, ARGESIM and ASIM.

\begin{tabular}{lll}
\hline SNE & \multicolumn{2}{l}{$\begin{array}{l}\text { Felix Breitenecker } \\
\text { felix.breitenecker@tuwien.ac.at }\end{array}$} \\
\hline Editor-in-Chief & office@sne-journal.org
\end{tabular}

\section{EUROSIM Congress and Conferences.}

Each year a major EUROSIM event takes place:

EUROSIM Congress. Every three years the EUROSIM Congress is organised by one of the EUROSIM societies. EUROSIM 2019, the $10^{\text {th }}$ EUROSIM Congress, was organised by CEA-SMSG, the Spanish Simulation Society, in La Rioja, Logroño, Spain, July 1-5, 2019.

$\rightarrow$ www.eurosim2019.com

EUROSIM 2022, the $11^{\text {th }}$ EUROSIM Congress, will be organised by DBSS, the Dutch Benelux simulation society, in Amsterdam, July 2022. $\rightarrow$ www.dutchbss.org

MATHMOD Vienna. This triennial conference is mainly organized by ASIM, the German simulation society, with main co-sponsors EUROSIM and IFAC.

MATHMOD 2021, the $10^{\text {th }}$ MATHMOD Vienna Conference on Mathematical Modelling will take place in Vienna, Februray 24-26, 2021. $\rightarrow$ www.mathmod.at

SIMS EUROSIM Conference. SIMS, the Scandinavian simulation society starts in 2020 with this conference series, organising every third year the annual SIMS Conference on a broader basis as SIMS EUROSIM Conference. Next is SIMS 2020 EUROSIM Conference on Modelling and Simulation, September 22-25, 2020, Oulu, Finland. $\rightarrow$ www.scansims.org 


\section{EUROSIM Member Societies}

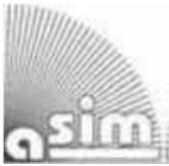

\section{ASIM \\ German Simulation Society \\ Arbeitsgemeinschaft Simulation}

ASIM (Arbeitsgemeinschaft Simulation) is the association for simulation in the German speaking area, servicing mainly Germany, Switzerland and Austria. ASIM was founded in 1981 and has now about 400 individual members (including associated), and 90 institutional or industrial members.

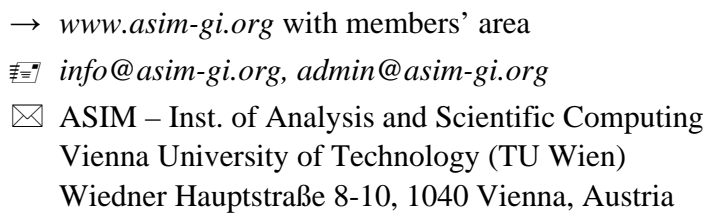

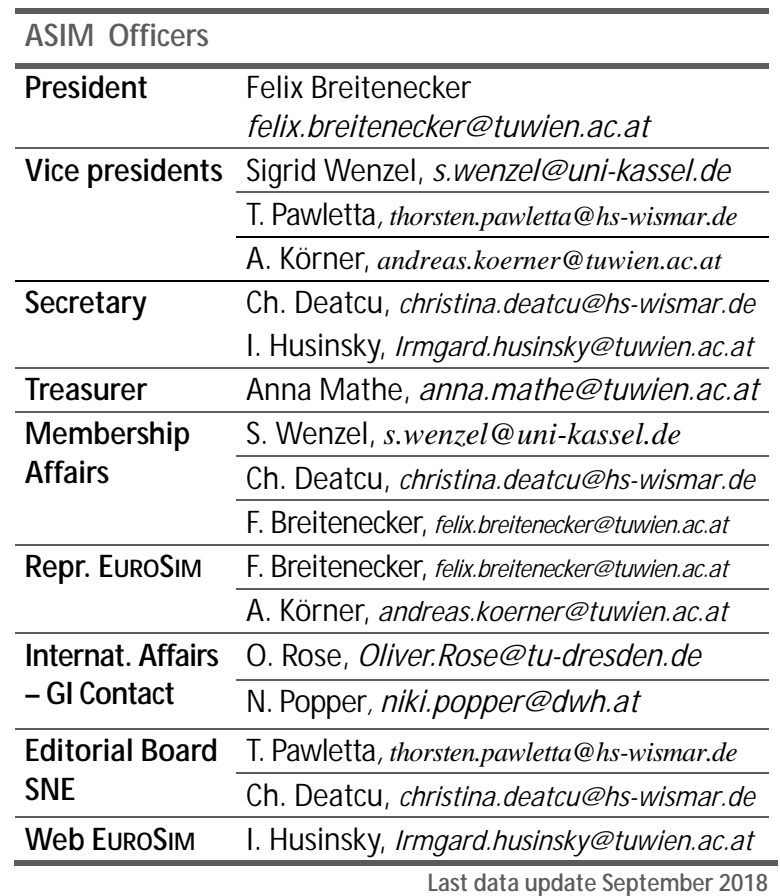

ASIM is organising / co-organising the following international conferences:

- ASIM Int. Conference 'Simulation in Production and Logistics' - biannual

- ASIM 'Symposium Simulation Technique' - biannual

- MATHM OD Int. Vienna Conference on Mathmatical Modelling - triennial

Furthermore, ASIM is co-sponsor of WSC - Winter Simulation Conference, of SCS conferences SpringSim and SummerSim, and of I3M and Simutech conference series.

\begin{tabular}{|c|c|}
\hline \multicolumn{2}{|c|}{ ASIM Working Committees } \\
\hline GMMS & $\begin{array}{l}\text { Methods in Modelling and Simulation } \\
\text { Th. Pawletta, thorsten.pawletta@ @s-wismar.de }\end{array}$ \\
\hline SUG & $\begin{array}{l}\text { Simulation in Environmental Systems } \\
\text { Jochen Wittmann, } \\
\text { wittmann@informatik.uni-hamburg.de }\end{array}$ \\
\hline STS & $\begin{array}{l}\text { Simulation of Technical Systems } \\
\text { Walter Commerell, commerell@hs-ulm.de }\end{array}$ \\
\hline SPL & $\begin{array}{l}\text { Simulation in Production and Logistics } \\
\text { Sigrid Wenzel, s.wenzel@ uni-kassel.de }\end{array}$ \\
\hline EDU & $\begin{array}{l}\text { Simulation in Education/Education in Simulation } \\
\text { A. Körner, andreas.koerner@tuwien.ac.at }\end{array}$ \\
\hline $\begin{array}{l}\text { BIG } \\
\text { DATA }\end{array}$ & $\begin{array}{l}\text { Working Group Data-driven Simulation in Life } \\
\text { Sciences; niki.popper@dwh.at }\end{array}$ \\
\hline $\begin{array}{l}\text { WORKING } \\
\text { GROUPS }\end{array}$ & $\begin{array}{l}\text { Simulation in Business Administration, in Traffic } \\
\text { Systems, for Standardisation, etc. }\end{array}$ \\
\hline
\end{tabular}

\section{CEA-SM SG - Spanish Modelling and Simulation Group}

CEA is the Spanish Society on Automation and Control and it is the national member of IFAC (International Federation of Automatic Control) in Spain. Since 1968 CEAIFAC looks after the development of the Automation in Spain, in its different issues: automatic control, robotics, SIMULATION, etc. The association is divided into national thematic groups, one of which is centered on Modeling, Simulation and Optimization, constituting the CEA Spanish Modeling and Simulation Group (CEA-SM SG). It looks after the development of the Modelling and Simulation (M\&S) in Spain, working basically on all the issues concerning the use of $M \& S$ techniques as essential engineering tools for decision-making and optimization.

$\rightarrow$ http://www.ceautomatica.es/grupos/

$\rightarrow$ emilio.jimenez@unirioja.es

simulacion@cea-ifac.es

$\triangle$ CEA-SMSG / Emilio Jiménez, Department of Electrical Engineering, University of La Rioja, San José de Calasanz 31, 26004 Logroño (La Rioja), SPAIN

\begin{tabular}{ll}
\hline CEA - SM SG Officers \\
\hline President & $\begin{array}{l}\text { Emilio J iménez, } \\
\text { emilio.jimenez@ unirioja.es }\end{array}$ \\
\hline Vice president & $\begin{array}{l}\text { Juan Ignacio Latorre, } \\
\text { juanignacio.latorre@ unavarra.es }\end{array}$ \\
\hline Repr. EUROSIM & Emilio Jiménez, emilio.jimenez@unirioja.es \\
\hline Edit. Board SNE & Juan Ignacio Latorre, \\
& juanignacio.latorre@ unavarra.es \\
\hline Web EUROSIM & Mercedes Perez mercedes.perez@ unirioja.es \\
\hline
\end{tabular}




\section{Ch CSSS - Czech and Slovak csss Simulation Society}

CSSS -The Czech and Slovak Simulation Society has about 150 members working in Czech and Slovak national scientific and technical societies (Czech Society for Applied Cybernetics and Informatics, Slovak Society for Applied Cybernetics and Informatics). CSSS main objectives are: development of education and training in the field of modelling and simulation, organising professional workshops and conferences, disseminating information about modelling and simulation activities in Europe. Since 1992, CSSS is full member of EUROSIM.

$\rightarrow$ www.fit.vutbr.cz/CSSS

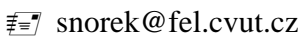

$\triangle$ CSSS / Miroslav Šnorek, CTU Prague

FEE, Dept. Computer Science and Engineering,

Karlovo nam. 13, 12135 Praha 2, Czech Republic

\begin{tabular}{ll}
\hline CSSS Officers & \\
\hline President & M iroslav Šnorek, snorek@fel.cvut.cz \\
\hline Vice president & M ikuláš Alexík, alexik@ frtk.fri.utc.sk \\
\hline Scientific Secr. & A. Kavička, Antonin.Kavicka@ upce.cz \\
\hline Repr. EuroSım & M iroslav Šnorek, snorek@ fel.cvut.cz \\
\hline Edit. Board SNE & M ikuláš Alexík, alexik@ frtk.fri.utc.sk \\
\hline Web EuroSım & Petr Peringer, peringer@ fit.vutbr.cz \\
\hline
\end{tabular}

\section{DBSS - Dutch Benelux Simulation Society}

The Dutch Benelux Simulation Society (DBSS) was founded in July 1986 in order to create an organisation of simulation professionals within the Dutch language area. DBSS has actively promoted creation of similar organisations in other language areas. DBSS is a member of EUROSIM and works in close cooperation with its members and with affiliated societies.

\section{$\rightarrow$ www.DutchBSS.org \\ 邫a.w.heemink@its.tudelft.nl \\ $\triangle$ DBSS / A. W. Heemink}

Delft University of Technology, ITS - twi,

Mekelweg 4, 2628 CD Delft, The Netherlands

DBSS Officers

\begin{tabular}{ll}
\hline President & M. Mujica M ota, m.mujica.mota@ hva.nl \\
\hline Vice president & A. Heemink, a.w.heemink@ its.tudelft.nl \\
\hline Treasurer & A. Heemink, a.w.heemink@its.tudelft.nl \\
\hline Secretary & P. M. Scala, p.m.scala@ hva.nl \\
\hline Repr. EuroSim & M. Mujica M ota, m.mujica.mota@ hva.nl \\
\hline Edit. SNE/Web & M. Mujica M ota, m.mujica.mota@ hva.nl \\
\hline
\end{tabular}

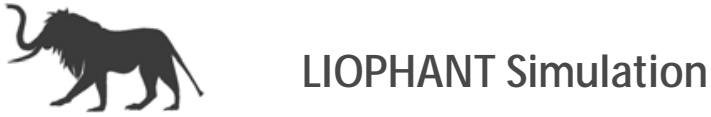

Liophant Simulation is a non-profit association born in order to be a trait-d'union among simulation developers and users; Liophant is devoted to promote and diffuse the simulation techniques and methodologies; the Association promotes exchange of students, sabbatical years, organization of International Conferences, courses and internships focused on $\mathrm{M} \& \mathrm{~S}$ applications.

$\rightarrow$ www.liophant.org

麦”info@liophant.org

$\triangle$ LIOPHANT Simulation, c/o Agostino G. Bruzzone, DIME, University of Genoa, Savona Campus via Molinero 1, 17100 Savona (SV), Italy

\begin{tabular}{ll}
\hline \multicolumn{2}{l}{ LOPHANT Officers } \\
\hline President & A.G. Bruzzone, agostino@itim.unige.it \\
\hline Director & E. Bocca, enrico.bocca@ liophant.org \\
\hline Secretary & A. Devoti, devoti.a@ iveco.com \\
\hline Treasurer & Marina Massei, massei@ itim.unige.it \\
\hline Repr. EuRoSIM & A.G. Bruzzone, agostino@ itim.unige.it \\
\hline Deputy & F. Longo, f.longo@ unical.it \\
\hline Edit. Board SNE & F. Longo, f.longo@ unical.it \\
\hline Web EuRoSIM & F. Longo, f.longo@ unical.it \\
\hline
\end{tabular}

\section{LSS - Latvian Simulation Society}

The Latvian Simulation Society (LSS) has been founded in 1990 as the first professional simulation organisation in the field of Modelling and simulation in the post-Soviet area. Its members represent the main simulation centres in Latvia, including both academic and industrial sectors.

\section{$\rightarrow$ www.itl.rtu.lv/imb/ \\ 䒠=”merkur@itl.rtu.lv \\ $\triangle$ LSS / Yuri Merkuryev, Dept. of Modelling and Simulation Riga Technical University Kalku street 1, Riga, LV-1658, LATVIA}

\begin{tabular}{ll}
\hline LSS Officers & \\
\hline President & Yuri Merkuryev, merkur@itl.rtu.Iv \\
\hline Vice President & Egils Ginters, egils.ginters@ rtu.lv \\
\hline Secretary & Artis Teilans, artis.teilans@ rta.Iv \\
\hline Repr. EuRoSIm & Egils Ginters, egils.ginters@rtu.Iv \\
\hline Deputy & Artis Teilans, artis.teilans@ rta.Iv \\
\hline Edit. Board SNE & Juri Tolujew, Juri.Tolujew@ iff.fraunhofer.de \\
\hline Web EuRoSIm & Vitaly Bolshakov, vitalijs.bolsakovs@ rtu.Iv \\
\hline
\end{tabular}
Last data update June 2019 


\section{KA-SIM Kosovo Simulation Society}

Kosova Association for Modeling and Simulation (KASIM, founded in 2009), is part of Kosova Association of Control, Automation and Systems Engineering (KACASE). KA-CASE was registered in 2006 as non Profit Organization and since 2009 is National Member of IFAC - International Federation of Automatic Control. KA-SIM joined EUROSIM as Observer Member in 2011. In 2016, KA-SIM became full member.

KA-SIM has about 50 members, and is organizing the international conference series International Conference in Business, Technology and Innovation, in November, in Durrhes, Albania, and IFAC Simulation Workshops in Pristina.

$\rightarrow$ www.ubt-uni.net/ka-case

莑elehajrizi@ubt-uni.net

$\triangle$ MOD\&SIM KA-CASE; Att. Dr. Edmond Hajrizi

Univ. for Business and Technology (UBT)

Lagjja Kalabria p.n., 10000 Prishtina, Kosovo

\begin{tabular}{ll}
\hline KA-SIM Officers & \\
\hline President & Edmond Hajrizi, ehajrizi@ ubt-uni.net \\
\hline Vice president & M uzafer Shala, info@ ka-sim.com \\
\hline Secretary & Lulzim Beqiri, info@ ka-sim.com \\
\hline Treasurer & Selman Berisha, info@ ka-sim.com \\
\hline Repr. EuRoSim & Edmond Hajrizi, ehajrizi@ ubt-uni.net \\
\hline Deputy & M uzafer Shala, info@ ka-sim.com \\
\hline Edit. Board SNE & Edmond Hajrizi, ehajrizi@ ubt-uni.net \\
\hline Web EuRoSIM & Betim Gashi, info@ ka-sim.com \\
\hline
\end{tabular}

\section{MIMOS - Italian Modelling and Simulation Association}

MIMOS (Movimento Italiano Modellazione e Simulazione - Italian Modelling and Simulation Association) is the Italian association grouping companies, professionals, universities, and research institutions working in the field of modelling, simulation, virtual reality and 3D, with the aim of enhancing the culture of 'virtuality' in Italy, in every application area.

M IM OS became EUROSIM Observer Member in 2016 and EUROSIM Full Member in September 2018.

$\rightarrow$ www.mimos.it

麦=roma@mimos.it-info@mimos.it

$\triangle$ MIMOS - Movimento Italiano Modellazione e Simulazione; via Ugo Foscolo 4, 10126 Torino via Laurentina 760, 00143 Roma

\begin{tabular}{ll}
\hline M IM OS Officers & \\
\hline President & Paolo Proietti, roma@mimos.it \\
\hline Secretary & Davide Borra, segreteria@mimos.it \\
\hline Treasurer & Davide Borra, segreteria@mimos.it \\
\hline Repr. EuroSim & Paolo Proietti, roma@mimos.it \\
\hline Deputy & Agostino Bruzzone, \\
& agostino@itim.unige.it \\
\hline Edit. Board SNE & Paolo Proietti, roma@mimos.it
\end{tabular}

Last data update December 2016

\section{NSSM - National Society for Simulation Modelling (Russia)}

NSSM - The Russian National Simulation Society (Национальное Общество Имитационного Моделирования - НОИМ) was officially registered in Russian Federation on February 11, 2011. In February 2012 NSS has been accepted as an observer member of EUROSIM, and in 2015 NSSM has become full member.

$\rightarrow$ www.simulation.su

莑三”. yusupov@iias.spb.su

$\triangle$ NSSM / R. M. Yusupov,

St. Petersburg Institute of Informatics and Automation

RAS, 199178, St. Petersburg, 14th lin. V.O, 39

\begin{tabular}{|c|c|}
\hline \multicolumn{2}{|l|}{ NSSM Officers } \\
\hline President & R. M. Yusupov, yusupov@iias.spb.su \\
\hline Chair Man. Board & A. Plotnikov, plotnikov@sstc.spb.ru \\
\hline Secretary & M. Dolmatov, dolmatov@simulation.su \\
\hline Repr. EUROSIM & $\begin{array}{l}\text { R.M. Yusupov, yusupov@iias.spb.su } \\
\text { Y. Senichenkov, } \\
\text { senyb@dcn.icc.spbstu.ru }\end{array}$ \\
\hline Deputy & B. Sokolov, sokol@iias.spb.su \\
\hline Edit. Board SNE & $\begin{array}{c}\text { Y. Senichenkov, senyb@mail.ru, } \\
\text { senyb@dcn.icc.spbstu.ru, }\end{array}$ \\
\hline
\end{tabular}

\section{PSCS - Polish Society for Computer} Simulation

PSCS was founded in 1993 in Warsaw. PSCS is a scientific, non-profit association of members from universities, research institutes and industry in Poland with common interests in variety of methods of computer simulations and its applications. At present PSCS counts 257 members. 
$\rightarrow$ www.eurosim.info, www.ptsk.pl/

拝三leon@ibib.waw.pl

$\triangle$ PSCS / Leon Bobrowski, c/o IBIB PAN, ul. Trojdena 4 (p.416), 02-109 Warszawa, Poland

\begin{tabular}{ll}
\hline PSCS Officers & \\
\hline President & Leon Bobrowski, leon@ibib.waw.pl \\
\hline Vice president & Tadeusz Nowicki, \\
& Tadeusz.Nowicki@wat.edu.pl \\
\hline Treasurer & Z. Sosnowski, zenon@ii.pb.bialystok.pl \\
\hline Secretary & Zdzislaw Galkowski, \\
& Zdzislaw.Galkowski@ simr.pw.edu.pl \\
\hline Repr. EuroSım & Leon Bobrowski, leon@ ibib.waw.pl \\
\hline Deputy & Tadeusz Nowicki, tadeusz.nowicki@ wat.edu.pl \\
\hline Edit. Board SNE & Zenon Sosnowski, z.sosnowski@ pb.ed.pl \\
\hline Web EuroSım & Magdalena Topczewska \\
& m.topczewska@ pb.edu.pl \\
\hline
\end{tabular}

\section{SIMS - Scandinavian Simulation Society}

SIMS is the Scandinavian Simulation Society with members from the five Nordic countries Denmark, Finland, Iceland, Norway and Sweden. The SIMS history goes back to 1959. SIMS practical matters are taken care of by the SIMS board consisting of two representatives from each Nordic country (Iceland one board member).

SIMS Structure. SIMS is organised as federation of regional societies. There are FinSim (Finnish Simulation Forum), MoSis (Society for Modelling and Simulation in Sweden), DKSIM (Dansk Simuleringsforening) and NFA (Norsk Forening for Automatisering).

$\rightarrow \quad$ www.scansims.org

麦=7 bernt.lie@usn.no

$\triangle$ SIMS / Bernt Lie, Faculty of Technology, Univ.College of Southeast Norway, Department of Technology, Kjølnes ring 56, 3914 Porsgrunn, Norway

\begin{tabular}{ll}
\hline SIMS Officers & \\
\hline President & Bernt Lie, Bernt.Lie@ usn.no \\
\hline Vice president & Erik Dahlquist, erik.dahlquist@ mdh.se \\
\hline Treasurer & Vadim Engelson, \\
& vadime@ mathcore.com \\
\hline Repr. EuRoSIm & Esko Juuso, esko.juuso@ oulu.fi \\
\hline Edit. Board SNE & Esko Juuso, esko.juuso@ oulu.fi \\
\hline Web EuRoSIm & Vadim Engelson, \\
& vadime@ mathcore.com \\
\hline
\end{tabular}

\section{SLOSIM - Slovenian Society for Simulation and Modelling}

SLOSIM - Slovenian Society for Simulation and Modelling was established in 1994 and became the full member of EUROSIM in 1996. Currently it has 90 members from both Slovenian universities, institutes, and industry. It promotes modelling and simulation approaches to problem solving in industrial as well as in academic environments by establishing communication and cooperation among corresponding teams.

$\rightarrow$ www.slosim.si

拝三”slosim@fe.uni-lj.si

$\triangle$ SLOSIM / Vito Logar, Faculty of Electrical

Engineering, University of Ljubljana,

Tržaška 25, 1000 Ljubljana, Slovenia

\begin{tabular}{ll}
\hline \multicolumn{2}{l}{ SLOSIM Officers } \\
\hline President & Vito Logar, vito.logar@fe.uni-lj.si \\
\hline Vice president & Božidar Šarler, bozidar.sarler@ung.si \\
\hline Secretary & Simon Tomažič, simon.tomazic@fe.uni-lj.si \\
\hline Treasurer & Milan Simčič, milan.simcic@fe.uni-lj.si \\
\hline Repr. EuRoSım & B.Zupančič, borut.zupancic@fe.uni-lj.si \\
\hline Deputy & Vito Logar, vito.logar@fe.uni-lj.si \\
\hline Edit. Board SNE & R. Karba, rihard.karba@fe.uni-lj.si \\
\hline Web EuRoSıM & Vito Logar, vito.logar@fe.uni-lj.si \\
\hline
\end{tabular}

\section{UKSIM - United Kingdom Simulation Society}

The UK Simulation Society is very active in organizing conferences, meetings and workshops. UKSim holds its annual conference in the March-April period. In recent years the conference has always been held at Emmanuel College, Cambridge. The Asia Modelling and Simulation Section (AMSS) of UKSim holds 4-5 conferences per year including the EMS (European Modelling Symposium), an event mainly aimed at young researchers, organized each year by UKSim in different European cities. Membership of the UK Simulation Society is free to participants of any of our conferences and their co-authors.

$\rightarrow$ uksim.info

莑" david.al-dabass@ntu.ac.uk

$\triangle$ UKSIM / Prof. David Al-Dabass

Computing \& Informatics,

Nottingham Trent University

Clifton lane, Nottingham, NG11 8NS, United Kingdom 


\begin{tabular}{ll}
\hline UKSIM Officers & \\
\hline President & $\begin{array}{l}\text { David Al-Dabass, } \\
\text { david.al-dabass@ntu.ac.uk }\end{array}$ \\
\hline Secretary & T. Bashford, tim.bashford@ uwtsd.ac.uk \\
\hline Treasurer & D. Al-Dabass, david.al-dabass@ntu.ac.uk \\
\hline $\begin{array}{l}\text { Membership } \\
\text { chair }\end{array}$ & G. Jenkins, glenn.l.jenkins@ smu.ac.uk \\
\hline Local/Venue chair & Richard Cant, richard.cant@ntu.ac.uk \\
\hline Repr. EuRoSIm & Dr Taha Osman, taha.osman@ntu.ac.uk \\
\hline Deputy & T. Bashford, tim.bashford@ uwtsd.ac.uk \\
\hline Edit. Board SNE & D. Al-Dabass, david.al-dabass@ntu.ac.uk \\
\hline &
\end{tabular}

\section{EUROSIM Observer Members}

\section{ROM SIM - Romanian M odelling and Simulation Society}

ROMSIM has been founded in 1990 as a non-profit society, devoted to theoretical and applied aspects of modelling and simulation of systems. ROMSIM currently has about 100 members from Romania and Moldavia.

$\rightarrow$ www.eurosim.info/societies/romsim/

麦=! florin_h2004@yahoo.com

$\triangle$ ROMSIM / Florin Hartescu,

National Institute for Research in Informatics, Averescu

Av. 8 - 10, 011455 Bucharest, Romania

\begin{tabular}{ll}
\hline \multicolumn{2}{l}{ ROM SIM Officers } \\
\hline President & N. N. \\
\hline Vice president & $\begin{array}{l}\text { Florin Hartescu, } \\
\text { florin_h2004@yahoo.com } \\
\text { Marius Radulescu, } \\
\text { mradulescu.csmro@yahoo.com }\end{array}$ \\
\hline Repr. EUROSIm & $\begin{array}{c}\text { Marius Radulescu, } \\
\text { mradulescu.csmro@yahoo.com }\end{array}$ \\
\hline Deputy & $\begin{array}{l}\text { Florin Hartescu, } \\
\text { florin_h2004@yahoo.com }\end{array}$ \\
\hline Edit. Board SNE & Constanta Zoe Radulescu, zoe@ ici.ro \\
\hline Web EuRoSim & $\begin{array}{l}\text { Florin Hartescu, } \\
\text { florin_h2004@yahoo.com }\end{array}$ \\
\hline &
\end{tabular}

\section{ALBSIM - Albanian Simulation Society}

The Albanian Simulation Society has been initiated at the Department of Statistics and Applied Informatics, Faculty of Economy at the University of Tirana, by Prof. Dr. Kozeta Sevrani.

The society is involved in different international and local simulation projects, and is engaged in the organisation of the conference series ISTI - Information Systems and Technology. In July 2019 the society was accepted as EUROSIM Observer Member.

$\rightarrow$ www.eurosim.info/societies/albsim/

䒠三”kozeta.sevrani@unitir.edu.al

$\triangle$ Albanian Simulation Goup, attn. Kozeta Sevrani

University of Tirana, Faculty of Economy

rr. Elbasanit, Tirana 355 Albania

\begin{tabular}{lc}
\hline Albanian Simulation Society- Officers \\
\hline Chairt & $\begin{array}{c}\text { Kozeta Sevrani, } \\
\text { kozeta.sevrani@ unitir.edu.al }\end{array}$ \\
\hline Repr. EUROSIM & $\begin{array}{c}\text { Kozeta Sevrani, } \\
\text { kozeta.sevrani@ unitir.edu.al }\end{array}$ \\
\hline Edit. Board SNE & $\begin{array}{c}\text { Albana Gorishti, } \\
\text { albana.gorishti@ unitir.edu.al } \\
\text { Majlinda Godolja, } \\
\text { majlinda.godolja@ feut.edu.al }\end{array}$ \\
& Last data update July 2019
\end{tabular}

\section{Societies in Re-Organisation}

The following societies are at present inactive or under re-organisation:

- CROSSIM

Croatian Society for Simulation Modelling

- FrancoSim - Société Francophone de Simulation

- HSS - Hungarian Simulation Society

- ISCS - Italian Society for Computer Simulation 


\section{Association Simulation News

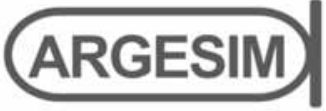

ARGESIM is a non-profit association generally aiming for dissemination of information on system simulation from research via development to applications of system simulation. ARGESIM is closely co-operating with EUROSIM, the Federation of European Simulation Societies, and with ASIM, the German Simulation Society. ARGESIM is an 'outsourced' activity from the Mathematical Modelling and Simulation Group of TU Wien, there is also close co-operation with TU Wien (organisationally and personally).

$\rightarrow$ www.argesim.org

奉: $\rightarrow$ office@argesim.org

$\bowtie \rightarrow$ ARGESIM/Math. Modelling \& Simulation Group, Inst. of Analysis and Scientific Computing, TU Wien Wiedner Hauptstrasse 8-10, 1040 Vienna, Austria Attn. Prof. Dr. Felix Breitenecker

ARGESIM is following its aims and scope by the following activities and projects:

- Publication of the scientific journal SNE Simulation Notes Europe (membership journal of EUROSIM, the Federation of European Simulation Societies) - www.sne-journal.org

- Organisation and Publication of the ARGESIM Benchmarks for Modelling Approaches and Simulation Implementations

- Publication of the series ARGESIM Reports for monographs in system simulation, and proceedings of simulation conferences and workshops

- Publication of the special series FBS Simulation Advances in Simulation / Fortschrittsberichte Simulation - monographs in co-operation with ASIM, the German Simulation Society

- Organisation of the Conference Series MATHMOD Vienna (triennial, in co-operation with EUROSIM, ASIM, and TU Wien) - www.mathmod.at

- Organisation of Seminars and Summerschools on Simulation

- Administration of ASIM (German Simulation Society) and administrative support for EUROSIM www.eurosim.info

- Support of ERASMUS and CEEPUS activities in system simulation for TU Wien

ARGESIM is a registered non-profit association and a registered publisher: ARGESIM Publisher Vienna, root ISBN 978-3-901608-xx-y, root DOI 10.11128/z...zz.zz. Publication is open for ASIM and for EUROSIM Member Societies.

\section{SNE - Simulation Notes Europe

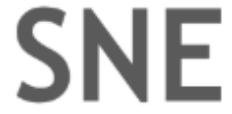

The scientific journal SNE - Simulation Notes Europe provides an international, high-quality forum for presentation of new ideas and approaches in simulation - from modelling to experiment analysis, from implementation to verification, from validation to identification, from numerics to visualisation - in context of the simulation process. SNE puts special emphasis on the overall view in simulation, and on comparative investigations.

Furthermore, SNE welcomes contributions on education in/for/with simulation.

SNE is also the forum for the ARGESIM Benchmarks on Modelling Approaches and Simulation Implementations publishing benchmarks definitions, solutions, reports and studies - including model sources via web.

$\rightarrow$ www.sne-journal.org,

拝=゙ $\rightarrow$ office@sne-journal.org,eic@sne-journal.org

$\triangle \rightarrow$ SNE Editorial Office

ARGESIM/Math. Modelling \& Simulation Group, Inst. of Analysis and Scientific Computing, TU Wien Wiedner Hauptstrasse 8-10, 1040 Vienna, Austria EiC Prof. Dr. Felix Breitenecker

SNE, primarily an electronic journal, follows an open access strategy, with free download in basic layout. SNE is the official membership journal of EUROSIM, the Federation of European Simulation Societies. Members of EUROSIM Societies are entitled to download SNE in highquality, and to access additional sources of benchmark publications, model sources, etc. On the other hand, SNE offers EUROSIM Societies a publication forum for postconference publication of the society's international conferences, and the possibility to compile thematic or event-based SNE Special Issues.

Simulationists are invited to submit contributions of any type - Technical Note, Short Note, Project Note, Educational Note, Benchmark Note, etc. via SNE's website:

\section{CNE SIMULATION $\checkmark$ NOTES EUROPE}

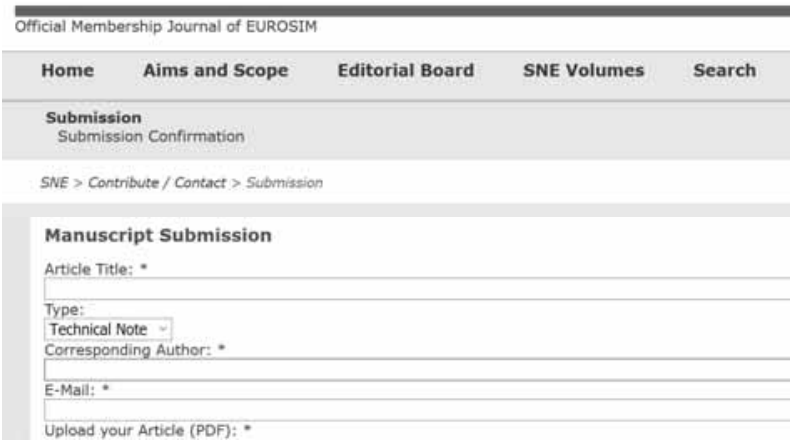



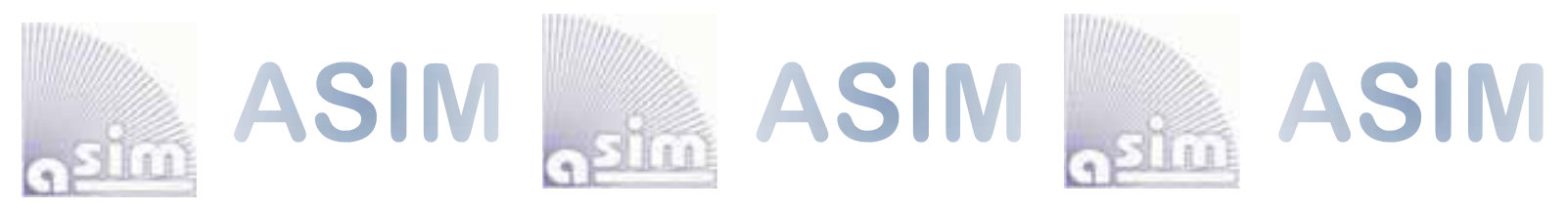

\section{ASIM Books - ASIM Book Series - ASIM Buchreihen}

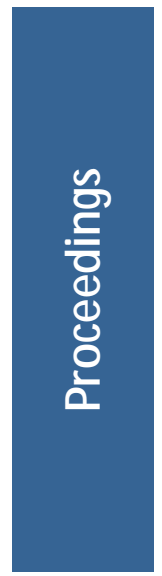

Simulation in Production and Logistics 2019 - 18. ASIM Fachtagung Simulation in Produktion und Logistik 18.-20. 9. 2019; M. Putz, A. Schlegel (Hrsg.), Verlag Wissenschaftliche Skripten Auerbach, 2019, ISBN print 978-3-95735-113-5, ISBN ebook 978-3-95735-114-2; ASIM M itteilung AM 172

Tagungsband ASIM SST 2018 - 24. ASIM Symposium Simulationstechnik, HCU Hamburg, Oktober 2018 C. Deatcu, T. Schramm, K. Zobel (Hrsg.), ARGESIM Verlag Wien, 2018; ISBN print: 978-3-901608-12-4; ISBN ebook: 978-3-901608-17-9; 10.11128/arep.56; ARGESIM Report 56; ASIM Mitteilung AM 168

Simulation in Production and Logistics 2017 - 17. ASIM Fachtagung Simulation in Produktion und Logistik Sigrid Wenzel, Tim Peter (Hrsg.); ISBN Print 978-3-7376-0192-4, ISBN Online 978-3-7376-0193-1, Kassel university press $\mathrm{GmbH}$, Kassel, 2017; ASIM M itteilung AM 164

Tagungsband ASIM SST 2016 - 23. Symposium Simulationstechnik, HTW Dresden, September 2016 T. Wiedemann (Hrsg.); ARGESIM Verlag Wien, 2016; ISBN ebook 978-3-901608-49-0; ARGESIM Report 52; ASIM Mitteilung AM 160

Kostensimulation - Grundlagen, Forschungsansätze, Anwendungsbeispiele T. Claus, F. Herrmann, E. Teich; Springer Gabler, Wiesbaden, 2019; Print ISBN 978-3-658-25167-3; Online ISBN 978-3-658-25168-0; DOI 10.1007/978-3-658-25168-0; ASIM Mitteilung AM 169

Simulation und Optimierung in Produktion und Logistik - Praxisorientierter Leitfaden mit Fallbeispielen. L. März, W. Krug, O. Rose, G. Weigert (Hrsg.); ISBN 978-3-642-14535-3, Springer, 2011; AM 130

Artur Schmidt: Variantenmanagement in der Modellbildung und Simulation unter Verwendung des SES/ M B Frameworks. FBS 30; ISBN ebook 978-3-903347-30-4, DOI 10.11128/fbs.30, ARGESIM Wien, 2019; ISBN print 978-3-903311-03-9, TUVerlag Wien (print on demand), 2019

Martin Bicher: Classification of Microscopic M odels with Respect to Aggregated System Behaviour. FBS 29; ISBN ebook 978-3-903347-29-8, DOI 10.11128/fbs.29, ARGESIM Wien, 2017; ISBN print 978-3-903311-00-8, TUVerlag Wien (print on demand), 2019

M artin Bachler: Model Based Methods for Early Diagnosis of Cardiovascular Diseases. FBS 28; ISBN ebook 978-3-903347-28-1, DOI 10.11128/fbs.28, ARGESIM Wien, 2017 ISBN print 978-3-903024-99-1, TUVerlag Wien (print on demand), 2019

Andreas Körner: A M athematical Characterisation of State Events in Hybrid M odelling. FBS 27; ISBN ebook 978-3-903347-27-4, DOI 10.11128/fbs.27, ARGESIM Vienna, 2016

Nikolas Popper: Comparative Modelling and Simulation: A Concept for Modular Modelling and Hybrid Simulation of Complex Systems. FBS 26; ISBN ebook 978-3-903347-26-7, DOI 10.11128/fbs.26, ARGESIM 2016

Gunnar M aletzki: Rapid Control Prototyping komplexer und flexibler Robotersteuerungen auf Basis des SBE-Ansatzes. FBS 25; ISBN ebook 978-3-903347-25-0, DOI 10.11128/fbs.25, ARGESIM Wien, 2019; ISBN Print 978-3-903311-02-2, TUVerlag, Wien (print on demand); 2019

Patrick Einzinger: A Comparative Analysis of System Dynamics and Agent-Based Modelling for Health Care Reimbursement Systems. FBS 24; ISBN ebook 978-3-903347-24-3, DOI 10.11128/fbs.24, ARGESIM Vienna, 2016

Martin Bruckner: Agentenbasierte Simulation von Personenströmen mit unterschiedlichen Charakteristiken. FBS 23; ISBN ebook Online 978-3-903347-23-6, DOI 10.11128/fbs.23, ARGESIM Wien, 2016

Stefan Emrich: Deployment of Mathematical Simulation Models for Space Management.

FBS 22; ISBN ebook 978-3-903347-22-9, DOI 10.11128/fbs.22, ARGESIM Publisher Vienna, 2016

Xenia Descovich: Lattice Boltzmann Modeling and Simulation of Incompressible Flows in Distensible Tubes for Applications in Hemodynamics. FBS 21; ISBN ebook 978-3-903347-21-2, DOI 10.11128/fbs.21, ARGESIM Vienna, 2016; ISBN Print 978-3-903024-98-4, TUVerlag Wien (print on demand), 2019

Florian Miksch: Mathematical Modeling for New Insights into Epidemics by Herd Immunity and Serotype Shift. FBS 20; ISBN ebook 978-3-903347-20-5, DOI 10.11128/fbs.20, ARGESIM Publisher Vienna, 2016; ISBN Print 978-3-903024-21-2, TUVerlag Wien (print on demand), 2016

Shabnam Tauböck: Integration of Agent Based Modelling in DEVS for Utilisation Analysis: The MoreSpace Project at TU Vienna. FBS 19; ISBN ebook 978-3-903347-19-9, DOI 10.11128/fbs.19, ARGESIM Vienna, 2016; ISBN Print 978-3-903024-85-4, TUVerlag Wien (print on demand), 2019

Download via ASIM webpage - www.asim-gi.org 

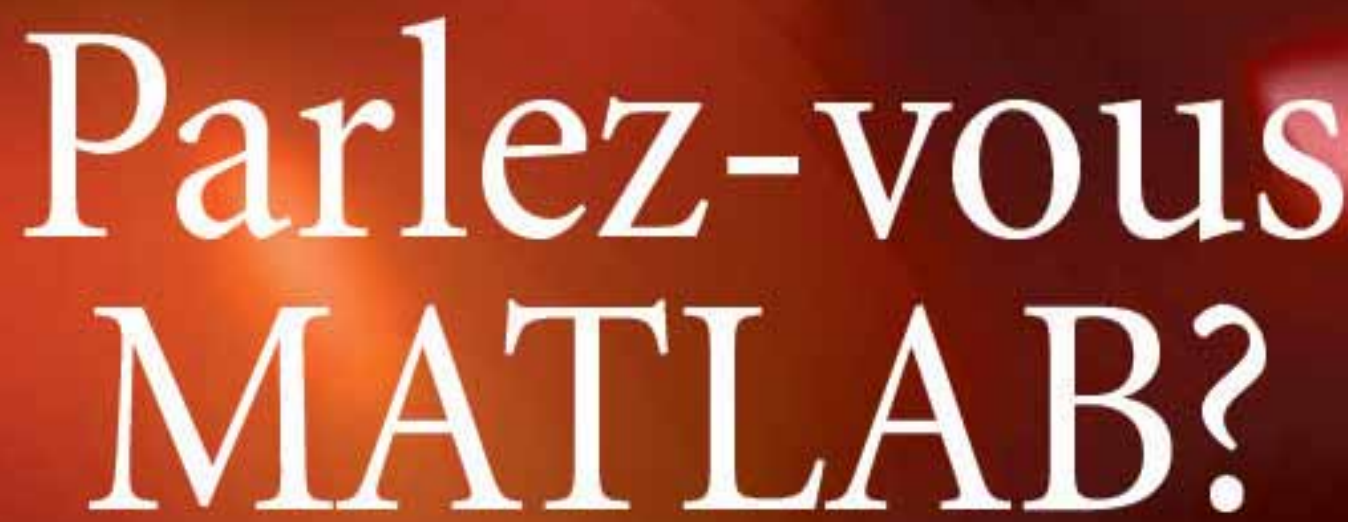

Uber eine Million Menschen wel tweit sprechen MATLAB. Ingenieure und Wissenschaftler in allen Bereichen - von der Luft- and Raumfahit tuber die Halbleiterindustrie bis zur Biotechnologie, Finanzdienstleistungen und Geo- und Mereswissenschaften - nutzen MATLAB, um ihre Ideen auszudrüdken. Sprechen Sie MATLAB?

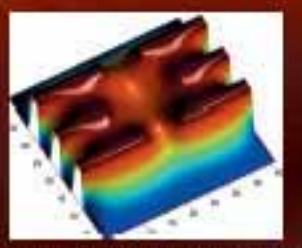

Modelliernug cines elektrisches Potentials in cinem Qunutram Dot.

Dieses Reispiel finden Sie untent mwer mathworks delic

The language of technical computing 